Portland State University

PDXScholar

Spring 7-7-2016

\title{
Watershed Management and Private Lands: Moving Beyond Financial Incentives to Encourage Land Stewardship
}

Matthew Thomas DeAngelo

Portland State University

Follow this and additional works at: https://pdxscholar.library.pdx.edu/open_access_etds

Part of the Environmental Sciences Commons, and the Sociology Commons Let us know how access to this document benefits you.

Recommended Citation

DeAngelo, Matthew Thomas, "Watershed Management and Private Lands: Moving Beyond Financial Incentives to Encourage Land Stewardship" (2016). Dissertations and Theses. Paper 3034.

https://doi.org/10.15760/etd.3029

This Thesis is brought to you for free and open access. It has been accepted for inclusion in Dissertations and Theses by an authorized administrator of PDXScholar. Please contact us if we can make this document more accessible: pdxscholar@pdx.edu. 
Watershed Management and Private Lands:

Moving Beyond Financial Incentives to Encourage Land Stewardship

by

Matthew Thomas DeAngelo

A thesis submitted in partial fulfillment of the requirements for the degree of

Master of Science

in

Environmental Science and Management

Thesis Committee:

Max Nielsen-Pincus, Chair

Eugene Foster

Yangdong Pan

Portland State University

2016 


\begin{abstract}
Public water utilities are tasked with providing high quality, inexpensive water often sourced from watersheds representing a diverse mix of public and private land ownership. There is increasing recognition amongst water resource managers of the role that private landowners play in determining downstream water quality, but bringing together landowners with a wide variety of land management objectives under the umbrella of watershed stewardship has proven difficult. Recently, a large number of "Payment for Watershed Services" programs have aimed to engage private landowners in watershed stewardship initiatives by offering financial incentives for adopting watershed best management practices. However, a growing field of research suggests that financial incentives alone may be of limited utility to encourage widespread and long-standing behavior change, and instead understanding landowner attitudes and non-financial barriers to stewardship program enrollment has become a focus of research.
\end{abstract}

This research examines a population of rural landowners representing a diversity of agricultural, forestry, recreational, and investment objectives in the Clackamas River watershed, Oregon. I designed and distributed a mail and web-based survey instrument intended to measure land uses and land ownership objectives, attitudes towards watershed stewardship programs, barriers to enrollment in stewardship programs, and preferred incentives and goals that would promote enrollment. I received 281 valid responses for a response rate of $29 \%$. I conducted two primary analyses: one focused on relating attitudes and barriers to intent to enroll in a watershed stewardship program, and one focused on identifying how diverse landowners differ according to factors influencing enrollment in stewardship programs. I found that landowners did not report financial considerations to 
be a primary barrier to enrollment and expressed low interest in receiving financial incentives. Instead, landowners reported that primary barriers related to lack of trust, ecological understanding, and concerns that stewardship program enrollment would be incompatible with their land management objectives. I do not discount the potential utility of financial incentives under certain circumstances, but emphasize the importance of addressing these other considerations before incentives can make a meaningful impact.

I compared how barriers to enrollment were perceived by landowners with different land management objectives relating to production, investment, and conservation. I found that landowner attitudes were differentiated from one another primarily by their use of land for production purposes; however, I found a large amount of diversity between producers and non-producers in the degree to which they considered investment and conservation objectives in their land management, and these two variables added further explanatory power to understanding fine-scale differences in how landowner typologies relate to conservation programs. 


\section{ACKNOWLEDGMENTS}

I would like to express my deepest appreciation to those who provided the guidance, support, and funding that was instrumental to the completion of this research. A huge number of individuals made this project possible, from professionals at natural resource agencies who offered advice to those who helped stuff envelopes and distribute survey materials. Though I cannot possibly thank everybody who helped me in this process, below I provide my sincerest thanks to those for whom this research would not be possible.

To my committee chair, Dr. Max Nielsen-Pincus: I could not have asked for a more supportive and open graduate advisor. With a persistent spirit of adventure and scholarship, his guidance allowed me to explore every rabbit-hole and promising lead without losing sight of the bigger picture. His rare mentoring style maintained a sense of academic collaboration while pushing me to think critically, to find support for, and to hone my ideas.

To my committee members, Dr. Yangdong Pan and Dr. Eugene Foster: These individuals acted as teachers both in the classroom and out. Dr. Pan's insistence on relating data to the real world and Dr. Foster's expertise on Oregon water policy provided the tools I needed to connect theory with practice.

To my community partners, Kim Swan and the Clackamas River Water Providers: A driving objective of mine was to perform research that could relate to tangible outcomes, and working with the CRWP offered me not only a venue, but also financial support to do so. Kim in particular patiently worked with me to develop questions that apply to a specific organization tasked with weighing the merits of various methods of landowner engagement. 
To my lab mates, Ashley Vizek, Cody Evers, Samantha Hamlin, Tyler Mahone, Anne Weaver, Sabra Comet, and Erin Upton: Working alongside these individuals was a true privilege; together, we explored theoretical concepts, advanced data analysis, and fundamental dilemmas in natural resource management while maintaining a sense of humor and developing close friendships. They provided the critical lens I needed to fully develop my research, and I owe a tremendous number of ideas to them.

In addition to the individuals, I would like to thank the Portland State University Department of Environmental Science and Management for affording me a teaching assistantship that supported me throughout this process. I would like to recognize the Edward D. and Olive C. Bushby Scholarship, which provided the funding necessary to print and distribute survey materials.

Finally, a very special thanks to the 281 respondents who took the time to fill out the survey, provide comments, and contact me to discuss the questionnaire. These individuals offered thoughtful insights that enlightened and challenged me, and I am so very grateful for the lessons that I was able to learn. 


\section{TABLE OF CONTENTS}

\section{Prefatory Materials}

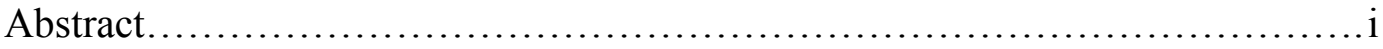

Acknowledgments................................................. iii

List of Tables........................................................vi

List of Figures........................................................ vii

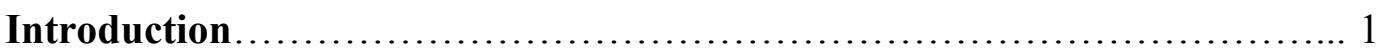

Research Overview................................................. 3

Context........................................................ 4

Survey Development and Implementation..............................5

\section{Chapter One}

Necessary but not sufficient: Attitudes as motivators and barriers to enrollment in watershed stewardship programs............................ 7

1. Introduction...................................................... 7

2. Methods....................................................... 13

3. Results.......................................................... 16

4. Discussion...................................................... 24

5. Conclusion.......................................................... 31

\section{Chapter Two:}

Stewardship Program Engagement with Diverse Landowners.................. 33

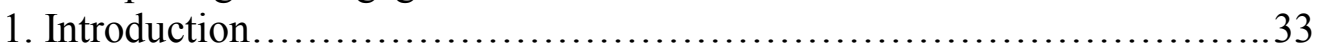

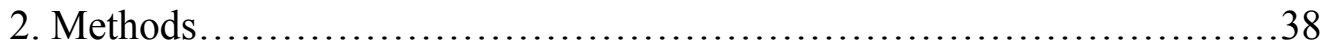

3. Results...................................................... 42

4. Landowner Typologies......................................... 45

5. Discussion................................................. 51

6. Conclusion................................................... 58

\section{Concluding Materials and Appendices}

Final Thoughts......................................................60

Works Cited...................................................... 62

Appendix A. Survey Mailer Materials...................................6 68

Appendix B. Data Summary Report..................................... 76

Appendix C. Internal Review Board Human Subjects Approval................110 


\section{LIST OF TABLES}

Table 1.1

Summary of demographic and property characteristics of survey respondents.

Table 1.2

Summary of single-item and indexed variables representing attitudes as motivators, attitudes as barriers, and land management objectives.

Table 1.3

Logistic regression model output comparing motivator, barrier, and combined models.

Table 2.1

Univariate distributions and 3-factor solution for responses to: "How important are the following factors when you are making decisions regarding your land?"

Table 2.2

Responses to A.) "To what extent do you agree or disagree with the following statements about why you might NOT participate in a watershed stewardship program?"; B.) "Would the following increase your interest in working with a watershed stewardship program?"; and C.) "How likely would you be to work with a watershed stewardship program on the following goals?"

Table 2.3

Land use, demographic, and parcel characteristics compared between landowner clusters. 


\section{LIST OF FIGURES}

Figure 0.1

The Clackamas River watershed in Oregon's Willamette River Basin

Figure 1.1

A conceptual model of the relationship between land management objectives, attitude, and intent to enroll in stewardship programs. (page 13)

Figure 1.2

Partial regression curves for the six attitude variables represented in the final attitudes model.

Figure 1.3.1

Kernel density distribution of land management orientation, split by group.

Figure 1.3.2 .23

Cumulative distribution curve of predicted probabilities of intent to enroll in stewardship programs as a function of attitude, compared between land management orientation groups.

Figure 1.4

Mean and standard error bars of combined model variables by land management orientation $(n=208)$.

Figure 2.1

Mean land management objectives and standard error bars compared between clusters.

Figure 2.2

A) Perceived barriers to enrollment in hypothetical watershed stewardship program among landowner typologies. B) Likelihood that listed incentives and goals would increase enrollment in hypothetical watershed stewardship program among landowner typologies.

Figure 2.3

Proportion of stream length represented by each landowner cluster in each subwatershed. 


\section{INTRODUCTION}

Spurred by the 1996 Safe Drinking Water Act Amendments that required assessment of public drinking water sources, many public water utilities have established source watershed protection programs aimed at addressing upstream land uses to preserve downstream drinking water quality (Bennett et al. 2014). However, a substantial portion of drinking watersheds are in private ownership, and bringing together landowners with a diverse array of land management objectives under the umbrella of watershed stewardship has proven difficult. Private rural land uses may negatively impact water quality through storm water runoff laden with pesticides, excess nutrient loadings from fertilizers, and irrigation runoff that adds salts and other pollutants into water supplies (Halcrow et al. 1982). Land conversion and deforestation may remove bank-stabilizing riparian vegetation, leading to increased soil erosion and suspended sediment in the water column, and the loss of shade in riparian zones may cause thermal pollution by exposing waterways to excess sunlight (Karr \& Schlosser 1978). The results can pose serious threats to aquatic life and can substantially increase the cost of treatment for downstream drinking water (Freeman 2008).

Despite the potential negative impacts of private rural land use, water resource managers increasingly recognize that many private landowners can and do act as watershed stewards through careful land management and protection of riparian zones (Ahnstrom 2008, Engel et al. 2008). As a result, a growing number of source watershed protection programs have utilized a "payment for watershed services" (PWS) framework to provide financial incentives to encourage or reward stewardship behaviors (Bennett et al. 2014). Such behaviors may include a variety of watershed-friendly land management practices, 
including maintenance or creation of riparian forests, nutrient load offsets, or wildfire mitigation activities (Bennett et al. 2014).

Payment for Watershed Services is not a new idea. For decades, the US Department of Agriculture (USDA) has incentivized the use of riparian buffers through its Conservation Reserve Enhancement Program (CREP), and until 2014 promoted Wetlands Conservation through the Wetlands Reserve Program. Though not specifically focused on watersheds, funds from the Conservation Stewardship Program (CSP), the Conservation Reserve Program (CRP), and the Environmental Quality Incentives Program (EQIP) have all been leveraged to assist landowners in implementation of best watershed management practices (Wood 1999). More recently, PWS programs have been established by water utilities primarily structured around protecting drinking water to remain in compliance with federal regulations and to avoid the construction of expensive treatment plants (Bennett 2014). Lurie et al. (2013) argue that local water utilities can play a particularly effective role in promoting watershed stewardship because of their significant knowledge with the watershed's social and ecological context. Notable examples of municipal PWS programs include the New York City Source Watershed Protection Program (New York), the Eugene Water and Electric Board's Voluntary Incentives Program (Oregon), and the Raleigh Upper Neuse Clean Water Initiative (North Carolina).

Despite the frequent use of incentives to promote stewardship behaviors, many incentive programs have been unable to achieve widespread enrollment and have been critiqued for providing insufficient payments to adequately compensate farmers (Engel 2008). Furthermore, Pirard et al. (2010) noted that incentives may only lead to temporary behavior changes that may revert after payments have ended. While incentive programs 
are intended to address financial barriers to land stewardship, they may not fully consider social factors, knowledge, and technological limitations (Ahnstrom 2008). Schneider and Ingram (1990) argue that knowledge of a population's motivations, attitudes, and barriers towards a given action is vital to designing effective programs. While PWS programs address financial barriers, a growing body of research suggests that non-financial factors such as attitude, personal values, sense of place, or social obligation may play a greater and more durable influence on landowner land stewardship decisions.

\section{Research Overview}

This research is guided by three primary objectives: (1) to evaluate the efficacy of financial incentives to promote enrollment in stewardship programs, (2) to gain insight into the relationship between attitude and land stewardship, and (3) to offer recommendations regarding how resource managers can effectively engage the landowner populace. Given the large number of water utilities applying a PWS framework, this research is centered around understanding enrollment in non-governmental stewardship programs. I evaluate these questions through two chapters; the first investigates the relationship between intent to enroll in stewardship programs and attitudes relating to financial and non-financial considerations. The second explores how diverse landowners perceive different barriers to enrollment and prefer different methods to engage with stewardship programs. Both of these chapters are geared towards providing policy-makers additional insight into the range of policy tools available to apply given a variety of situations.

The project focused on a specific group of rural landowners in the Clackamas River watershed, Oregon. While findings described in the following chapters provide further evidence regarding the diversity of attitudes and land management objectives represented 
by landowners, these findings are intended to be applied primarily to source watershed protection of the Clackamas River watershed. If one conclusion can be readily made from this research, it is that understanding the social intricacies of place is absolutely vital to designing sustainable and equitable land stewardship programs.

\section{Context}

The Clackamas River is the center of a 243,000 hectare watershed characterized by a patchwork of agricultural, semi-urban, and forested lands. Eight separate drinking water utilities draw drinking water from the Clackamas River and supply water to over 300,000 customers in Washington and Clackamas counties. While the upper $72 \%$ of the watershed is publically owned land primarily in the Mount Hood National Forest, the downstream portion of the watershed is almost entirely in private agricultural, forestry, and residential ownership. As such, the watershed offers a complex system representative of a diverse range of landowners for which to explore these research questions.

In order to maintain water quality amidst increasing development pressure and production intensity, Clackamas County and the relevant water utilities have formed a consortium known as the Clackamas River Water Providers (CRWP) to implement source watershed protection measures (CRWP 2010). The CRWP have noted that the application of agri-chemicals poses a significant threat to drinking water quality; the United States Geologic Survey has identified over 1,200 known contaminants in the watershed (Carpenter 2008), and 17 potentially harmful pesticides have been detected at significant levels throughout the watershed (Schmidt 2012). Additionally, loss of riparian shade and excess thermal loads have been identified as priority issues in the watershed (CRWP 2010) and recently gained media attention due to record water temperatures recorded throughout 
the basin (Roth 2015). In their 2010 Drinking Water Protection Plan, the CRWP outlined the need to work with both commercial and small acreage rural landowners in a program to promote watershed stewardship. This study is aimed at informing the creation of such a program by understanding attitudes and barriers to enrollment.

\section{Survey Development and Implementation}

The primary data used in this research were collected through a questionnaire-based survey of rural landowners in the Clackamas River watershed. The survey instrument was designed to measure attitudes and beliefs regarding watershed stewardship, to educate respondents on the range of features that watershed stewardship programs could take specific to the Clackamas River watershed, and to identify the diversity of land management objectives represented in the watershed. The survey was developed with assistance from the CRWP and was reviewed by resource managers familiar with the survey sample, including officials representing local water utilities, the Oregon Department of Agriculture, the United States Geological Survey, and the local Soil and Water Conservation District.

The questionnaire was administered via mail and web to a randomly selected group of 1,030 private rural landowners within the Clackamas River watershed. Landowners were considered eligible if their property was (1) outside of the Urban Growth Boundary; (2) at least 2 acres in size; (3) zoned as agricultural, rural, or forestry land; and (4) no more than 100 feet from a stream at the property border (Figure 0.1). Because nursery operations have been noted as a particular concern to water quality in the Clackamas River watershed (Schmidt 2012), any nursery operating within the watershed was considered eligible and was contacted to participate in the survey. To enhance response rate (Dillman 2000), 
landowners were contacted four times from August to September, 2015, via the Dillman Tailored Design Method, which included an initial postcard, followed up by a first round of questionnaires, a reminder postcard, and a second wave of questionnaires for nonrespondents.

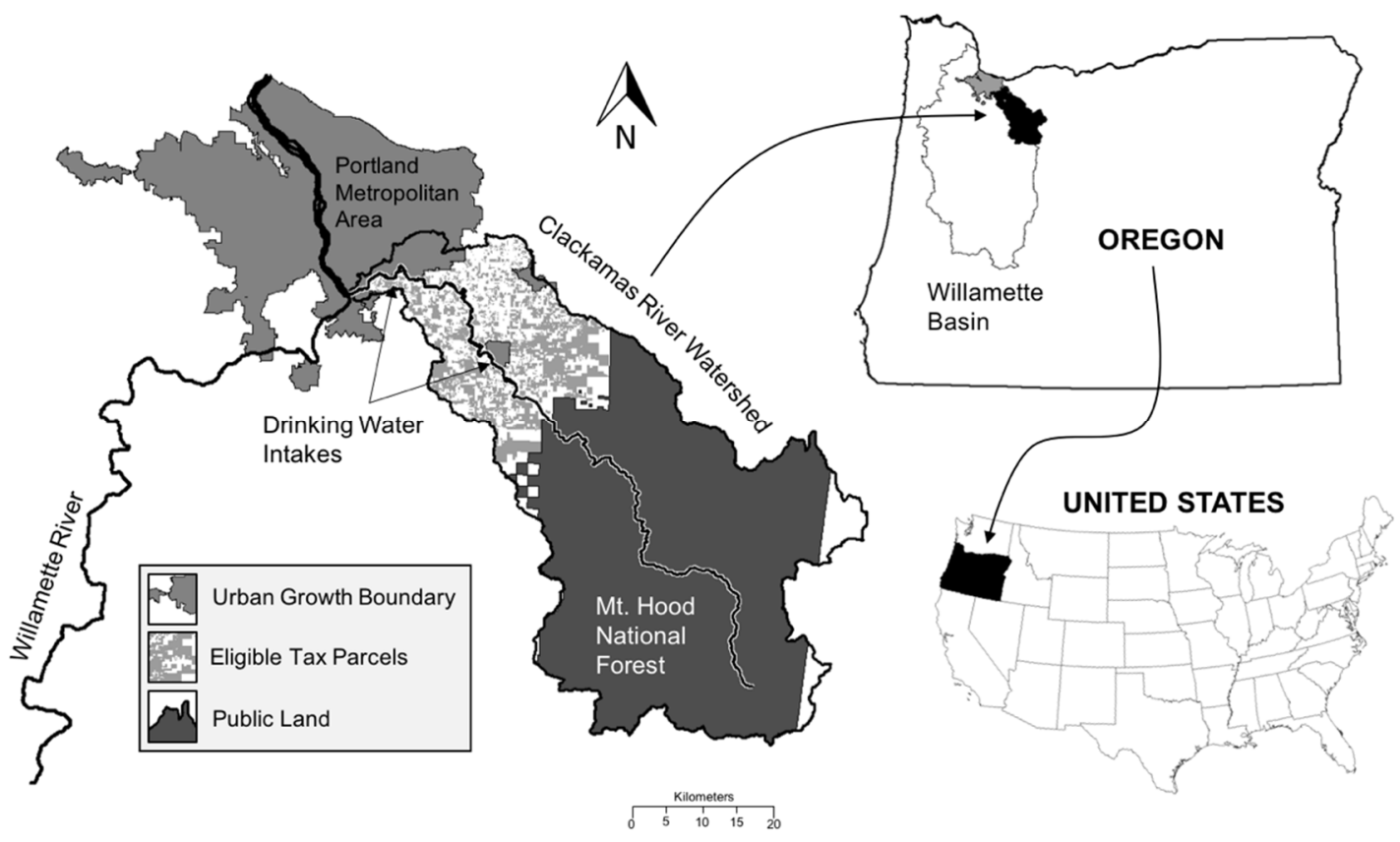

Figure 0.1

The Clackamas River watershed in Oregon's Willamette River Basin. Eligible tax parcels refer to taxlot parcels outside of the urban growth boundary, greater than 2 acres in size, and within 100 feet of a waterbody at the property's edge. 


\section{CHAPTER ONE}

\section{Necessary but not sufficient: Attitudes as motivators and barriers to enrollment in watershed stewardship programs}

In this chapter, I build on past literature by evaluating the relationship between attitudes, perceived barriers, and land management objectives relating to enrollment in watershed stewardship programs. I investigate this question through a survey of private rural residential, agricultural, and forestry landowners in the Clackamas River, OR, and I apply these findings to discuss policy recommendations to encourage watershed stewardship amongst landowners.

\section{INTRODUCTION}

Schneider and Ingram's well-cited paper “Behavioral Assumptions of Policy Tools" (1990) stresses that policy-makers may utilize a combination of authority, incentive, capacity-building, and symbolic tools dependent on local context. The authors argue that effective use of these tools begins with understanding the relevant population's motivations for and barriers to performing the desired action, and to recognize that behavior is influenced by an individual's longer-term objectives. Accordingly, PWS programs have been critiqued for assuming that landowners are limited only by financial considerations, and monetary incentives are sufficient to promote widespread and long-lasting behavior change (Engel et al. 2008, Pirard et al. 2010). Coupled with relatively low enrollment rates in similar programs like the Conservation Reserve Program (Stubbs 2014), these critiques have prompted a number of researchers to investigate the broader suite of attitudes, barriers, and non-financial objectives related to landowner stewardship behaviors (Ahnstrom 2008). 


\subsection{Attitudes as Motivators of Stewardship}

Attitude refers to an individual's favorable or unfavorable appraisal of a behavior or object in question (Ajzen 1991) and has frequently been used to understand private landowner motivations for stewardship behaviors. Positive attitudes towards conservation have been linked with higher program enrollment rates (Ahnstrom 2008), the adoption of best management practices (Beedell and Rehman 2009, Baumgart-Getz et al. 2012), and increased success per unit of money invested (Coleman et al. 1992).

Many landowner studies have utilized Ajzen's (1991) Theory of Planned Behavior (TPB) as a useful framework for understanding how attitudes relate to the adoption of conservation behaviors (Beedell and Rehman 1999, Corbett 2002, Rosenberg and Margerum 2008, Ahnstrom 2008, Armstrong and Stedman 2012, Baumgart-Getz et al. 2012, Thompson et al. 2014). The TPB suggests that a behavior can be understood by examining three components of attitude: (1) beliefs about the outcome of the behavior, (2) perceived norms regarding the adoption of the behavior, and (3) the perceived behavioral control to complete the behavior (Ajzen 1991). Behavior itself is often measured as intent to perform an action. Though intent does not necessarily correspond directly to observable behavior, it offers a useful proxy when observed behavior data is not available. Measures for perceived behavioral control have had relatively low success at explaining stewardship behavior (e.g. Beedell and Rehman 1999, Corbett 2002), and some have gone so far as to question whether this concept offers a useful distinction from the other components of attitude (Trafimow and Duran 1998). Attitudes regarding behavioral outcomes and social/personal norms, on the other hand, offer more fruitful grounds on which to understand stewardship behaviors. 
The landowner literature suggests beliefs regarding a behavior's outcome for both the environment and oneself influence stewardship behavior. Armstrong and Stedman (2008) noted the belief that implementation of riparian buffers would lead to improved watershed outcomes was a key predictor of rural landowner intent to perform that action, and Baumgart-Getz et al. (2012) reviewed a number of studies and noted that more general concepts of environmental attitude and awareness may also help predict behavior. Conversely, Woods et al. (2014) studied a group of producers and noted the importance of believing that watershed stewardship behaviors would provide personal financial benefit, whereas behaviors without a perceived personal benefit were perceived less favorably.

Behavioral alignment with social and moral norms is another important component relating to attitude. The perceived norms of neighbor actions (Fischer and Charnley 2012), the social norm regarding appearance of a property (Chin et al. 2008), and membership in social networks (Reimer and Prokopy 2014) have all been related with landowner stewardship action. Ryan (2009) found that moral norms of stewardship ethic and selfaccountability for water quality were closely associated with stewardship activities of noncommercial riparian landowners.

Despite the large number of studies investigating the relationship between attitude and the decision to adopt stewardship practices, few look specifically at how landowner attitudes impact the decision to enroll in stewardship programs. Baumgart-Getz et al. (2012) analyzed 46 studies relating to farmer adoption of best management practices in the United States, and only two were specifically focused on factors influencing program enrollment. This is a significant gap given that stewardship programs are a necessary medium through which landowner behavior change is encouraged. Of the studies that do 
focus on enrollment in stewardship programs, the vast majority are heavily focused on government-sponsored programs (e.g. Esseks and Kraft 1988, Napier et al. 1988, Corbett 2002, Song et al 2014, Reimer and Prokopy 2014). Because government skepticism tends to influence opinions in the United States (Steel et al. 1994), it is necessary to distinguish how attitudes relate to enrollment in the growing number of non-government programs sponsored by drinking water utilities.

\subsection{Attitudes as Barriers to Stewardship}

While many related studies have been framed around investigating how attitudes motivate stewardship, it appears that attitudes may also act as substantial barriers to enrollment in stewardship programs. Kahnemen and Tversky's (1979) Prospect Theory provides a strong rationale for consideration of barriers in attitudes modeling. Prospect theory suggests that individuals make decisions based on perceived losses or gains relative to their current position, and individuals are more sensitive to losses than they are to gains. This may suggest that negative attitudes regarding the outcomes of stewardship programs more have a more potent impact on intent than positive attitudes. As evidence of the importance of considering attitudes as barriers, landowners have reported support for environmental and water quality goals in a variety of contexts without correlating directly to stewardship behavior (e.g. Carr and Tait 1991, Ryan et al. 2003, Greiner et al. 2009). Evaluation of attitudes as barriers is particularly important given that negative attitudes have been shown to drive up transaction costs beyond the assessed value of the stewardship action in question (Grolleau and McCann 2012).

Practical considerations such as perception of financial limitations, knowledge barriers, and time constraints may partly explain low adoption of stewardship behaviors 
(Williams 2002, Woods et al. 2014). However, less tangible attitudes relating to lack of trust in conservation agencies and concerns for loss of private property rights show much more distinct and consistent negative relationship with stewardship behavior in the literature (Greiner et al. 2009, Kallstrom and Ljung 2005, Armstrong and Stedman 2011). In particular, a lack of trust in government appears to be a particularly important barrier to stewardship (Rosenberg and Margerum 2008, Smith et al. 2013). More broadly, Ma et al. (2010) included a catch-all measure in the belief that programs are incompatible with land management goals, and found a significant negative relationship with stewardship behavior.

\subsection{Land Management Objectives}

A substantial amount of research suggests that attitudes towards stewardship are ultimately colored by a landowner's objectives for managing their land (Majumdar et al. 2008, Greiner et al. 2009). Due to the large footprint of agricultural lands in the United States, production-based objectives are particularly heavily represented in the literature. Commonly, producers have been classified as either profit-maximizers or land stewards, with the notion that these objectives are mutually exclusive (Thompson et al. 2014). While some evidence supports this dichotomy (e.g. Carr and Tait 1991, Ryan et al. 2003), many farmers expres an interest in both profit-maximization and land stewardship, creating a sort of tension that can be difficult to resolve (Sullivan et al. 1996, Thompson et al. 2014). The complex relationship can be partly understood through a Dual Interest Theory framework, which suggests that intent to adopt conservation behaviors is driven by weighting the relative utility of profit objectives and other objectives (Sheeder and Lynne 2011). As described by Chouinard et al. (2008), “[Producers] may participate in these activities for 
the social good or because they believe it is the 'right thing to do' even if it requires personal sacrifice."

While Dual Interest Theory has been less frequently applied to non-operator landowners, several studies have compared non-operator landowners with their operator counterparts and have come to seemingly contradictory conclusions that support application of this framework beyond the typical producer. Kaplowitz and Witter (2008) found that non-commercial landowners were generally more environmentally aware and more likely to implement riparian buffers on their property, whereas Armstrong and Stedman (2011) compared a similar population, and found that residential landowners were generally less willing to implement buffers due to aesthetic preferences. Such findings suggest that non-operator landowners are also characterized by diverse motivations. Despite the lack of consensus, it is clear that whether a landowner relies on their land for income or not plays an important distinction in how they engage with stewardship behaviors.

\subsection{Research Questions and Hypotheses}

While the existing literature has provided a wealth of evidence that attitudes and land management objectives influence the adoption of land stewardship practices, I aimed to investigate these concepts in conjunction with one another as part of a conceptual model to understand intent to enroll in stewardship programs. Based on my literature review, I compare the relationship between attitudes as motivators and barriers of intent to enroll in stewardship programs. Because of the low explanatory power associated with perceived behavioral control, I focus this study on attitudes relating to outcome evaluation and social and moral norms. I evaluate how production and environmental land management 
objectives color intent to enroll, with the hypothesis that individuals interested primarily in profit will have more negative attitudes than individuals interested primarily in protecting the environment, and as a result will report a lower average intent to enroll (Figure 1.1).

I place this study in a broader context by discussing my findings in light of Schneider and Ingram's (1990) four classes of policy tools to address this population's attitudes, barriers, and land management objectives relating to land stewardship. I conclude with
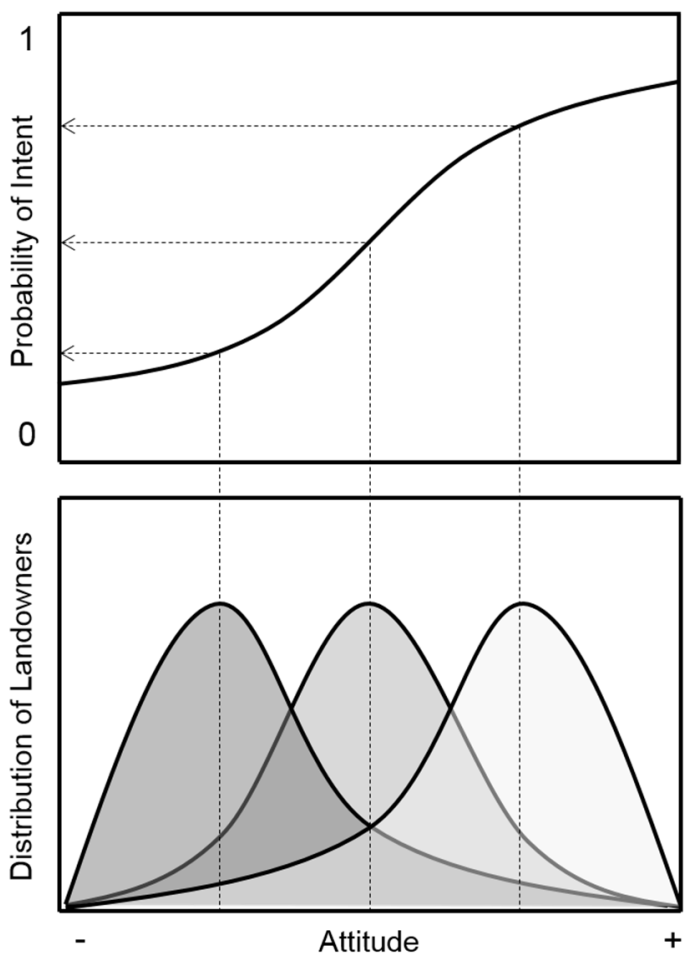
Land Management Objective $\square$ Profit / Production $\square$ Average $\square$ Environmental

Figure 1.1. A conceptual model of how land management objectives and attitude relate to intent to enroll in stewardship programs.

some broadly applicable considerations for application in source watershed stewardship programs.

\section{METHODS}

Related to this study, I asked respondents to express their agreement or disagreement to statements representing attitudes hypothesized to either motivate or to act as barriers to enrollment in stewardship programs. I measured all responses to these statements using variations of a 5 point Likert Scale (Likert 1932). Motivating attitudes were measured by asking respondents to rate degree of agreement or disagreement with (1) statements regarding interest in receiving incentives to enroll and (2) statements regarding belief in positive outcomes to both the environment and to self. Barrier attitudes were 
measured by asking respondents to rate degree of agreement with (1) statements regarding perceived barriers to enrollment in stewardship programs and (2) statements regarding belief in negative outcomes to both the environment and to self. Land management objectives were measured by asking respondents to rate the importance profit/production objectives and environmental objectives from "not at all important" to "very important." Positive and negative outcome beliefs were measured utilizing a modified version of the Awareness of Consequences and Environmental Concern scale (Stern et al. 1994).

After respondents had completed a series of questions pertaining to potential program features, the survey asked, "Now that you know a little bit more about the potential features of a watershed conservation program in the Clackamas River watershed, how likely would you say you are to participate in such a program if the program was tailored to your responses above?" This question was designed to measure behavioral intent to participate in a stewardship program and was used as the dependent variable in my analyses.

\subsection{Data Analysis}

All analyses were performed in R Studio (Version 3.2.3). Because the population contained both rural residential and agricultural properties, I compared demographics and property characteristics from respondents to both the most recent National Agricultural Statistics Service Census of Agriculture (USDA 2012) for Clackamas County and the most recent American Community Survey (US Census Bureau 2009-2013) for census tracts represented in the study area.

I investigated polychoric correlations between variables ('Psych' R Package, Revelle 2015) in order to avoid potential issues with multi-collinearity. Polychoric 
correlations are a modified version of the Pearson correlation coefficient used when an ordinal variable is theorized to represent an underlying normally distributed variable (see Drasgow 1988) as is the case with Likert-scale data. Highly correlated variables that held face validity were consolidated into single indices by taking the mean of component variables. All indices were evaluated for internal consistency using Chronbach's alpha (Chronbach 1951).

Though the independent variable - intent to enroll in a watershed stewardship program - was initially based on a 5-item Likert scale, I transformed this variable to a dichotomous scale represented by 1 (likely or very likely to enroll) or 0 (not sure, unlikely, or very unlikely to enroll). I chose this route because my question ultimately was to identify factors distinguishing the split between likely and unlikely participants, and logistic regression offered the most statistically robust and easily interpretable technique to accomplish this goal. Furthermore, logistic regression does not hold strict assumptions regarding normality and continuity of data, making it appropriate for use with Likert data.

To evaluate the effect of attitudes as both motivators and barriers to enrollment in stewardship programs, I created two separate logistic regression models - an "attitudes as motivators model" utilizing variables hypothesized to encourage enrollment intent, and an "attitudes as barriers model" utilizing variables hypothesized to discourage enrollment intent. I assessed model significance by performing a chi-square test against a null model and by calculating the Nagelkerke $\mathrm{R}^{2}$. I weighed variable importance by calculating the odds ratio for each variable, and I evaluated these models for issues with multi-collinearity by calculating the variance inflation factor (VIF). Typically, a VIF $>2$ indicates potential multi-collinearity. 
Following the creation of the initial two models, I performed a stepwise model reduction on each based on the Akaike Information Criterion (AIC), a measure of relative model quality (Akaike 1973). At each step in this iterative process, the variable most negatively influencing model quality as evaluated by AIC is dropped before the reduced set of variables is reevaluated. Following this reduction procedure, remaining variables from each model were put together into a combined model representing both motivator and barrier variables. Another stepwise AIC reduction was performed on the combined model to establish a final model representing the variables explaining the greatest amount of variance in the dataset.

To evaluate the hypothesized effect land management objective on attitude, I measured three variables representing profit/production and three variables representing environmental objectives. I consolidated these into variables into indices by taking the three-item mean and confirmed the validity of these indices by examining correlations between variables and calculating Chronbach's alpha. First, I checked if either of these variables related to intent to enroll on their own. Then, I weighed these two variables against one another by taking the difference between the two indices and creating a new variable termed "land management orientation." Theoretically, this variable represents individuals who consider environmental objectives more important than profit/production objectives by positive values and individuals with inverse objectives by negative values. Based on this variable, I split the sample into three classes of landowners: Profit/Production Oriented, Neutrally Oriented, and Environmentally Oriented. I then utilized the final attitudes model to evaluated how these groups differ in predicted enrollment intent. I compared how these groups differed relating to each variable represented in the combined 
attitude model using a Tukey HSD test (Tukey 1949), and evaluated how this relates to intent to enroll by comparing differences in predicted intent to enroll as defined by the combined model.

\section{RESULTS}

Seventy-two surveys (6.5\%) were returned as undeliverable, leading to an effective sample of 958. I received 279 valid responses - a $29 \%$ response rate. Compared with the reference data sources, the sample tended to be older (median age 63) and more educated (48\% with a college degree). Property size, agricultural sales, gender, and income tended to fall within the range of values represented by the reference sources (Table 1.1).

Table 1.1

Summary of demographic and property characteristics of survey respondents.

\begin{tabular}{lc|lc}
\hline Sample Size & 281 & Median Age (Years) & 63 \\
Median Property Size (Acres) & 19.3 & $\%$ Male & $64.2 \%$ \\
\% College Graduate & $47.6 \%$ & $\%$ Conservative & $48.1 \%$ \\
\% Without Sales in 2014 & $58.8 \%$ & $\%$ Liberal & $27.0 \%$ \\
$\%$ With Sales $>$ \$1000 in 2014 & $31.9 \%$ & $\%$ Income > \$75K & $56.5 \%$ \\
\hline
\end{tabular}

\subsection{Data Summary}

I was able to consolidate measured variables into simplified indices to reduce the total number of variables used in the attitudes modeling. Inter-variable correlations revealed two constructs within the measured attitude items: "Financial Incentives" (alpha $=0.92$ ) represents four variables expressing interest in receiving monetary incentives, whereas "Social Barriers" $(a l p h a=0.71)$ represents three variables expressing the influence of one's neighbors or community to prevent enrollment. The highest rated motivator attitudes were the beliefs that functioning stream ecosystems are important for a clean water supply (the Ecosystem Belief, mean $=4.35$ ), that watershed conservation benefits 
everyone in the watershed (the Universal Benefit Belief, mean $=3.75$ ), and that watershed conservation is the right thing to do (the Moral Belief, mean = 3.72). Respondents frequently cited practical barriers to enrollment, including the perception of insufficient information (Informational Barriers, mean $=3.83$ ), finances (Financial Barriers, mean $=$ 3.23) and time (Time Barriers, mean =3.12). Furthermore, many respondents reported less concrete concerns that enrollment could lead to regulatory implications (Regulatory Barriers, mean $=3.73$ ) and they lacked trust in conservation agencies or organizations (Trust Barriers, mean $=3.32$ ). Generally, individuals reported more positive attitudes towards watershed stewardship than they did negative attitudes, but they also were more likely to report perceived barriers compared with expressing an interest in receiving incentives to enroll (Table 1.2).

My analysis confirmed the existence of two distinct land management objectives: Profit/Production Objectives $($ alpha $=0.86)$ and Environmental Objectives $($ alpha $=0.82)$ (Table 1.2). Profit/Production Objectives represented three variables relating to the importance of producing farm or timber products, providing income, and managing a business through land production. Environmental Objectives represented three variables relating to the importance of protecting open space and aesthetic beauty, the health of waterways, and native wildlife and vegetation. Environmental Objectives $($ mean $=4.11)$ were reported much more frequently than Profit/Production Objectives (mean $=2.53$ ). 


\section{Table 1.2}

Summary of single-item and indexed variables representing attitudes as motivators, attitudes as barriers, and land management objectives. Bolded items were utilized in logistic regression. The groupings represent responses to the following questions: (Panel A) "Would the following increase your interest in working with a watershed conservation program?" (Panel B) "In general, do you agree or disagree with the following statements regarding watershed conservation in the Clackamas River watershed?" (Panel C) "To what extent do you agree or disagree with the following statements about why you might NOT participate in a watershed conservation program?" (4) "How important are the following factors when you are making decisions regarding your land?"

\begin{tabular}{|c|c|c|c|}
\hline \multicolumn{2}{|r|}{ Panel A. Attitudes as Motivators: variables hypothesized to encourage intent to enroll } & Mean & SD \\
\hline \multirow{7}{*}{ 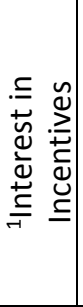 } & Marketing: Improved marketing for products from my land $(n=251)$ & 2.67 & 1.30 \\
\hline & Technical Assistance: Staff to help you implement your project ( $\mathrm{n}=252$ ) & 3.17 & 1.35 \\
\hline & Financial (alpha $=0.92)(n=256)$ & 3.20 & 1.21 \\
\hline & Annual cash incentives for participating $(n=255)$ & 3.42 & 1.35 \\
\hline & Mean One-time cash bonus for signing up $(n=254)$ & 3.25 & 1.34 \\
\hline & A cash bonus for joint participation with neighbors $(n=253)$ & 3.07 & 1.33 \\
\hline & Discounts at local retailers $(n=249)$ & 3.03 & 1.36 \\
\hline \multirow{6}{*}{ 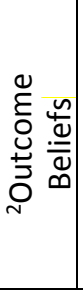 } & Universal Benefit: Watershed conservation benefits everyone $(n=251)$ & 3.75 & 1.12 \\
\hline & Moral: Watershed conservation is just the right thing to do $(n=249)$ & 3.88 & 1.01 \\
\hline & $\begin{array}{l}\text { realize }(n=249) \\
\text { realic }\end{array}$ & 3.72 & 1.10 \\
\hline & Responsibility: Pollution from my land harms people downstream $(n=250)$ & 2.62 & 1.50 \\
\hline & Degradation: Development threatens water quality ( $n=247)$ & 3.62 & 1.19 \\
\hline & Ecosystem: Functioning ecosystems are important for clean water $(n=248)$ & 4.35 & 0.81 \\
\hline \multicolumn{2}{|r|}{ Panel B. Attitudes as Barriers: variables hypothesized to discourage intent to enroll } & Mean & SD \\
\hline \multirow{9}{*}{ 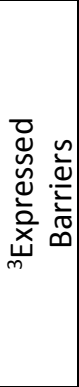 } & Time: I don't have time to participate in a program like this $(n=247)$ & 3.12 & 1.15 \\
\hline & Financial: My finances won't allow it $(n=248)$ & 3.23 & 1.10 \\
\hline & Informational: I don't know enough about these programs $(n=248)$ & 3.83 & 1.15 \\
\hline & Social (alpha $=0.71)(n=246)$ & 2.63 & 0.87 \\
\hline & My neighbors or community would give me a hard time $(n=244)$ & 2.45 & 1.04 \\
\hline & No one in my community participates in these types of programs $(n=244)$ & 2.61 & 0.92 \\
\hline & I'm uncomfortable with the attention programs like these bring $(n=246)$ & 2.80 & 1.24 \\
\hline & Trust: I don't trust the organizations that run these programs $(n=244)$ & 3.32 & 1.20 \\
\hline & Regulatory: I'm concerned about legal or regulatory implications ( $n=244)$ & 3.73 & 1.21 \\
\hline \multirow{4}{*}{ 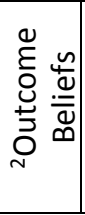 } & Incompatible: Conservation programs are incompatible with my goals ( $n=263$ ) & 2.46 & 1.12 \\
\hline & Threat to livelihood: Watershed conservation will threaten my livelihood & 2.40 & 1.15 \\
\hline & Restrictive: Watershed conservation might limit my personal freedoms $(n=250)$ & 3.25 & 1.25 \\
\hline & $\begin{array}{l}\text { Denial: While some local areas may have seen declines in water quality, overall } \\
\text { water quality in the watershed is not in decline }(n=249)\end{array}$ & 2.86 & 1.03 \\
\hline \multicolumn{2}{|r|}{ Panel C. Land Management Objectives: importance to land management decisions } & Mean & SD \\
\hline \multirow{8}{*}{ 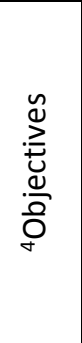 } & Profit / Production (alpha $=0.86)(n=262)$ & 2.53 & 1.39 \\
\hline & Produce high quality farm or timber products for market $(n=259)$ & 2.75 & 1.70 \\
\hline & Provide income for me and my family ( $n=260$ ) & 2.53 & 1.50 \\
\hline & Grow/manage a business through my land's production $(n=256)$ & 2.25 & 1.46 \\
\hline & Environmental (alpha $=0.82)(n=267)$ & 4.11 & 0.96 \\
\hline & Preserve open space or aesthetic beauty $(n=262)$ & 3.98 & 1.23 \\
\hline & Protect the health of waterways on or near my property $(n=264)$ & 4.21 & 1.05 \\
\hline & Protect local wildlife or native vegetation $(n=266)$ & 4.14 & 1.04 \\
\hline
\end{tabular}




\subsection{Logistic Regression Models}

The attitudes as motivators model revealed three variables that held a significant positive relationship $(\alpha<0.1)$ with intent to participate: Technical Assistance Incentives $(\mathrm{p}<0.001)$, the Universal Benefit Belief $(\mathrm{p}=0.034)$, and the Ecosystem Belief $(\mathrm{p}=0.008)$ (Table 1.3). Stepwise AIC reduction revealed no additional variables contributing to model quality. The Ecosystem Belief had the highest odds ratio (odds=2.557), indicating that the model was particularly sensitive to this variable. The model was highly significant when compared against the null model $\left(\mathrm{p}<0.001\right.$, Nagelkerke $\left.\mathrm{R}^{2}=0.411\right)$.

The attitudes as barriers model revealed three variables to hold a significant negative relationship $(\alpha<0.1)$ with intent: Trust Barriers $(p=0.086)$, the Incompatible Belief $(p<0.001)$, and the Threat to Livelihood Belief $(p=0.061)$ (Table 1.3). Stepwise AIC reduction suggested that Time Barriers $(p=0.193)$ and Social Barriers $(p=0.112)$ contribute to model quality, and so these variables were maintained for inclusion in the combined model. The Incompatible Belief had the lowest odds ratio (odds $=0.498$ ), indicating that intent seemed to be particularly sensitive to this variable. The model performed similarly to the encouraging factors model and was highly significant compared against the null $\left(\mathrm{p}<0.001 ;\right.$ Nagelkerke $\left.\mathrm{R}^{2}=0.369\right)$. 
Table 1.3

Logistic Regression model output comparing motivator, barrier, and combined models (*p $<0.1)$.

\begin{tabular}{|c|c|c|c|c|c|c|c|}
\hline & Variable & $\beta$ & S.E. & $\mathrm{p}$-val & VIF & Odds Ratio & $\begin{array}{c}\text { Contrib } \\
\text { AIC? }\end{array}$ \\
\hline \multirow{10}{*}{ 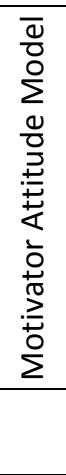 } & Marketing Incentives & -0.204 & 0.173 & 0.240 & 1.619 & 0.816 & \multirow{3}{*}{$\checkmark$} \\
\hline & Technical Assistance & 0.713 & 0.195 & $0.000 *$ & 1.579 & 2.040 & \\
\hline & Financial Incentives & 0.214 & 0.198 & 0.279 & 1.490 & 1.238 & \\
\hline & Universal Benefit Belief & 0.437 & 0.206 & $0.034^{*}$ & 1.379 & 1.548 & \multirow[t]{6}{*}{$\checkmark$} \\
\hline & Moral Belief & 0.255 & 0.254 & 0.315 & 1.578 & 1.291 & \\
\hline & Public Health Belief & -0.152 & 0.210 & 0.467 & 1.507 & 0.859 & \\
\hline & Responsibility Belief & 0.152 & 0.124 & 0.222 & 1.183 & 1.164 & \\
\hline & Degradation Belief & -0.252 & 0.186 & 0.174 & 1.428 & 0.777 & \\
\hline & Ecosystem Belief & 0.988 & 0.371 & $0.008^{*}$ & 1.357 & 2.686 & \\
\hline & Variable & $\beta$ & S.E. & $p$-val & VIF & Odds Ratio & $\begin{array}{c}\text { Contrib } \\
\text { AIC? }\end{array}$ \\
\hline \multirow{10}{*}{ 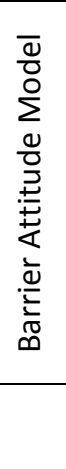 } & Time Barriers & -0.251 & 0.193 & 0.193 & 1.439 & 0.778 & \multirow[t]{2}{*}{$\checkmark$} \\
\hline & Financial Barriers & -0.112 & 0.196 & 0.570 & 1.394 & 0.894 & \\
\hline & Social Barriers & -0.383 & 0.241 & 0.112 & 1.211 & 0.682 & $\checkmark$ \\
\hline & Trust Barriers & -0.282 & 0.164 & $0.086^{*}$ & 1.183 & 0.754 & \multirow[t]{2}{*}{$\checkmark$} \\
\hline & Informational Barriers & 0.032 & 0.161 & 0.842 & 1.085 & 1.033 & \\
\hline & Incompatible Belief & -0.684 & 0.180 & $0.000 *$ & 1.135 & 0.505 & $\checkmark$ \\
\hline & Threat to livelihood Belief & -0.315 & 0.169 & $0.061^{*}$ & 1.167 & 0.729 & \multirow[t]{3}{*}{$\checkmark$} \\
\hline & Restrictive Belief & 0.053 & 0.163 & 0.747 & 1.363 & 1.054 & \\
\hline & Denial Belief & -0.131 & 0.192 & 0.494 & 1.207 & 0.877 & \\
\hline & Variable & $\beta$ & S.E. & p-val & VIF & Odds Ratio & $\begin{array}{c}\text { Contrib } \\
\text { AIC? }\end{array}$ \\
\hline \multirow{6}{*}{ 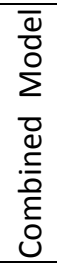 } & Time Barriers & -0.302 & 0.175 & $0.085^{*}$ & 1.039 & 0.740 & $\checkmark$ \\
\hline & Trust Barriers & -0.325 & 0.169 & $0.054^{*}$ & 1.090 & 0.723 & $\checkmark$ \\
\hline & Incompatible Belief & -0.425 & 0.192 & $0.027^{*}$ & 1.094 & 0.654 & $\checkmark$ \\
\hline & Threat to Livelihood Belief & -0.423 & 0.171 & $0.013^{*}$ & 1.080 & 0.655 & $\checkmark$ \\
\hline & Technical Assistance & 0.638 & 0.173 & $0.000 *$ & 1.075 & 1.893 & $\checkmark$ \\
\hline & Ecosystem Belief & 0.653 & 0.310 & $0.035^{*}$ & 1.087 & 1.922 & $\checkmark$ \\
\hline \multicolumn{2}{|c|}{ Model Comparison } & & \multicolumn{2}{|c|}{$\mathrm{df}$} & \multicolumn{2}{|c|}{$p$-val $\left(\chi^{2}\right)$} & Nagelkerke $\mathrm{R}^{2}$ \\
\hline \multicolumn{2}{|c|}{ Motivator Attitude } & & \multicolumn{2}{|c|}{210} & \multicolumn{2}{|c|}{$1.11 \mathrm{E}-12^{*}$} & 0.411 \\
\hline \multicolumn{2}{|c|}{ Barrier Attitude Model } & & \multicolumn{2}{|c|}{212} & \multicolumn{2}{|c|}{$3.41 \mathrm{E}-11^{*}$} & 0.369 \\
\hline \multicolumn{2}{|c|}{ Combined Attitude } & 217 & \multicolumn{2}{|c|}{210} & \multicolumn{2}{|c|}{$2.20 \mathrm{E}-16^{*}$} & 0.476 \\
\hline
\end{tabular}

The combined attitude model contained six variables consisting of Time Barriers $(p=0.085)$, Trust Barriers $(p=0.054)$, the Incompatible Belief $(p=0.084)$, the Threat to Livelihood Belief $(p=0.013)$, Technical Assistance Incentives $(p<0.001)$, and the Ecosystem Belief $(p=0.035)$. This combined model was highly significant $(p<0.001)$ and performed better than either the negative or positive models independently (Nagelkerke $\left.\mathrm{R}^{2}=0.476\right)$ 
For these six variables, I developed partial regression probability curves that isolate the impact of each variable by outputting predicted probabilities for that variable while holding all other variables constant at their mean. Amongst the variables I found to significantly explain intent to enroll, each performed substantially better at explaining a lack of intent to enroll rather than intent to enroll; amongst respondents who reported negative attitudes, the model uniformly predicted an intent to enroll of near 0 (Figure 1.2). Likewise, the positive attitude variables never predicted a probability of enrollment greater than $50 \%$, but not holding positive attitudes almost guaranteed a total lack of intent to enroll.
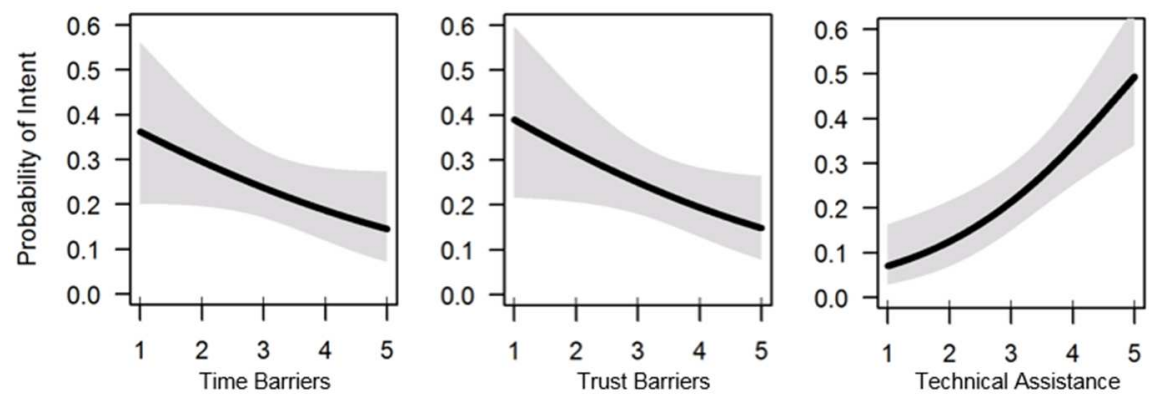

Figure 1.2

Partial regression curves for the six attitude variables represented in the combined model.
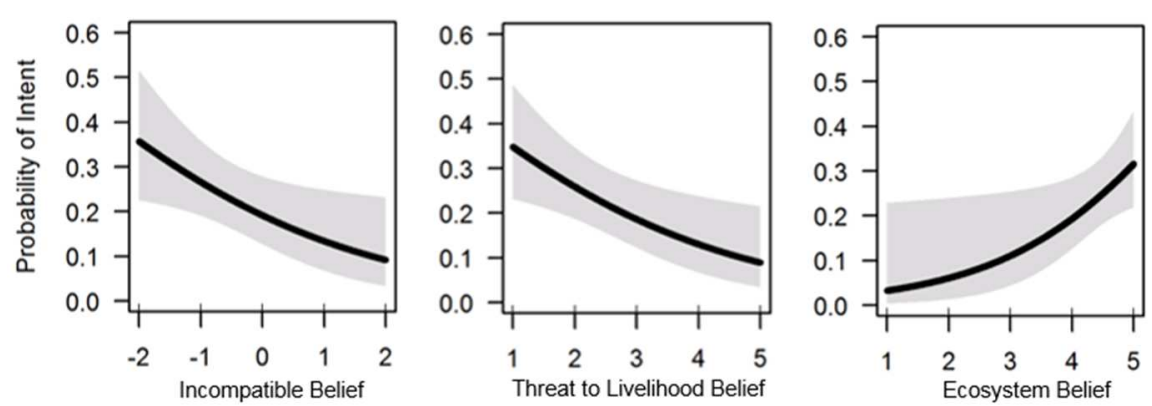

Note that these represent the influence of each of these variables on intent to enroll with all other variables held constant at their mean.

\subsection{Land Management Orientation}

I classified 23 respondents as "Profit/Production" oriented (Land Management

Orientation $<0), 83$ respondents as "Neutral" $(0>$ Land Management Orientation $<2)$ and 103 respondents as "Environmental” (Land Management Orientation > 2) (Figure 1.3.1). Neutral individuals were classified as such because, despite having a slight edge 
towards environmental objectives, they tended to fall in the middle of the respondent distribution and thus represented no strong land management orientation compared with the rest of the population.

Figure 1.3.2 shows the cumulative distribution of predicted enrollment probability for each of the three groups. The Tukey HSD test between groups showed a significant difference between the Environmental and Neutral groups $(\mathrm{p}=0.011)$ and between Environmental and Profit/Production groups $(\mathrm{p}=0.001)$. However, I did not detect a difference in predicted intent to enroll probability between the Neutral and Profit/Production groups $(\mathrm{p}=0.210)$. In general, I noted an increasing average predicted enrollment intent from profit/production to neutral to environmental groups, and this matched trends seen in the observed data.
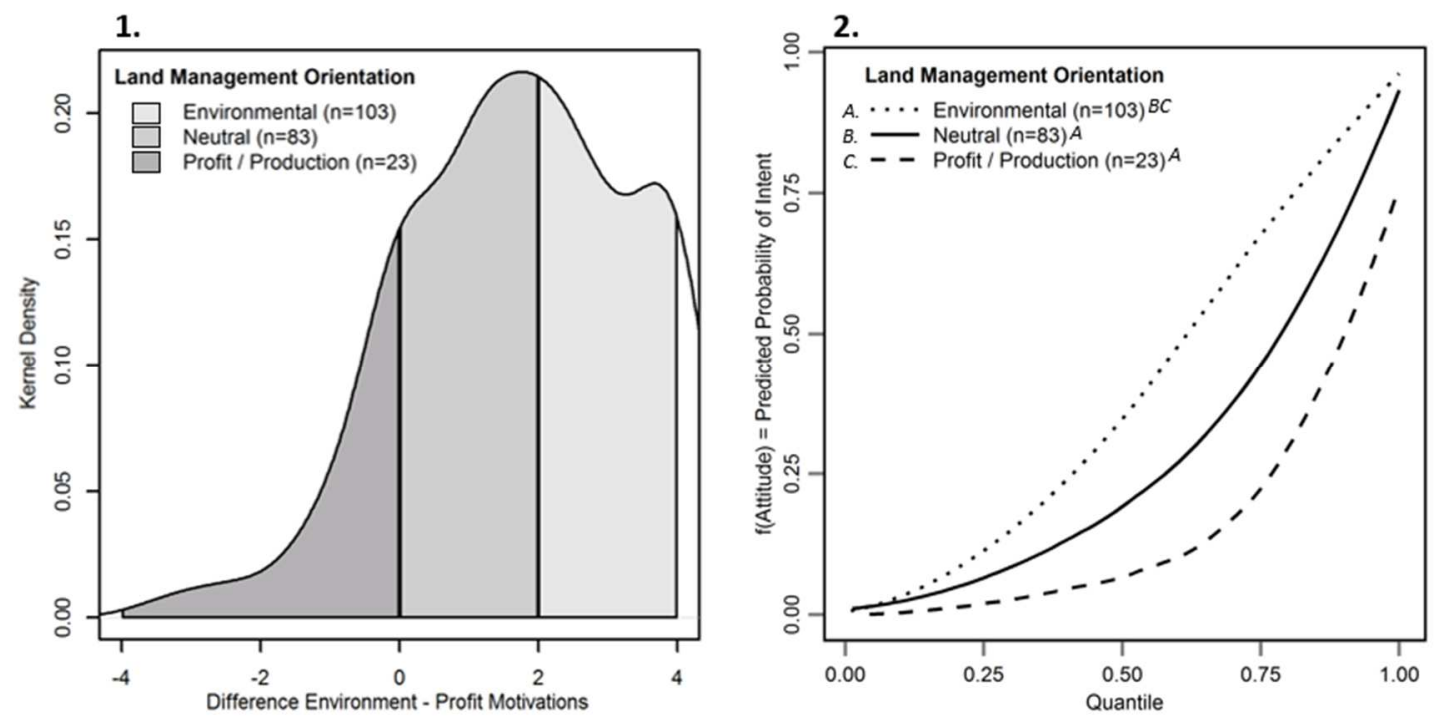

Figure 1.3

(1) Kernel density distribution of Land Management Orientation, split by group. (2) Cumulative distribution curve of predicted probabilities as a function of attitude compared between land management orientation groups. Significant differences between groups (Tukey HSD $\alpha<0.05$ ) are indicated by associated letters A, B, and C. 


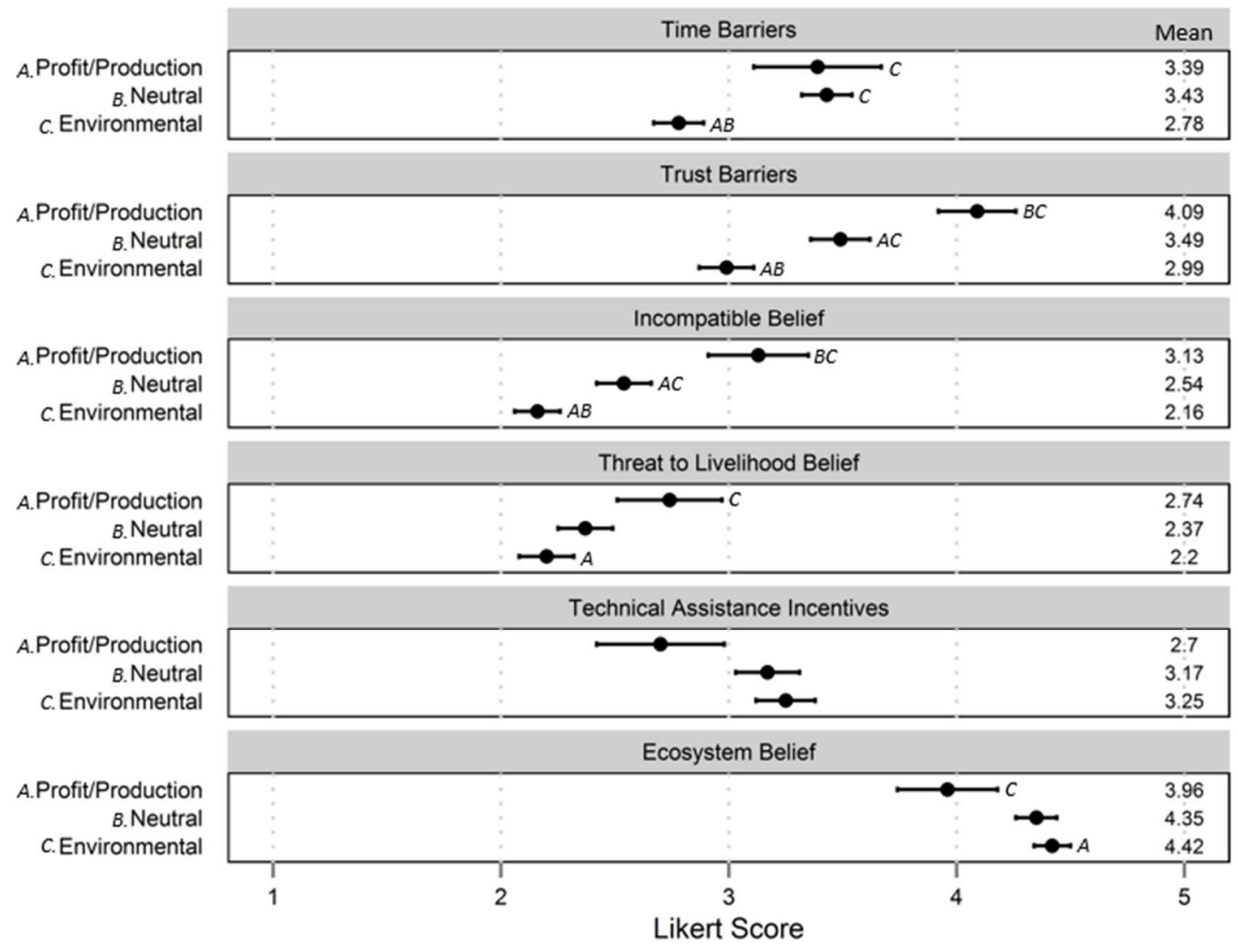

Figure 1.4

Mean and standard error bars of combined model variables by land management orientation $(n=208)$. Significant differences between groups (Tukey HSD $\alpha<0.1$ ) is indicated by associated letters $A, B$, and C.

When comparing differences between groups for each variable, I found that Profit/Production oriented landowners were the most likely $(\alpha<0.1)$ to perceive Trust Barriers and to report the Incompatible Belief, followed by Neutral respondents and Environmental respondents. I found similar relationships in the perception of Time Barriers and the Threat to Livelihood Belief. Environmentally oriented landowners were significantly more likely to hold the Ecosystem Belief compared with Profit/Production oriented landowners. I found no difference between groups in relation to interest in Technical Assistance Incentives (Figure 1.4). 


\section{DISCUSSION}

Though response rate was lower than anticipated, it is not unprecedented for this population; a previous questionnaire of agricultural landowners in the watershed conducted by the Clackamas River Basin Council in 2013 used the same methods and reported a $20.3 \%$ response rate. I found strong support for my initial conceptual model that attitudes can act as both motivators and barriers to enrollment in watershed stewardship programs. Furthermore, my findings support the hypothesis that land management objectives color attitudes that are relevant to enrollment intent. However, the relationship between land management objective, attitude, and enrollment intent was more complicated than I anticipated.

Previous studies have noted a positive relationship between environmental objectives and stewardship practices (Greiner et al. 2009, Arbuckle et al. 2009). Though I found that many individuals reported a high importance of protecting the environment and local waterways through their land management, this did not correspond to intent to enroll in a watershed stewardship program. These findings indicate that respondents tended to consider protection of the environment to be a moral imperative to be completed by selfinitiative, rather than through a formalized program to accomplish this goal. One respondent noted, "We have always maintained [our land] by ourselves without outside help or interference." These findings suggest that a lack of intent to enroll does not indicate an aversion to stewardship, but it appears that attitudes may prevent enrollment in stewardship programs.

Likewise, I found no relationship between profit/production objectives and intent to enroll. McCann et al. (1997) reported a similar finding; they surveyed conventional and 
organic farmers, and found no difference with regard to the percent of their incomes derived from farming. However, they did find a difference between environmental attitudes of conventional and organic farmers, suggesting that land management objectives may play an unresolved role in attitude. I examined this role by evaluating the relative importance of profit/production objectives and environmental objectives through the "land management orientation" index, and I found that when profit/production objectives took precedence over environmental objectives, attitudes were significantly more negative (Figure 1.4) and lead to a lower intent to enroll (Figure 1.3.2).

Carr and Tait (1991) surveyed farmers in the UK, and found that profit/production motives tended to take precedence over environmental motives. My findings suggest that relatively few respondents $(\mathrm{n}=23)$ reported profit/production motives to be substantially more important than environmental motives; however, individuals who reported similar influences of profit/production and environmental motives were less likely to report enrollment intent compared with purely environmentally motivated individuals. This indicates that environmental and profit/production motives on their own are not prerequisite or exclusive of enrollment in stewardship programs, but the relationship between these variables can help to explain differences in attitude. Profit/production objectives appear to moderate the influence of environmental considerations and lead to a lower predicted enrollment intent.

When I examined how attitudes relate to enrollment, I found that attitudes uniformly predict a lack of enrollment intent as opposed to intent; this suggests that attitudes are necessary, but not sufficient, conditions that must be addressed in order to ensure enrollment. The application of Prospect Theory (Kahneman and Tversky 1979) may 
offer an additional explanation of the relationship between attitude and intent. While I initially proposed the use of Prospect Theory as rationale for including negative attitudes in the model, my findings suggest that negative attitudes not only play an important role in influencing decision making, but in fact individuals seem to avoid action based on negative attitudes, whereas positive attitudes seem to have a less clearly defined relationship with behavioral intent. Interestingly, Ljung et al. (2012) found a similar concept to be true regarding attitudes towards hunting: negative attitudes universally predicted a lack of intent to hunt, but positive attitudes had little relationship to the act of hunting itself. Heberlein (2012) explains this phenomenon can be observed because possessing positive attitudes towards an action does not necessarily correspond to possessing the means to complete that action.

It seems that holding each of the appropriate attitudes independent of one another is not enough, and as such program tools should aim to address these attitudes in conjunction with one another. In order to further elaborate which policy tools are likely to be useful in the context of these findings, I return to Schneider and Ingram's (1990) policy tools to help understand effective means of engaging this population in watershed stewardship.

Authority Tools prohibit or require action through enforceable regulation. Though I did not include regulatory concerns in the attitude model as this variable was unstable when included, respondents did tend to report this to be a significant barrier to enrollment. Regulatory tools have proven highly unpopular in similar contexts (Lurie et al. 2013), and Sullivan et al. (1996) reported lack of trust in the government to be a high concern amongst landowners. Despite informing respondents that the CRWP are not a regulatory body and 
as such stewardship programs would not involve regulatory repercussions, there remained a high concern that enrollment would lead to regulatory implications.

The models showed a negative relationship between the enrollment and the perception that stewardship programs would threaten the respondent's livelihood, and I believe these concerns are primarily a concern for a loss of the lifestyle associated with using one's land for production values. Similar studies of farmers have found a relationship between the farming livelihood and lifestyle qualities such as independence (Sullivan et al. 1996) and closeness to nature (Schoon and Grotenhuis 2000). Kallstrom and Ljung (2005) found that when farmers felt that they had reduced control in decision making due to heightened regulation it threatened their ability to continue farming. As such, authority tools are likely a contentious method to encourage stewardship behavior, and stewardship programs should consider how to address this concern. For example, resource managers may work with federal and state regulators to institute a property rights assurances that participation will not lead to additional regulatory burden.

Incentive Tools assume individuals are utility maximizers, and attempt to encourage or discourage voluntary behavior with financial or other tangible benefits. While the PWS framework has attempted to encourage voluntary program participation through financial incentives, my findings support the growing field of research that imply the limited ability of PWS programs to fully account for landowner behavior. While financial barriers were somewhat widely reported, I did not find a significant relationship between enrollment intent and the perception of financial barriers or interest in receiving financial incentives to participate. This may support the notion that watershed stewardship programs have overemphasized financial payments to promote behavior, or it may indicate that 
respondents currently believe that they will be sufficiently compensated for enrollment. My findings support those reported by Ma et al. (2010), who described a conceptual model in which PES payments were considered as one of many tools to encourage enrollment, and demonstrated that for some farmers, payments simply will not change enrollment decision.

My framing of financial considerations as a barrier may limit interpretation here. While financial barriers and assistance overcoming those barriers may not significantly improve enrollment, it is possible that financial incentives beyond covering basic stewardship costs could still improve enrollment. Reimer and Prokopy (2014) found that a "lack of perceived benefit" was a significant deterrent to participating; when financial incentives are sufficient to outweigh the perceived risks associated with program participation, it is possible that finances may act as motivators. However, large financial incentives require substantial capital investment, and my findings imply that other tools should be considered first as a means to alter attitude and to lower such high transaction costs.

Capacity Tools assume individuals will partake in an action given the removal of barriers, and as such these tools involve the provision of training and resources to enable individuals to perform an action. My results suggest two primary barriers that may be addressed through capacity tools: the belief that stewardship programs are "incompatible" with a landowner's goals for his/her land and the belief that landowners did not have enough time to participate in such a program. Ma et al. (2010) reported a similar finding that perception of incompatibility amongst a strictly farm population was a key limitation to enrollment in stewardship programs. Individuals may be financially and technically 
capable of participation, but if these programs are seen as an inconvenience, landowners have little rationale to join.

Interestingly, I found that individuals who were responsive to receiving technical assistance through a dedicated staff member who can help to implement program strategies were significantly more likely to participate. This makes sense - some individuals will not participate because they simply do not have the time to engage in an activity that is incompatible with their primary land management objectives. However, receiving technical assistance can help to overcome this hurdle.

Symbolic Tools assume individuals are motivated by internal judgments and beliefs, and as such these tools attempt to showcase how a given policy direction is consistent with an individual's attitudes. My study focused on the importance of attitudes and provides further empirical support for the utilization of symbolic policy tools to encourage behavior. Amongst attitudes, I found lack of belief that functioning stream ecosystems are important for clean water (the Ecosystem Belief) and a lack of trust in conservation agencies (Trust Barriers) to be important deterrents to enrollment.

While individuals widely reported the Ecosystem Belief, those that did not hold this belief were much less likely to enroll. This item is distinguished from other environmental attitude items in that it focused on the outcomes of protecting ecosystem health rather than the causes of ecosystem degradation. In another survey of rural landowners, Armstrong and Stedman (2011) found a similar relationship; they failed to detect a relationship between knowledge of water quality issues and intent to implement riparian buffers, but they identified a strong relationship with belief in positive outcomes of buffer implementation. This may suggest that, regardless of beliefs about the state of watershed 
degradation, individuals must first believe that protecting environmental attributes of the watershed will lead to tangible improvements in water quality.

I found the perception of Trust Barriers to be a highly significant deterrent to enrollment intent. Smith et al. (2013) described the importance of trust between individuals and conservation agencies related to shared values and moral and technical competencies - the belief that agencies can make ethically grounded decisions based on the best available science. In one study, farmers reported lack of credibility of extension offices and NRCS programs - often citing that these programs were underfunded, behind the times, and too focused on expensive "special projects" (Woods et al. 2014). Another study noted that farmers frequently felt excluded from meaningful engagement with conservation programs and that the responsible agencies discounted farmer knowledge regarding the land (Harrison et al. 1998). Some studies have suggested that conservation program outcomes can be improved through social connections between individuals and other landowners (Armstrong and Stedman 2011), or with conservation organizations (Flitcroft et al. 2009, Muradian 2010). In these instances, conservation programs were successful because they established relationships and larger social norms within the community. As a result, I suggest that building trust between source water protection organizations and the local community is a vital first towards program success. An alternative route may include working through existing trusted organizations (such as local soil and water conservation districts, watershed councils, or producer organizations) within the community who have firmly established working relationships with landowners.

Surmounting initial barriers to enrollment will be difficult; respondents in the study were highly averse to program enrollment when negative outcomes were perceived, and 
yet positive attitudes did not guarantee intent to enroll. To help overcome such aversion, Lurie et al. (2013) suggested that enrollment may be encouraged by offering short term contracts to allow landowners to participate on a trial basis, after which a more long-term contract may be signed. Such trial programs may offer a key window in which relationships can be built and the key attitudes of trust, ecological understanding, and perceptions of incompatibility can be addressed.

\section{CONCLUSION}

This study represents landowners in a unique social, ecological, and political landscape, and while my general critiques of PWS and emphasis on consideration of alternate policy tools may be broadly applicable, my results re-affirm the importance of community-based knowledge as a prerequisite to program success. There are likely few, if any, universally significant independent variables to explain stewardship program enrollment, and I join other authors who have called for the study of specific landowner populations rather than grouping all landowners together (Greiner et al. 2009, Woods et al. 2014). I suggest that stewardship programs should allow sufficient flexibility to adapt not only to the entire population, but when possible to each individual landowner's needs and objectives.

Studying the relationship between attitudes and stewardship program enrollment is crucial not only because watershed-scale stewardship actions are mediated through stewardship programs, but program enrollment has been linked with long term changes in attitude (Wilson and Hart 2001). Provided that these changes in attitude are positive, overcoming initial barriers to enrollment can be an important first step towards fostering a widespread culture of stewardship. 


\section{CHAPTER TWO}

\section{Stewardship Program Engagement with Diverse Landowners}

In the previous chapter, I found evidence that land management objectives influence attitude and stewardship intent. In this chapter, I dive deeper into this concept by identifying distinct groupings of landowners dependent on their primary land management objectives and creating typologies based on these objectives. I discuss key divisions in perceived barriers to enrollment in stewardship programs between these typologies, as well as how these typologies differ in their preferred incentives and management actions relating to watershed stewardship.

\section{INTRODUCTION}

Watersheds often are comprised of a large number of landowners with diverse interests and objectives for their land. In these cases, private landowners are the necessary mediators by which downstream water quality is determined (Ahnstrom et al. 2008), and understanding these objectives is crucial to engage these landowners in watershed stewardship. In recent years, rising rates of exurban development have added additional complexity and challenges to these landscapes, replacing large swaths of agricultural and timber lands with amenity-driven rural landowners (Brown et al. 2005). These land use changes have had important consequences for the both the ecological functioning of rural landscapes as well as the dominant methods by which private lands are managed (Dale et al. 2005).

Despite the rising rates of complexity in land ownership, most federal conservation programs remain geared towards commercial agricultural and timber landowners. Many of these programs rely on the classic agricultural economics assumption that operator 
landowners inherently make decisions based on the net profitability of these choices (Koontz 2001), and as such are structured around offering financial incentives to promote desired land management behaviors (e.g. Conservation Reserve Program, Environmental Quality Incentives Program). While I have previously argued that such programs are not a panacea for promoting stewardship amongst financially-motivated land operators, they may be particularly problematic as a means to encourage behavior amongst the growing numbers of landowners who do not rely on their land for financial gain (Koontz 2001).

As a first step towards designing and implementing conservation programs compatible with a wider array of land management objectives, researchers have begun to consider the inter-relationship between financial and non-financial objectives in describing distinct groupings of landowners. At the coarsest level, landowners may be characterized by their utilization of land or lack thereof for production and income - often manifested as a distinction between foresters (Majumdar et al. 2008) or farmers (Kaplowitz and Witter 2008) and non-operator landowners. This distinction offers an easily identifiable way of characterizing landowners based on external criteria, and such typologies can be somewhat easily distinguished using simple demographic and property characteristics (e.g. Majumdar et al. 2008, Nielsen-Pincus et al. 2015). Yet perhaps unsurprisingly, this simple dichotomy appears insufficient to explain adoption of stewardship behaviors; for example, past studies have found non-operator residential landowners to be both more (Kaplowitz and Witter 2008, Arbuckle et al. 2008) and less (Armstrong and Stedman 2011) likely to engage in stewardship behavior compared with their producer counterparts. While the inclusion of both producer and non-producer landowners in the land stewardship literature is an 
important first step, it appears that such categories are somewhat fluid (Majumdar et al. 2008) and more fine-scale description of land management objectives is needed.

A brief (and by no means exhaustive) review of the literature highlights the increasing recognition of complexity associated with land ownership objectives. Kline et al. (2000) measured the pursuit of lifestyle amenities in addition to profit and production objectives to describe different types of landowners. Maybery et al. (2005) noted that many landowners were divided in their views of the environment, and considered environmental conservation as differentiating characteristic amongst landowners. More recently, NielsenPincus et al. (2015) identified five key land management considerations that could be used to describe landowners in the wildland-urban interface: pursuit of natural/lifestyle amenities, forest/timber management, home and family, agricultural production, and development. Below, I explore in more detail the variety of objectives theorized to influence producer and non-producer engagement with land stewardship initiatives.

\subsection{Producers}

Due to the large footprint and historical dominance of agricultural and forestry land uses in the United States, adoption of stewardship practices amongst producer landowners is well represented in the literature. While both farmers and foresters have expressed general support for environmental outcomes in a variety of contexts, past research suggests that perceived barriers may inhibit stewardship behavior. Napier et al. (1998) utilized Rogers (1983) Diffusion model to explain participation in government sponsored soil erosion control problems, and suggested that four key attitudes must be present in order for a farmer to consider enrollment: the farmer must believe that (1) a problem exists, (2) the costs of enrollment are reasonable, (3) the desired practices are relevant to farm operations, 
and (4) the benefits outweigh the costs. Fischer (2012) described similar set of conditions necessary for engaging commodity-driven non industrial private forestlands (NIPF) owners in stewardship initiatives, including perception of financial benefit, marketability, and compatibility with their values as family forest owners. Further evidence supports the notions that producer enrollment is ultimately dependent on whether such practices limit or enhance land productivity (Woods et al. 2014), and whether or not the farmer perceives a self-benefit to utilizing these practices (Reimer and Prokopy 2014). Additional barriers to enrollment may include perception of regulatory limitations (Reimer and Prokopy 2014) and risk (Greiner et al. 2009).

While the above literature provides a broad understanding of how producer attitudes relate to enrollment in stewardship programs, the question remains: how and why do producers differ in these key attitudes? Petrzelka et al. (1996) theorized that farmers can be split as "sustainable" or "conventional," defined by a view of whether humans should dominate or harmonize with nature. Similarly, Sullivan et al. (1996) surveyed conventional and organic farmers, and found that farmers in both groups shared many perceived barriers and were not differentiated according to economic considerations, but were split by their views on nature. Maybery et al. (2005) equate conventional farmers with those who are driven primarily by economics, and sustainable farmers as those who are driven primarily by maintaining the farming lifestyle and closeness to nature. Greiner et al. (2009) surveyed ranchers in Australia and found that financial considerations did not appear to be an important predictor of stewardship behavior, and instead stewardship was differentiated primarily by level of interest in conservation and lifestyle objectives.

\subsection{Non-Producers}


The heavy focus on commercial producers fails to represent the growing presence of non-production oriented land management objectives represented within a typical watershed (Rosenberg and Margerum 2008), including small acreage hobby farmers, residential homeowners, and real estate investors. These groups may cumulatively have a large impact on the landscape; between 1950 and 2000, the amount of land in the United States populated at exurban densities increased five-fold, the majority of which has resulted as the result of conversion of agricultural and forestry lands (Brown et al. 2005). Kaplowitz and Witter (2008) compared non-commercial residential landowners to commercial producers, and found that non-commercial landowners were generally more accepting of their responsibility for watershed degradation and were more willing to place riparian buffers on their lands. Conversely, Armstrong and Stedman (2011) compared a similar population, and found that residential landowners were less willing to implement buffers due to aesthetic preferences. Such unclear relationships suggest that all non-operator homeowners cannot be classified into one category, and instead more fine-scale distinction of objectives may further elaborate stewardship behavior.

Pannell and Wilkinson (2009) investigated residential landholders, and described two major objectives: those driven by environmental objectives, and those driven by aesthetic objectives. Similarly, Ryan (2009) differentiated non-commercial riparian landowners by stewardship ethic, and suggested that stewardship related to perceptions of personal accountability for watershed degradation and feasibility of restoration to be key variables. Fischer (2012) split non-producer forest landowners objectives into three classes: amenity (residents driven by the rural lifestyle), recreation (absentee landowners who utilize the property as a second home), and passive (absentee landowners without a 
clearly defined ownership objective). The authors found that absentee landowners were generally less likely to actively manage their land to minimize wildlife risk likely due to perceptions of "inconvenience" for their limited time on their property. Petrzelka et al. (2009) noted a similar relationship; absentee landowners tended to report a high interest in conservation but exhibited low enrollment rates in conservation programs.

\subsection{Research framework}

The primary objectives of this research were to (1) test whether production objectives influence perceived barriers and preferred methods of engagement with stewardship programs, (2) classify landowners according to the relative importance of production and less-easily identifiable land management objectives theorized to influence stewardship behavior, and (3) compare how these groups differ in the aforementioned perceived barriers and preferred methods of engagement. According to Nielsen-Pincus et al. (2015), an effective landowner classification system will produce classes that are "readily interpretable, represent distinct suites of landowner motivations, and link those motivations to preferred land management strategies," and I take a similar approach in defining appropriate landowner classes. Based on my literature review, I expected landowner typologies to be defined primarily by use of land for production purposes, with further refinement by consideration of other objectives such as conservation, recreation, or investment considerations. In general, I expected producers to perceive greater financial barriers to enrollment and to be more interested in receiving financial incentives compared with non-producers.

Following determination of landowner typologies, I explore the distribution of landowners by comparing the makeup of four different sub-watersheds: the Clackamas 
mainstem, Clear Creek, Deep Creek, and Eagle Creek. These four watersheds are characterized by similar sizes and land use makeup, and are difficult to distinguish from one another by simply looking at tax parcel data. However, I hypothesized that the distribution of landowner typologies may be different between subwatersheds and may help to target policy interventions.

\section{METHODS}

Amongst other things, the survey instrument was designed to measure land management objectives, property and demographic characteristics, perceived barriers to enrollment in stewardship programs, and preferred methods of engagement with stewardship programs. All analyses were performed in R Studio (Version 3.2.3).

\subsection{Land Management Objectives}

I asked respondents to rate the importance of various land management objectives on a 5 point Likert scale from "not at all important" to "very important." These objectives included environmental, recreational, financial, and production oriented objectives. Though similar studies separate farmers and foresters (e.g. Nielsen-Pincus et al. 2015), I was interested in creating groups based on the more general relationship between land use for production or for lifestyle, and I did not attempt to differentiated these groups from one another.

To identify the underlying dimensions of land management objectives, I performed an exploratory factor analysis using polychoric correlations on land management objectives ('Psych' R Package, Revelle 2015) using varimax rotation. Polychoric correlations are a modified version of the Pearson correlation coefficient used when an ordinal variable is theorized to represent an underlying normally distributed variable (see 
Drasgow 1988) as is the case with Likert-scale data. I identified three factors which I interpret to represent "Production" objectives (associated with the production and sale of farm and/or timber products), "investment" objectives (associated with maximizing return on investment or development potential), and "conservation" objectives (associated with the pursuit environmental and to a lesser extent recreational objectives) (Table 2.1).

\subsection{Production Objective Regression Models}

In order to test if production objectives on their own could help to explain differences in attitude, I performed an Ordinary Least Squares regression utilizing the factor score from production as a predictor of each of the eight listed variables independent of one another (Table 2.2, “coef" column). I considered production to be a significant predictor of attitude when $\mathrm{p}<0.05$. 
Table 2.1

Univariate distributions and 3-factor solution for responses to: "How important are the following factors when you are making decisions regarding your land?" Percent important indicates percentage of respondents marking "important" or "very important." (Factor loadings greater than 0.4 are bolded for emphasis).

\begin{tabular}{|c|c|c|c|c|c|c|}
\hline \multirow[b]{2}{*}{ Goals and Objectives } & \multirow{2}{*}{$\begin{array}{c}\text { Percent } \\
\text { Important }\end{array}$} & \multirow{2}{*}{ Mean ${ }^{A}$} & \multirow{2}{*}{ SD } & \multicolumn{3}{|c|}{ Rotated Factor Loadings } \\
\hline & & & & Product. & Conserv. & Invest. \\
\hline Produce farm or timber products & $38 \%$ & 2.70 & 1.70 & 0.85 & 0 & 0.18 \\
\hline Provide income & $27 \%$ & 2.48 & 1.50 & 0.78 & 0.04 & 0.31 \\
\hline Run a business & $20 \%$ & 2.21 & 1.46 & 0.9 & -0.01 & 0.3 \\
\hline Provide recreational opportunities & $50 \%$ & 3.43 & 1.34 & 0.11 & 0.44 & 0.2 \\
\hline Preserve open space & $70 \%$ & 3.97 & 1.23 & -0.08 & 0.82 & -0.05 \\
\hline Protect wildlife & $75 \%$ & 4.14 & 1.04 & -0.05 & 0.89 & -0.12 \\
\hline Protect local waterways & $77 \%$ & 4.21 & 1.05 & 0.04 & 0.79 & 0.1 \\
\hline Enhance investment potential & $51 \%$ & 3.40 & 1.40 & 0.3 & 0.13 & 0.67 \\
\hline Enhance development potential & $21 \%$ & 2.28 & 1.42 & 0.33 & -0.05 & 0.72 \\
\hline Eigenvalue & & & & 2.37 & 2.31 & 1.25 \\
\hline$\%$ Variance explained & & & & $26 \%$ & $26 \%$ & $14 \%$ \\
\hline
\end{tabular}

${ }^{A}$ Responses range from not at all important (1) to very important (5)

\subsection{Landowner Typologies}

I utilized the factor scores to perform a k-means cluster analysis to identify distinct groupings of landowners by land management objective. I used the $\mathrm{R}$ base function kmeans() to perform the cluster analysis using 10,000 iterations, which ultimately converged on a five cluster solution. I assigned each of the respondents to the appropriate cluster, and I calculated the mean of each measured land management objective for each landowner cluster (Figure 2.1) and compared them to one another to create descriptive landowner typologies.

\subsection{Landowner and Property Characteristics}

I queried socio-demographic characteristics of the respondents, including education, income, political ideology, value of agricultural sales, ownership tenure, and age. Using ESRI ArcGIS (version 10.2), I measured the total acreage owned by each landowner by calculating the sum total acreage of all tax parcels registered to that individual within the confines of the Clackamas River watershed. Additionally, I calculated 
the total kilometers of streams on each landowner's property by overlaying tax parcels and streams identified in the USGS National Hydrography Dataset. Last, I defined four subwatersheds in which respondents were represented (Clackamas Mainstem, Deep Creek, Clear Creek, and Eagle Creek) and assigned each landowner to the watershed in which they had the greatest amount of property.

\subsection{Barriers to Enrollment}

I asked respondents to rate their level of agreement (from "strongly disagree" to "strongly agree" with four statements explicitly relating to reasons that would prevent them from enrolling in a watershed stewardship program. I chose these barriers to enrollment based on those shown to influence landowners in the literature: practical barriers such as financial limitations and time constraints (Williams 2002, Woods et al. 2014), and less tangible barriers relating to lack of trust (Rosenberg and Margerum 2008, Smith et al. 2013) and concerns for regulatory implications as a consequence of enrollment (Greiner et al. 2009, Kallstrom and Ljung 2005, Armstrong and Stedman 2011).

\subsection{Preferred Methods of Engagement}

I asked respondents to rate their likelihood of enrolling in a watershed stewardship program if (a) offered any of 6 different incentives and (b) the program involved working towards any of seven separate land management goals. I looked to reduce the number of variables represented by performing an exploratory factor analysis on each of these two groups, and creating indices by taking the mean of variables shown to represent an underlying data structure. I evaluated the internal consistency of these indices by calculating Chronbach's alpha. This analysis revealed two main types of incentives: "financial incentives" (alpha $=0.93)$ and "assistance implementing project" (alpha=0.84); 
and two types of land management goals: "agrichemical reduction" (alpha $=0.89)$ and "riparian habitat improvements" (alpha $=0.92)$.

\subsection{Within Group Comparisons}

I tested both for significant differences among landowner typologies and between each group individually compared with all other groups combined (that is, whether each group tends to be significantly higher or lower than the mean of all other groups). For presence/absence (land use) and non-Likert ordinal (income, political tendency, and value of agricultural sales) data, I utilized a Chi-square test for goodness of fit. Because this test resulted in expected frequencies for some groups of less than 5, I utilized Monte Carlo pvalue simulations with 2000 replicates to create more conservative and accurate representations of significance. I tested for differences in continuous data (age, ownership tenure, $\log ($ property size), and $\log ($ stream length on property) $)$ by running an analysis of variance test (ANOVA). For Likert scale ordinal data (barriers and preferred methods of engagement), I compared differences in means among groups by utilizing an ANOVA. I tested for differences between groups by utilizing a Mann-Whitney $U$ test, a nonparametric test that holds no assumption of normality and performs with almost equal efficiency to the student's t-test.

\section{RESULTS}

Seventy-two surveys (6.5\%) were returned as undeliverable, leading to an effective sample of 958. I received 268 responses with sufficient data to complete the cluster analysis, representing $28 \%$ of the sample. Because the population contained both rural residential and agricultural properties, I compared demographics and property characteristics from respondents to both the most recent National Agricultural Statistics 
Service Census of Agriculture (USDA 2012) for Clackamas County and the most recent American Community Survey (US Census Bureau 2009-2013) for census tracts represented in the study area. Compared with these two data sources, the sample tended to be older (median age 63 ) and more educated ( $48 \%$ with a college degree). Property size, agricultural sales, gender, and income tended to fall within the range of values represented by the reference sources.

Goals relating to conservation were the top land management objectives and included "preserve open space" $($ mean $=3.97)$, "protect wildlife" $($ mean $=4.14)$, and "protect local waterways" $($ mean $=4.21)$. "Provide recreational opportunities" $($ mean $=$ 3.43) and "enhance investment potential" (mean $=3.4$ ) were also widely reported. production-oriented goals such as "produce farm or timber products" $($ mean $=2.70)$, "provide income" (mean $=2.48)$, and "run a business" (mean = 2.21) were less frequently reported, but had the highest standard deviations, reflecting the mixed sample of both producers and non-producers. "Enhance development potential" $($ mean $=2.28)$ was also infrequently reported (Table 2.1).

Respondents tended to agree that "regulatory barriers" (mean $=3.71)$ were the greatest obstacle to enrollment in stewardship programs, followed by "trust barriers" (mean $=3.31)$, "financial barriers" ( mean $=3.20)$, and "time barriers" ( mean $=3.1)$. Respondents were generally ambivalent regarding the potential to receive "financial incentives" (mean $=3.19$ ), "assistance implementing project" $($ mean $=2.95)$, and to work towards "fertilizer/pesticide reduction" (mean $=3.13$ ). Respondents tended to most agree that they would be interested in working towards "riparian habitat improvements" $($ mean $=3.72)$ (Table 2.2) 


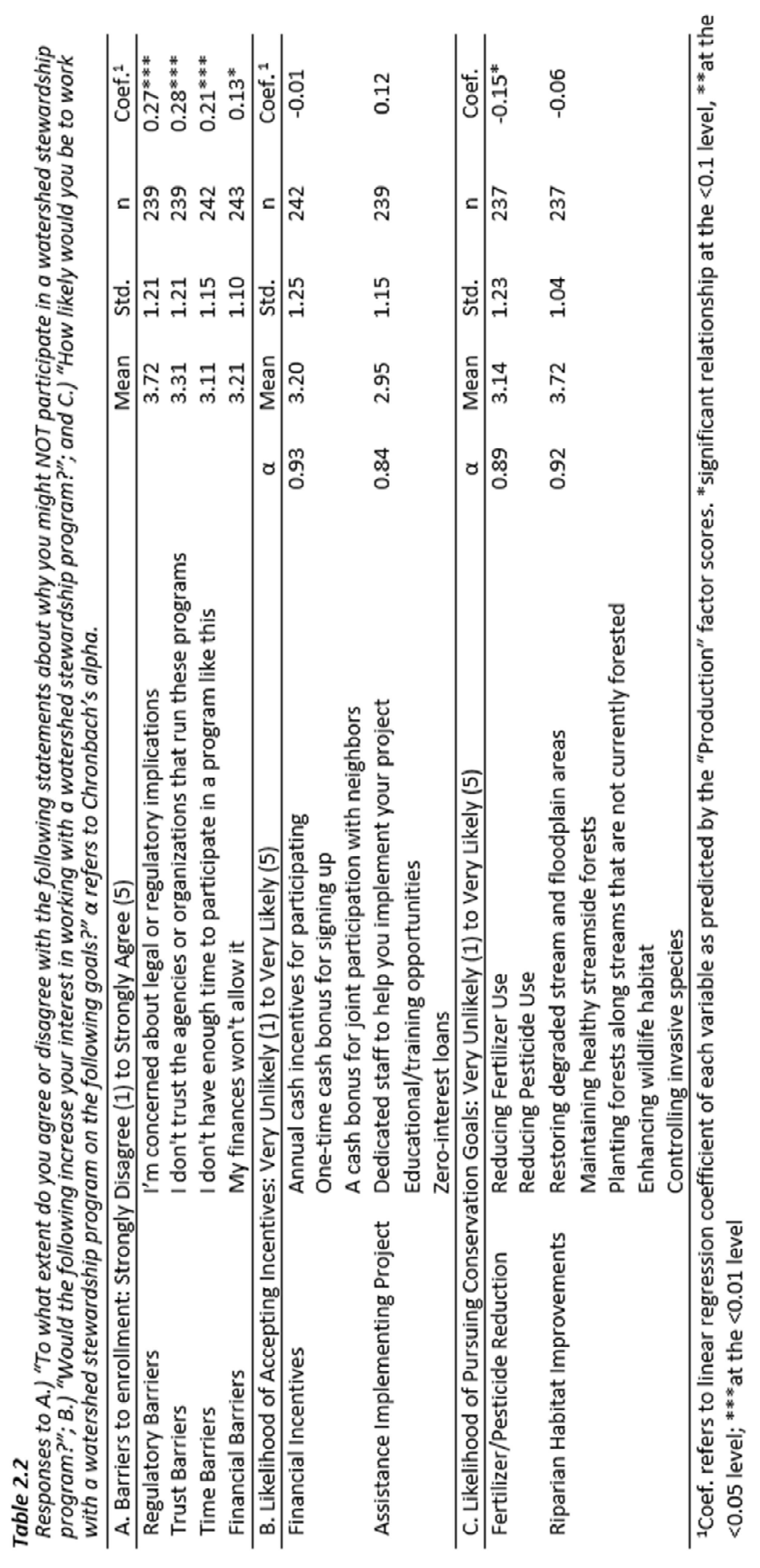


The factor scores for production objectives were negatively associated with the perception of all barriers, and were particularly strongly associated with the perception of Regulatory and Trust Barriers $(\mathrm{p}<0.01)$. Furthermore, production objectives were weakly negatively associated with interest in pursuing fertilizer/pesticide reduction goals $(p<0.1)$ (Table 2.2).

\section{LANDOWNER TYPOLOGIES}

The cluster analysis revealed five distinct landowner typologies, named according to the importance each group placed on production, investment, and conservation objectives (Figure 2.1). Two typologies reported particularly low production scores and can be classified as non-producers: "Lifestyle Homeowners" $(\mathrm{n}=69)$ and "Amenity Investors" $(\mathrm{n}=47)$. Two typologies reported particularly high production scores and can be classified as producers: "Lifestyle Producers" $(\mathrm{n}=53)$ and "High-value Producers" (n $=46$ ). The two non-producer typologies and the two producer typologies tended to respond more similarly to one another compared with responses between producers and nonproducers. A fifth group, "Disengaged Landholders" $(\mathrm{n}=53)$, reported low scores for all three listed objectives and tended to be the most distinct group in terms of mean response. These differences in land management objectives translated into differences among groups regarding whether they tended to agree $(>3)$, disagree $(<3)$, or be neutral $(\sim 3)$ to each of the perceived barriers and preferred methods of program engagement (Figure 2.2). In the following sections, I describe each of these groups in more detail and attempt to interpret the diversity of responses exemplified. 


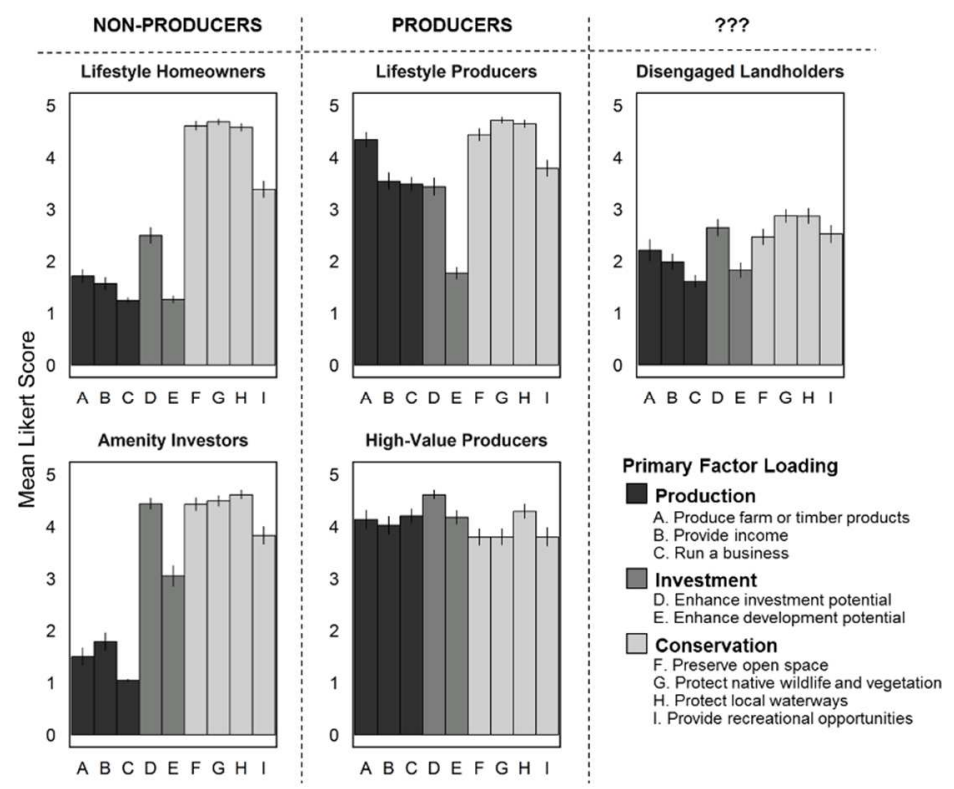

Figure 2.1

Mean land management objectives and standard error bars compared between clusters. Primary factor loading indicates the top factor on which each variable loaded onto.

\subsection{Non-Producer Typologies}

Non-producer typologies tended to report low production (mean $<2$ ) and high conservation scores (mean $>4$ ), and tended to have smaller property sizes, report fewer agricultural or forestry land uses on their land, and report little to no agricultural sales from their property. Additionally, these two groups were the most likely typologies to reside on their property $(>90 \%)$. These non-producer typologies tended to perceive fewer barriers to enrollment in stewardship programs and were generally more interested in working with a stewardship program on the listed land management strategies. They were the only two groups to not perceive time barriers to enrollment (mean $<3$ ). However, Lifestyle Homeowners and Amenity Investors were differentiated by their views of their property as an investment; an objective which seems to weakly influence how these groups perceive barriers and prefer to engage in watershed stewardship programs. 


\section{Table 2.3}

Land use, demographic, and parcel characteristics compared between landowner clusters. All data come from survey responses except for Property Size and Stream Length, which were calculated using ArcGIS.

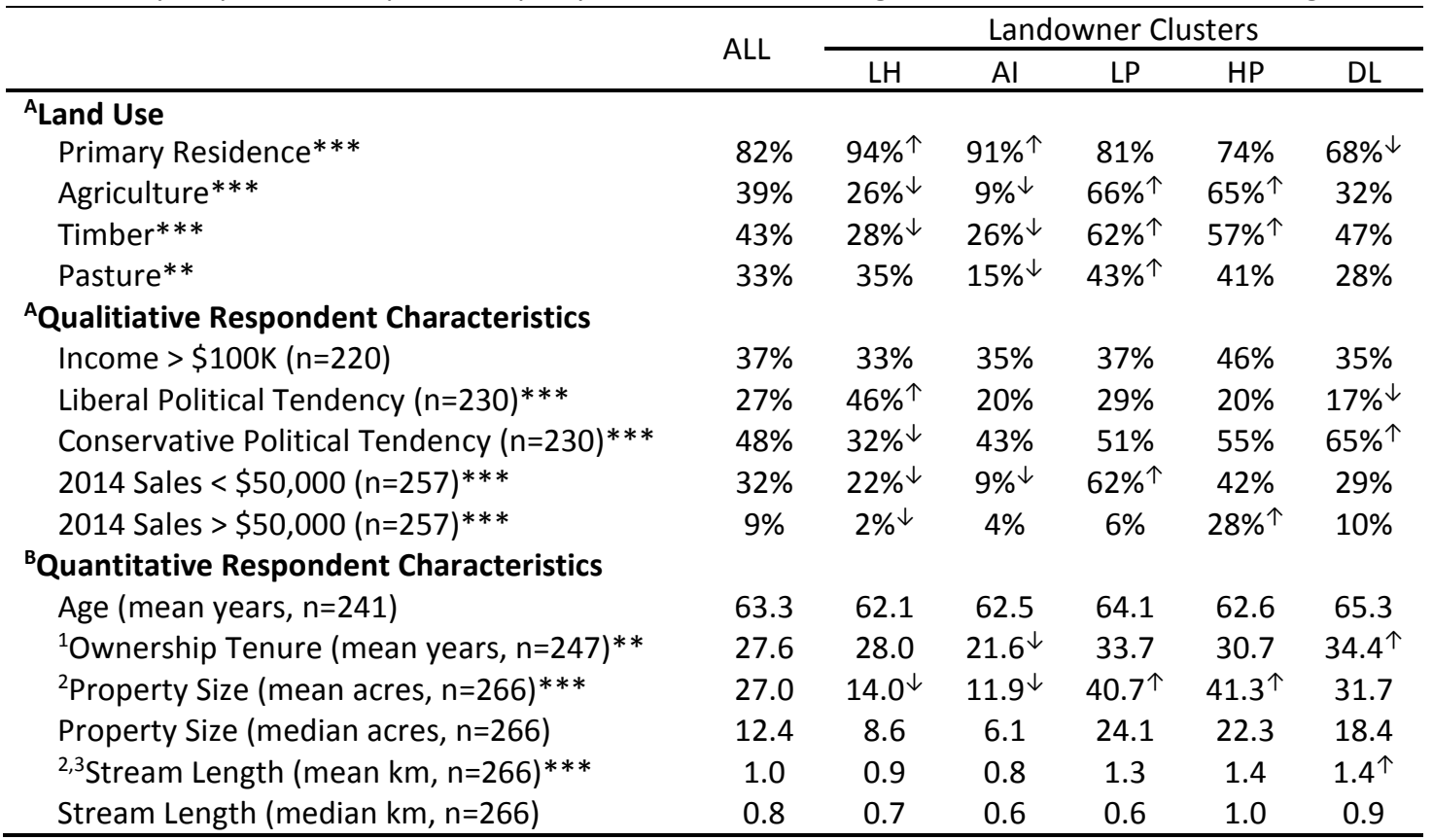

Notes: ${ }^{1}$ Represents only ownership < 80 years to correct for outliers in data. ${ }^{2}$ Significance levels refer to test on log-transformed data to correct for non-normality. ${ }^{3}$ Significant levels refer to only properties with streams on site.

LH = Lifestyle Homeowners, AI = Amenity Investors, LP = Lifestyle Producers, IP = High-value Producers, $\mathbf{D L}$ $=$ Disengaged Landholders

${ }^{A}$ All tests in section run with chi square test using Monte Carlo p-value simulations (2000 replicates).

${ }^{B}$ All tests in section run using ANOVA

*significant within group differences at the $<0.1$ level, **at the $<0.05$ level; ***at the $<0.01$ level

$\uparrow$ significantly higher at $<0.05$ level compared with all other groups combined

$\downarrow$ significantly lower at $<0.05$ level compared with all other groups combined

\subsubsection{Lifestyle Homeowners $(n=69,26 \%)$}

Lifestyle Homeowners were the largest and generally the most enthusiastic group about program enrollment, and they perceived significantly fewer trust barriers (mean $=$ $2.84)$ and time barriers $($ mean $=2.81)$ than any other group. Additionally, this group is the only landowner cluster that tended to be more politically liberal $(46 \%)$ than conservative $(22 \%)$, a characteristic that firmly distinguishes them from Amenity Investors. While respondents in this group are classified as "non-producers," there were some reported agricultural (26\%), timber (28\%), and pasture (35\%) land uses, and $24 \%$ of this group 
reported some (primarily low value) agricultural sales in 2014. Therefore, production is not excluded as a land use amongst these landowners, but it seems likely that productionoriented land uses are recreationally-driven.

\subsubsection{Amenity Investors $(n=47,18 \%)$}

Amenity Investors are characterized by somewhat higher recreational $(\sim 4)$ and investment land management objectives (3-4) compared with Lifestyle Homeowners. They responded similarly to Lifestyle Homeowners regarding perceived barriers and preferred methods of program engagement, but tended to report somewhat higher Trust Barriers $($ mean $=3.14)$ and a greater interest in receiving financial incentives $($ mean $=3.38)$. They were least likely landowner group to report agricultural (9\%) or pasture (15\%) land uses, and were also the least likely to report any agricultural sales (13\%). However, approximately $26 \%$ of this group reported Timber as a land use of their property, indicating that a portion of this group may represent non-industrial private forestland owners (NIPF) who may not actively manage their land for timber, but instead reserve the potential for future timber harvest on their property. They had the shortest ownership tenure of any group $($ mean $=21.6$ years $)$.

\subsection{Producer Typologies}

The two producer typologies were differentiated from other typologies primarily by their high production scores and frequent agricultural and timber land uses. They tended to own the largest properties (median $>22$ acres) and reported the highest frequency of agricultural sales $(\sim 70 \%)$. Both typologies tended to perceive more regulatory, trust, and time barriers to enrollment compared with non-producer typologies. Additionally, where non-producer typologies tended not to perceive financial barriers, producers weakly 
reported the perception of financial barriers (Lifestyle Producers mean $=3.41$; High-value Producers mean $=3.25$ ). I did not detect a difference between interest in incentives between producer and non-producer typologies; however, producers tended to be less interested in the listed land management strategies compared with non-producers. The two classes of producers were split primarily by their consideration of investment potential in their land management.

A. Barriers to Enrollment
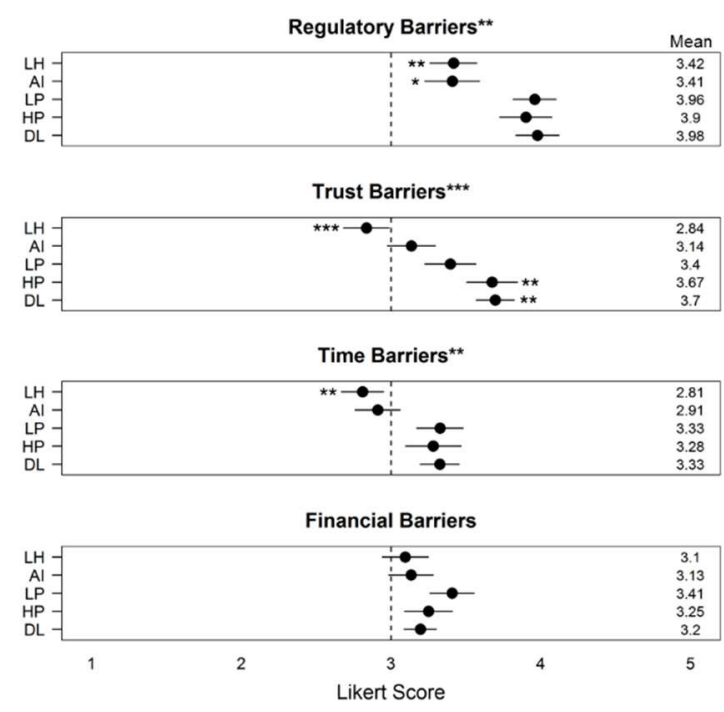

B. Preferred Methods of Engagement

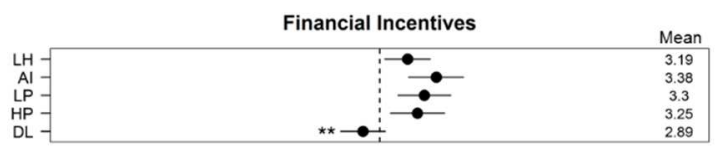

Assistance Implementing Project ${ }^{\star \star \star}$

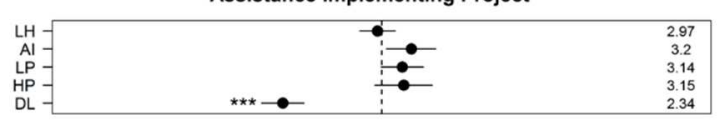

Fertilizer/Pesticide Reduction*
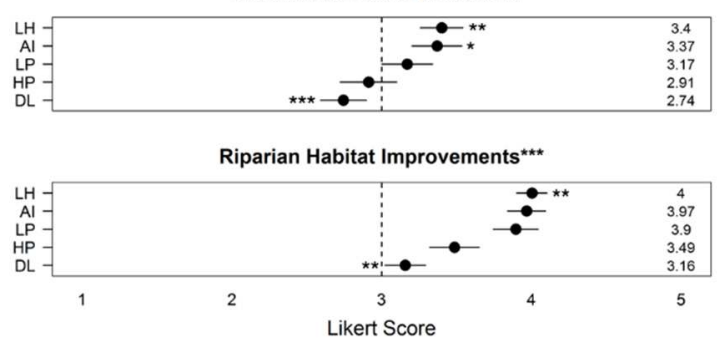

Figure 2.2

A) Perceived barriers to enrollment in hypothetical watershed stewardship program among landowner typologies. Scale ranges from strongly disagree (1) to strongly agree (5). The center line indicates neither agree nor disagree (3).

B) Likelihood that listed incentives and goals would increase enrollment in hypothetical watershed stewardship program among landowner typologies. Scale ranges from very unlikely (1) to very likely (5). The center line indicates neither likely nor unlikely (3).

Significance levels on plot titles refer to results of ANOVA among all clusters for that variable. Significance levels on error bars within plots refer to results of Mann-Whitney U Test of that group compared with all other groups combined. To the right indicates significantly higher, whereas to the left indicates significantly lower.

${ }^{*}$ significant at the $<0.1$ level, **at the $<0.05$ level, ${ }^{* * *}$ at the $<0.01$ level

$\mathbf{L H}=$ Lifestyle Homeowners, $\mathbf{A} \mathbf{I}=$ Amenity Investors, $\mathbf{L P}=$ Lifestyle Producers, $\mathbf{I P}=$ High-value Producers, DL $=$ Disengaged Landholders 


\subsubsection{Lifestyle Producers $(n=53,20 \%)$}

Lifestyle Producers are differentiated from High-value Producers by their low investment scores, marginally lower production scores, and marginally higher conservation scores. This group was the most likely group to report low-value agricultural sales $(62 \%<$ $\$ 50,000)$, and was highly unlikely to report high value agricultural sales $(6 \%>\$ 50,000)$. They tended to be somewhat more interested in fertilizer/pesticide reduction $($ mean $=3.17)$ and substantially more interested in pursuing riparian habitat improvements $($ mean $=3.9)$ compared with High-value producers. These individuals appear to represent low-value producers who are motivated more by maintaining a rural lifestyle compared with maximizing returns through their land management.

\subsubsection{High-value Producers $(n=46,17 \%)$}

High-value Producers are characterized by high scores for all three objectives (mean $>4$ ), and they were the most likely group to report high value agricultural sales $(28 \%>\$ 50,000)$. They were most strongly differentiated from Lifestyle Producers by consideration of their property for development potential $(>4)$, and were less strongly differentiated by a marginally higher investment score. They tended to be disinterested in fertilizer/pesticide reduction (mean $=2.91)$ and marginally interested in pursuing riparian habitat improvements $($ mean $=3.49)$. While this group values the recreational and conservation aspects of landownership, they emphasize strong monetary motivations, and their land management is likely to be ultimately influenced by whatever brings top dollar.

\subsection{Disengaged Landholders $(n=53,20 \%)$}

I identified one group - Disengaged Landholders - that was difficult to classify according to land management objective as they reported low scores for all three listed 
objectives (mean scores $<3$ ). Though this group reported low production scores, it was difficult to label them as "non-producers" because this group was somewhat likely to report agricultural (32\%), timber (47\%), and pasture (28\%) land uses, and about half of this group (49\%) reported agricultural sales. This group is difficult to identify according to readily available property or demographic characteristics, as they tended to fall somewhere between producers and non-producers in terms of income and property size, and were only marginally older than the other groups (mean age $=65.3$ years, not significant). However, three characteristics indicate that this group represents a distinct subset of landowners: they were the least likely group to reside on their property $(68 \%)$, tended to report significantly longer ownership tenures compared with other groups (mean $=34.4$ years), and they were by far the most politically conservative group $($ mean $=65 \%)$.

\subsection{Distribution of Landowner Typologies}

I found no significant difference in the frequency of each cluster represented in each subwatershed, but I did find a significant difference in relative percentage of stream lengths represented between each watershed; Lifestyle Homeowners tend to dominate Eagle Creek (35\% of streams) and Deep Creek (30\% of streams), whereas Disengaged Landholders tend to dominate Clear Creek (35\% of streams) and the Clackamas Mainstem ( $25 \%$ of streams) (Figure 2.3). The percentage of stream kilometers represented tended to be more even in the Clackamas Mainstem, which is geographically between Deep/Eagle Creek and Clear Creek, showing a general increase in representation of conservation scores from east to west across the watershed. 

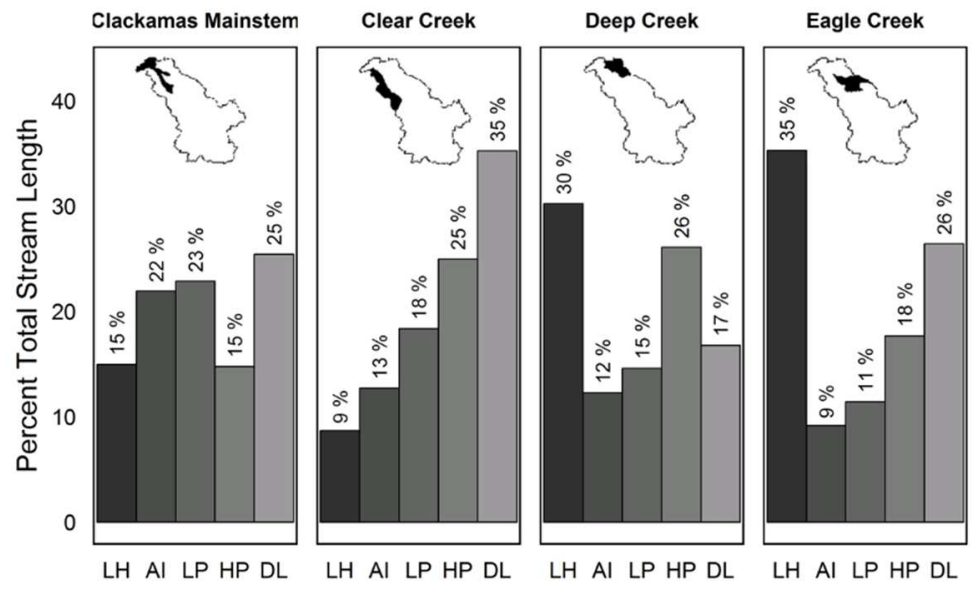

Figure 2.3

Landowner Typologies

Proportion of stream length represented by each landowner cluster in each subwatershed (Chisq $\mathrm{p}=0.0 .0035$ ). Inset maps identify subwatershed boundaries within the Clackamas River watershed.

$\mathbf{L H}=$ Lifestyle Homeowners, $\mathbf{A} \mathbf{I}=$ Amenity Investors, $\mathbf{L P}=$ Lifestyle Producers, $\mathbf{I P}=$ High-value Producers, $\mathbf{D L}$ $=$ Disengaged Landholders

\section{DISCUSSION}

Landowners within the Clackamas River watershed demonstrated a diversity of objectives, and this diversity translated into differences in perceived barriers and preferred methods of engagement with stewardship programs. The relationship between land management objectives and land stewardship is not new; Kline et al. (2000), Majumdar et al. (2009), Fischer (2012), and others have come to similar conclusions. However, my research adds clarity to the relationship between land management objective and stewardship by (1) providing evidence that production objectives act as the dominant variable relating to one's interest in land stewardship, (2) suggesting that one's consideration of conservation and investment objectives moderate the influence of production considerations, and (3) identifying the importance of disengaged landowners as a small but potentially influential group who may require special policy interventions to engage in stewardship, or who may be difficult to engage at all. 


\subsection{Land Management Objective and Stewardship}

As suggested by Koontz (2001), I expected that production objective would correspond with greater financial barriers and greater interest in receiving financial incentives. However, I found only marginal differences between producers and nonproducers relating to interest in incentives and no differences relating to perceived financial barriers. Instead, producers differed from non-producers primarily in their greater perception of barriers relating to trust, regulatory concerns, and perceived lack of time. This may be explained by the fact that producers, regardless of ultimate financial motive, are fundamentally in the business of managing land, whereas watershed stewardship programs are in the business of changing land management behaviors. Therefore, enrollment in a watershed stewardship program represents more than a single act; instead, it represents a commitment to change long-standing behaviors.

Though few if any studies have compared perceptions of trust and concerns for regulation between producer and non-producer typologies, I detected strong differences between these groups in regards to these variables. The literature has mostly been silent on these concepts amongst non-producers, but various authors have long suggested that lack of trust and regulatory concerns can be important barriers amongst producers. Sullivan et al. (1996) emphasized a widely reported lack of trust in the government amongst a diverse group of farmers, and Harrison et al. (1998) emphasized that a common reason for lack of trust related to farmers feeling excluded from meaningful engagement with conservation programs. Kallstrom and Ljung (2005) found a widespread concern amongst farmers that heightened regulation would threaten their ability to continue farming. Similarly, Greiner et al. (2009) equated regulatory concerns as a primary risk factor for ranchers to engage 
with conservation agencies. One respondent described that these concepts of trusts and concerns for regulation are in fact closely related; "As for trust in governmental organizations, mandates and burdens by the state legislature and appointed committees consisting of people who own no forest land and do not understand those who do, bothers me greatly." A common underlying theme amongst all of these findings is that producers feel policy makers cannot be trusted to represent their unique goals and needs.

Contrary to suggestions that producers can be split into "sustainable" and “conventional" (Maybery et al. 2005) categories based on land management objective, my findings suggest that producers were perhaps more effectively differentiated according to consideration of their property's investment potential. Lifestyle Producers" and "Highvalue Producers" reported only modest differences in conservation score, but were starkly differentiated in their investment scores. These differences translated into a greater interest in pursuing fertilizer/pesticide reduction goals and riparian habitat improvements amongst Lifestyle Producers. This may be due to the fact that riparian restoration activities and fertilizer/pesticide reduction may be associated with decreases in land productivity. While Lifestyle Producers may be more accepting of such strategies because such losses in productivity are unlikely to diminish their ability to continue their farming lifestyle, Highvalue Producers may be concerned by the potential loss in profitability.

Past studies have tended to consider non-producers to be motivated primarily by lifestyle objectives (Nielsen-Pincus et al. 2015, Fischer 2012); while I found this to be true for both Amenity Investors and Lifestyle Homeowners, the data suggest that non-producers may exhibit more diversity in objective than previously described as these groups were divided by their interest in utilizing their property for investment and development 
purposes. However, this diversity did not translate into substantial differences in response, as these two groups reported only minor differences in perceptions of Trust Barriers. It is likely that further data relating to more investment-specific land use considerations are needed to help understand if and how these landowner groups differ.

\subsection{The Special Case of Disengaged Landholders}

Disengaged Landowners were difficult to describe and even more difficult to understand as they reported a wide diversity of land uses, were generally the most negative group, and yet were characterized by a general lack of strong land management objectives. This group may represent an important new grouping that is less easily characterized by the traditional concepts of land ownership objectives. It is possible that this group represents "non-cooperators," individuals averse to stewardship programs in general who tend to disagree with all statements. Finley et al. (2006) observed a similar group of forest landowners in a survey of landowner interest in working with neighbors on stewardship objectives. Similarly, Kline et al. (2000) described a group of "passive [forestland] owners" who were motivated primarily by the gratification of property ownership but were not motivated to engage in active land management. Most likely, additional research is needed to accurately represent the land ownership objectives of this group; some potential land management objectives that we did not measure may include a high value of independence (Sullivan et al. 1996, Greiner at al. 2009) or pursuit of peace and quiet (Maybery et al. 2005, Nielsen-Pincus et al. 2015).

Notably, Disengaged Landholders were characterized by high rates of political conservatism (65\%). This partly explains this groups lack of interest in enrollment; past decades have seen increasing polarization in political ideology regarding support for 
environmental programs, with conservatives tending to lack support (Nielsen-Pincus et al. 2014). While political ideology may be an important consideration of this group, this variable may be difficult to consider when establishing initial relationships with landowners; therefore, it is important to consider more readily available demographic information.

There were two defining demographic features of this group that may help to explain the observed trends - they were the least likely group to reside on their property, and they were the group with the longest mean ownership tenure. The high rate of absentee landownership may partially explain the generally negative attitudes and high barriers perceived by this group; Creighton et al. (2002) suggested that lack of on-site residence of a similar population may have led to a diminished sense of place and subsequent lack of stewardship ethic. Bourassa (1991) described the concept of the non-resident as the "detached outsider" who is more concerned with visual aesthetics and less concerned about emotional or symbolic aspects of place.

This phenomenon is typically used to describe visitors and not landowners, and it does not fit well with my observation that Disengaged Landholders tended to report the longest ownership tenure of any group. This fact, coupled with the high rate of absentee landownership and the high average age of Disengaged Landholders, could indicate that many of these individuals are long-time landowners who are no longer able to reside on and/or actively manage their property, and instead they may be legacy landholders who are uninterested in actively pursuing any active management objectives on their property. This description certainly does not describe all landholders in this group, as this group represented a large range of demographic and parcel characteristics, and it appears likely 
that a far greater combination of explanatory variables explain the trends observed in this group.

The very recognition of this group is particularly important as they were the dominant landowner type in two subwatersheds and tend to be highly negative and offer few signals for preferred methods of engagement, if any, with stewardship programs. They tended to be highly uninterested in receiving technical or educational assistance, and were close to neutral regarding interest in receiving financial incentives. This may correspond with findings from Fisher (2012), who noted that a group of absentee forestland owners tended to view fuel treatments as inconvenient. She suggests offering third party contractors to perform on-site work, which may decrease the burden associated with stewardship.

\subsection{Landowner Targeting}

Majumdar et al. (2009) and Nielsen-Pincus (2015) stress the importance of having information about landowner typology demographics, parcel characteristics, and location to help policy makers target policy interventions. My research further shows the practicality of this concept - to an extent. While I noted substantial differences in property characteristics between non-producers and producers/absentee landowners, I was unable to identify easily recognizable demographic and parcel characteristics between more specific landowner typologies. Such easily recognizable traits alone would be unable to identify the divide in attitude between Lifestyle Homeowners and Amenity Investors, as well as the divide between Lifestyle Producers and High-value Producers. However, this may suggest that a good starting place to discuss land stewardship may be to first gain an understanding of an individual's land management objectives. 
Contrary to Nielsen-Pincus et al. (2015), I did not detect significant differences between landowner frequencies between different subwatersheds. However, I did find differences in the portion of stream that each landowner typology represented. This may be an even more important metric, as it suggests that Eagle Creek and Deep Creek may be particularly fruitful areas to focus on stream intervention due to the large portion of stream represented by Lifestyle Homeowners, whereas Clear Creek may be a less cost effective area for restoration due to the heavy presence of Disengaged Landowners.

Each of these sub-watersheds contain similar makeups of agricultural, forestry, and residential land uses, but face different water quality stressors. Data regarding landowner typologies can be coupled with existing information regarding concerns in the watershed to help policy makers to prioritize areas for intervention. The Clackamas sub-basin Total Maximum Daily Load (DEQ 2006) listed water quality standard exceedances for bacteria in the Clackamas Mainstem, Deep Creek, and Clear Creek watersheds, and exceedance for temperature in the Clackamas Mainstem and Eagle Creek watersheds. The current Clackamas Agricultural Water Quality Management Plan (ODA 2015) specified that Deep Creek is the top priority for agri-chemical reductions in the watershed, followed by Eagle and Clear Creeks. This suggests that watershed stewardship programs may want to start initiatives focused on riparian restoration and shade provisioning amongst the relatively liberal and engaged Lifestyle Homeowners in Eagle Creek; another initiative may focus on septic system upgrades amongst Lifestyle Homeowners to address bacterial loadings in Deep Creek; and a third initiative may focus on working with the relative high frequency of Lifestyle Producers in the Clackamas mainstem. While limiting program interventions to these areas are unlikely to achieve significant improvements in water quality, these 
suggestions offer strong starting places by which to establish a reputation, build trust, and achieve early on the ground program successes.

\section{CONCLUSION}

My findings lead to four primary conclusions: (1) land management objectives may be closely related to engagement with stewardship programs; (2) production objectives act as a master variable that is moderated by conservation and investment objectives, (3) some landowners are more easily classified according to a general lack of interest as opposed to strong land management objective, and (4) financial incentives are of limited utility amongst all described landowner typologies.

1. As suggested by Nielsen-Pincus et al. (2015), I was able to detect 5 distinct landowner clusters with distinct motivations for land management that were readily interpretable and were able to be linked with differences in preferred land management strategies. However, my findings suggest that some diversity in land management objective is difficult to predict by simply observing demographic and land use characteristics. Further research (similar to Sullivan et al. 1996) is needed to examine whether differences in land management objective translates into onthe-ground conservation action.

2. Landowners differentiated by production objective (e.g. producers and nonproducers) tended to be consistently different from one another in terms of mean response, whereas investment and conservation objectives provided less strong differentiations between groups. However, this divide in production consideration does not correspond to divide in perception of financial barriers or interest in 
financial incentives (contrary Koontz 2001); instead, I found less tangible differences of opinion relating to lack of trust and concern for regulation.

3. Some landowners (e.g. disengaged landholders) are not easily classified according to traditional concepts of land ownership objective; additional research is needed to understand the objectives driving land ownership in this group.

4. Financial barriers were weakly perceived and financial incentives were weakly desired across all landowner typologies. This general lack of interest in the financial aspects of watershed stewardship supports critiques (Engel et al. 2008, Pirard et al. 2010) and findings (Greiner et al. 2009, Ma et al. 2010) regarding the limited utility of incentives to encourage widespread adoption of stewardship behavior.

In conclusion, I make the fairly obvious but important claim that the first consideration for engaging with landowners should be to understand their ultimate objectives for land ownership, as this may provide a tremendous amount of insight into their needs preferred methods of engagement. Identifying landowner typologies is an important exercise in demonstrating the diversity of objectives represented in a watershed, but applying these concepts require individual-scale attention, collaboration, and consideration. 


\section{FINAL THOUGHTS}

I have spent the last two years pouring over journal articles, crunching numbers, and staring into space trying to make sense of a jumble of data. While navigating through the scholarship of it all, it can be difficult to forget that this research is not about "Amenity Investors," or "Lifestyle Producers," or even landowners at all. It is fundamentally about people, real people, who have their own unique stories and perspectives on land stewardship. If there is one thing that I have learned, it is people cannot be neatly classified, and behavior cannot be cleanly explained. The best that we can do is to try to acknowledge this diversity in the experience of land ownership so that, as policy makers and resource managers, we can better conserve the land and serve the people connected to it.

This work challenged me and my worldview. I am a longtime outdoorsman; a fisherman, a backpacker, a climber, a paddler. I am also a longtime environmentalist, and I thought my perspectives on what it meant to steward the land were set. I have enjoyed an occasional trip into the Clackamas River watershed to fish, or to hike along the Clackamas River trail, or to get away from the noise and people so inescapable at my home in Portland. My relationship with the Clackamas, and with nature in general, is one primarily of recreation. I head into rural places when I want to escape the city; I leave when I am finished. As a consequence, I have never come to know a piece of land, its changes with the season, and its connections to the surrounding landscape like the people who live on it. I don't know what it's like to rely on a piece of land for my livelihood or my lifestyle or my identity, and I don't know what it's like to have such an integral part of my self be subjected to regulation, non-profit intervention, and downstream interests. I have been humbled to hear from people who do. Almost all respondents reported high "conservation 
objectives" for their land, and almost all demonstrated an understanding of the relationship between healthy ecosystems and clean water. But while these might be my only objectives, landowners must balance these objectives with sometimes conflicting values, and they are faced with hard choices about how to responsibly manage their land.

Policy makers have long addressed rural land management issues with an oversimplified notion that people are both limited by and motivated by money, and the payments for environmental services framework has partly grown out of this concept. Resounding throughout my work is a finding that finances are not a primary barrier to land stewardship in the Clackamas watershed, and accordingly financial incentives are not a panacea to accomplish water quality objectives. Instead, a common theme that emerged was that individuals were limited more by a lack of trust and a general feeling that stewardship initiatives were incompatible with their lifestyle. To say that money is not a concern would be foolish; money talks, and we all operate within the confines of what money allows. However, to say that money can be directly translated into stewardship outcomes would be downright wrong. Financial incentives are necessary to overcome those final hurdles to land stewardship, but what is really needed are human connections, common goals, and a more broad-scale understanding of the inter-connectedness of all who live, work, and rely on the Clackamas River watershed. These are the building blocks on which a culture of stewardship can be fostered. 


\section{WORKS CITED}

Ahnström, J., J. Höckert, H.L. Bergeå, C.A. Francis, P. Skelton, and L. Hallgren. 2008. Farmers and nature conservation: What is known about attitudes, context factors and actions affecting conservation? Renewable Agriculture and Food Systems 24:38-47.

Ajzen, I. 1991. The theory of planned behavior. Organizational Behavior and Human Decision Processes 50:179-211.

Arbuckle, J., C. Valdivia, A. Raedeke, J. Green, and J. Rikoon. 2009. Non-operator landowner interest in agroforestry practices in two Missouri watersheds. Agroforestry Systems 75(1): 73-82.

Armstrong, A., and R. C. Stedman. 2012. Landowner willingness to implement riparian buffers in a transitioning watershed. Landscape and Urban Planning 105:211-220.

Baumgart-Getz, A., L.S.Prokopy, and K. Floress. (2012). Why farmers adopt best management practice in the United States: A meta-analysis of the adoption literature. Journal of Environmental Management, 96(1): 17-25.

Beedell, J.D.C., and T. Rehman. 1999. Explaining farmers' conservation behaviour: Why do farmers behave the way they do? Journal of Environmental Management. $57: 165-176$.

Bennett, D.E., H. Gosnell, S. Lurie, and S. Duncan. 2014. Utility engagement with payments for watershed services in the United States. Ecosystem Services 8:5664.

Bourassa, S.C. 1991. The Aesthetics of Landscape. New York: Belhaven Press.

Brown, D.G., K.M. Johnson, T.R. Loveland, and D.M. Theobald. 2005. Rural land-use trends in the conterminous United States, 1950-2000. Ecological Applications 15: 1851-1863.

Carpenter, K.D., S. Sobieszczyk, A.J. Arnsberg, and F.A. Rinella. 2008. Pesticide Occurrence and Distribution in the Lower Clackamas River Basin, Oregon, 20002005. http://pubs.usgs.gov/sir/2008/5027/

Carr, S., and J. Tait. 1991. Differences in the attitudes of farmers and conservationists and their implications. Journal of Environmental Management 32:281-294.

Chin et al. 2008. Perceptions of wood in rivers and challenges for stream restoration in the United States. Environmental Management 41:893-903.

Chouinard, H.H., T. Paterson, P.R. Wandschneider, and M. Adrienne. 2014. Will Farmers Trade Profits for Stewardship? Heterogeneous Motivations for Farm Practice Selection for Farm Heterogeneous Motivations Practice Selection. Land Economics 84(1): 66-82.

Clackamas River Basin Council (CRBC). 2013. Organic and Sustainable Farming Certification Report. http://clackamasproviders.org/images/stories/FullFarmCertificationReport.pdf

Clackamas River Water Providers (CRWP). 2010. Drinking Water Protection Plan for the Clackamas River. http://www.clackamasproviders.org/drinking-water-protection/

Coleman, D., B. Crabtree, J. Fround, and L. O'Carrol. 1992. Comparative Effectiveness 
of Conservation Mechanisms. Manchester University, UK.

Corbett, J.B. 2002. Motivations to participate in riparian improvement programs: applying the theory of planned behavior. Science Communication 23(3): 243-263.

Creighton, J.H., D.M. Baumgartner, and K.A. Blatner. 2002. Ecosystem management and nonindustrial private forest landowners in Washington state, USA. Small-scale Forest Economics, Management and Policy 1:55-69.

Dale, V., S. Archer, M. Change, and D. Ojima. 2005. Ecological impacts and mitigation strategies for rural land management. Ecological Applications 15(6):1879-1892.

Dillman, D. 2000. Mail and Internet Surveys - the Tailored Design Method (2nd ed.) New York: Wiley.

Drasgow F. 1988/ Polychoric and polyserial correlations. In Kotz L, Johnson NL (Eds.), Encyclopedia of Statistical Sciences. Vol. 7 (pp. 69-74). New York: Wiley.

Engel, S., S. Pagiola, and S. Wunder. 2008. Designing payments for environmental services in theory and practice: An overview of the issues. Ecological Economics 65:663-674.

Esseks, D.J., and S.E. Kraft. 1988. Why eligible landowners did not participate in the first four signups of the Conservation Reserve Program. Journal of Soil and Water Conservation 43(3): 251-256.

Finley, A.O. et al. 2006. Interest in cross-boundary cooperation: identification of distinct types of private forest owners. Forest Science 52(1):10-22.

Fischer, P. 2012. Identifying policy target groups with qualitative and quantitative methods: the case of wildfire risk on nonindustrial private forest lands. Forest policy and economics 25:62-71.

Fischer, P., and S. Charnley. 2012. Risk and cooperation: managing hazardous fuel in mixed ownership landscapes. Environmental management 49:1192-207.

Flitcroft, R.L., D.C. Dedrick, C.L. Smith, C.A. Thieman, and J.P. Bolte. 2009. Social Infrastructure to Integrate Science and Practice: the Experience of the Long Tom Watershed Council, 14(2): 36.

Freeman, J., R. Madesen, and K. Hart. 2008. Statistical Analysis of Drinking Water Treatment Plant Costs, Source Water Quality, and Land Cover Characteristics. The Trust for Public Land. https://www.tpl.org/sites/default/files/cloud.tpl.org/pubs/water-landuse-waterwhitepaper.pdf

Greiner, R., L. Patterson, and O. Miller. 2009. Motivations, risk perceptions and adoption of conservation practices by farmers. Agricultural Systems 99(2-3): 86-104.

Grolleau, G., and L.M.J. McCann. 2012. Designing watershed programs to pay farmers for water quality services: case studies of Munich and New York City. Ecological Economics 76:87-94.

Halcrow, H.G., E.O. Heady, and M.L. Cotner (eds). Soil Conservation Policies, Institutions and Incentives. Soil Conservation Society of America Press, Ankeny, IO.

Harrison, C.M., J. Burgess, and J. Clark. 1998. Discounted knowledges: farmers' and residents' understandings of nature conservation goals and policies. Journal of Environmental Management 54:305-320. 
Heberlein, T.A. 2012. Navigating Environmental Attitudes. Conservation Biology 26(4): 583-585.

Kahneman, D., and A. Tversky. 1979. Prospect Theory: An Analysis of Decision under Risk. Econometrica, 47(2): 263-291.

Källström, H.N., and M. Ljung. 2005. Social sustainability and collaborative learning. AMBIO: A Journal of the Human Environment 34:376-382.

Kaplowitz, M. D., and S.G. Witter. 2008. Agricultural and residential stakeholder input for watershed management in a mid-Michigan watershed. Landscape and Urban Planning 84(1): 20-27.

Karr, J.R., and I.J. Schlosser. 1978. Water resources and the land water interface. Science 201(4532):229-234.

Kline, J.D., R.J. Alig, and R.L. Johnson. 2000. Fostering the production of nontimber services among forest owners with heterogeneous objectives. Forest Science 46(2):302-311.

Koontz, T. M. 2001. Money talks-But to whom? Financial versus non-monetary motivations in land use decisions. Society and Natural Resources 14:51-65.

Likert, R. 1932. A technique for the Measurement of Attitudes. Archives of Psychology 140:1-55

Ljung, P. E., S. J. Riley, T. A. Heberlein, and G. Ericsson. 2012. Eat prey and love: game meat consumption and attitudes toward hunting. Wildlife Society Bulletin 36(4):669-675.

Lurie et al. 2013. PES marketplace development at the local scale: the Eugene Water and Electric Board as a local watershed services marketplace driver. Ecosystem Services 6:93-103.

Ma, S., S.M. Swinton, F. Lupi, and C.B. Jolejole. 2010. Why farmers opt not to enroll in payment-for-environmental-services programs. Selected paper prepared for presentation at the Agricultural and Applied Economics Association's 2010 AAEA, CAES, and WAEA Joint Annual Meeting in Denver, CO, 25-27 July.

Majumdar, I., L. Teeter, and B. Butler. 2008. Characterizing family forest owners: A cluster analysis approach. Forest Science 54(2): 176-184.

Majumdar, I., L.D. Teeter, and B.J. Butler. 2009. Using extant data to determine management direction in family forests. Society \& Natural Resources, 22, 867883.

Maybery, D., L. Crase, and C. Gullifer. 2005. Categorising farming values as economic, conservation, and lifestyle. Journal of Economic Psychology 26:59-72.

Mccann, E., S. Sullivan, D. Erickson, and R. De Young. 1997. Environmental Awareness, Economic Orientation, and Farming Practices: A Comparison of Organic and Conventional Farmers. Environmental Management, 21(5), 747-758.

Muradian, R., E. Corbera, U. Pascual, N. Kosoy, and P.H. May. 2010. Reconciling theory and practice: An alternative conceptual framework for understanding payments for environmental services. Ecological Economics 69:1202-1208.

Napier, T. L., C.S. Thraen, and S.M. Camboni. 1988. Willingness of Land Operators to Participate in Government-Sponsored Soil Erosion Control Programs. Journal of Rural Studies 4(4): 339-347.

Nielsen-Pincus, M., R.G. Ribe, and B.R. Johnson. 2015. Spatially and socially 
segmenting private landowner motivations, properties, and management: a typology for the wildland urban interface. Landscape and urban planning 137:112.

Nielsen-Pincus, M., P. Hickson, D. Bennett, H. Gosnell, and R. Parker. 2014. The influence of sense of place on willingness to pay for payments for ecosystem services. Submitted to Environmental Management.

Oregon Department of Agriculture (ODA). 2012. Clackamas River Sub-Basin Agricultural Water Quality Management Plan.

Oregon Department of Environmental Quality (DEQ) 2006. Willamette River Basin TMDL, Chapter 6: Clackamas River Sub-basin.

Pannell, D.J., and R. Wilkinson. 2009. Policy mechanism choice for environmental management by non-commercial "lifestyle" rural landholders. Ecological economics 68:2679-2687.

Petrzelka, P., T. Buman, and J. Ridgely. 2009. Engaging absentee landowners in conservation practice decisions: A descriptive study of an understudied group. Journal of Soil and Water Conservation 64(3):94-99.

Petrzelka, P., P.F. Korsching, and J.E. Malia. 1996. Farmers' attitudes and behavior toward sustainable agriculture. Journal of Environmental Education. 28(1):38-44.

Pirard, R., R. Billé, and T. Sembrés. (2010). Upscaling payments for environmental services (PES): critical issues. Tropical Conservation Science, 3, 249-261.

Reimer, A. P., and L.S. Prokopy. 2014. Farmer Participation in U.S. Farm Bill Conservation Programs. Environmental Management 53:318-332.

Rogers, E.M. 1983. Diffusion of Innovations. The Free Press, New York.

Roth, S. 2015. Willamette, Clackamas hit record high temperatures. KGW News. http://legacy.kgw.com/story/news/local/2015/07/09/willamette-clackamas-rivershit-record-high-temperatures/29937445/

Rosenberg, S., R.D. Margerum. 2008. Landowner motivations for watershed restoration: lessons from five watersheds. Journal of Environmental Planning and Management, 51(4), 477-496.

Ryan, L., D. Erickson, and R. De Young. 2003. Farmers motivations for adopting conservation practices along riparian zones in a mid-western agricultural watershed. Journal of Environmental Planning and Management 46:19-37.

Schmidt, J. (2012). Final Memorandum: GIS Forestry Activities Risk Analysis. http://www.clackamasproviders.org/images/stories/GIS_Forestry_Activities_Anal ysis Results.pdf

Schneider, A., and H. Ingram. 1990. Behavioral assumptions of policy tools. The Journal of Politics 52:510-529.

Schoon, B. and R. Te Grotenhuis. 2000. Values of farmers, sustainability and agricultural policy. Journal of Agricultural and Environmental Ethics 12:17-27

Sheeder, R.J., and G.D. Lynne. 2011. Empathy-conditioned conservation: "Walking in the shoes of others" as a conservation farmer. Land Economics 87(3): 433-452.

Smith, J.W., J.E. Leahy, D.H. Anderson, and M.A. Davenport. 2013. Community/Agency trust and public involvement in resource planning. Society and Natural Resources 26(4):452-471. 
Stubbs, M. 2014. Conservation Reserve Program (CRP): Status and Issues. Congressional Research Service. http://nationalaglawcenter.org/wpcontent/uploads/assets/crs/R42783.pdf

Song, N., F.X. Aguilar, and B.J. Butler. 2014. Cost-share program participation and family forest owners' past and intended future management practices. Forest Policy and Economics 46: 39-46.

Steel, B. S., N.P. Lovrich, and J.C. Pierce. 1994. Trust in natural resource information sources and postmaterialist values: A comparative study of U.S. and Canadian citizens in the Great Lakes area. Journal of Environmental Systems 22:123-136.

Stern, P.C., and T. Dietz. 1994. The Value Basis of Environmental Concern. Journal of Social Sciences 50(3):65-84.

Sullivan, S., E. Mccann, R. De Young, and D. Erickson. 1996. Farmers' attitudes about farming and the environment: A survey of conventional and organic farmers. Journal of Agricultural and Environmental Ethics 9:123-143.

Thompson, A.W., A. Reimer, and L.S. Prokopy. 2014. Farmers' views of the environment: the influence of competing attitude frames on landscape conservation efforts. Agriculture and Human Values 32:385-399.

Trafimow, D. and A. Duran. 1998. Some tests of the distinction between attitude and perceived behavioural control. British Journal of Social Psychology 37:1-14.

United States Census Bureau American Community Survey (USCB-ACS). 2009 - 2013. https://www.census.gov/programs-surveys/acs/

United States Department of Agriculture National Agricultural Statistics Service (USDANASS2012). Census of Agriculture, 2012. http://www.agcensus.usda.gov/Publications/2012/Full_Report/Volume_1, Chapte r 2 County Level/Oregon/st41_2 001 001.pdf

Williams, D.R. 2002. When Voluntary, Incentive-Based Controls Fail: Structuring a Regulatory Response to Agricultural Nonpoint Source Water Pollution. Washington University Journal of Law and Policy 9(1):21-121.

Wilson, G. A., and K. Hart. 2001. Farmer participation in agri-environmental schemes: towards conservation-oriented thinking? 41: 254-274.

Wood, D.G. 1999. Federal Role in Addressing — and Contributing to - Non-point Source Pollution. United States General Accounting Office.

Woods, B.R., E. Luloff, D. Osmond, and D. Hoag. 2014. Toward a synthesis: lessons from thirteen cropland watershed-scale studies. Society \& Natural Resources 27:341-357. 


\title{
APPENDIX A. SURVEY MAILER MATERIALS
}

\section{School of the Environment}

Department of Environmental Science \& Management

Natural Resources Management Lab

Post Office Box 751

Portland, Oregon $97207-0751$

www.pdx.edu/esm

\begin{abstract}
Lohn Doe,
We are contacting you to ask for your help in a study on the land stewardship experiences and opinions amongst landowners in the Clackamas River watershed. This study is being conducted by Dr. Max Nielsen-Pincus and Matthew DeAngelo from the Portland State University Department of Environmental Science and Management in collaboration with the Clackamas River Water Providers (CRWP), a consortium of drinking water utilities operating in the Clackamas River watershed.

As part of this study, we request that you complete the enclosed questionnaire about your properties in the Clackamas River watershed and your perspective on different measures to maintain its environment. Participation in this study is an opportunity for you to voice your opinions about programs that promote watershed stewardship while supporting the needs of watershed landowners. This research will contribute to a growing body of work regarding the role that public utilities and the private sector can play in strengthening and supporting the environmental and economic benefits of local watersheds. As a thank you for submitting your completed survey, you will be automatically entered into a drawing to receive a $\$ 100$ gift card.
\end{abstract}

For convenience, we are also offering the questionnaire in a web-based form. If you would prefer to complete the questionnaire online, you may enter the link and four-digit passcode listed below:

http://tinyurl.com/ClackamasWatershed

Passcode: 1234

Please complete the questionnaire and mail it back to us in the enclosed postage-paid envelope, or complete the web version. Your responses are entirely confidential, and your name will never be connected to your answers. Your decision to take part in this study is completely voluntary, you may skip any questions you do not want to answer, and you have the right to end your participation at any time. When you complete and return the attached questionnaire, it means that you have read and understood this information, and you agree to take part in this study.

If you have questions or concerns about your participation in this study or about your rights as a research participant, please contact the Human Subjects Research Review Committee at:

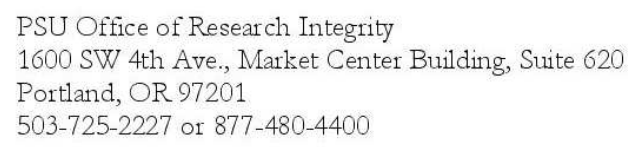

Thank you very much for your time and support of this study. Sincerely,

Max Nielsen-Pincus

Max Nielsen-Pincus

Assistant Professor

\section{Matt DeAngelo}

Matt DeAngelo

M.S. Graduate Student

503-451-0394 / deange12@pdx.edu 
Farms, Forests, \& Water

\section{A SURVEY OF LANDOWNERS IN THE CLACKAMAS RIVER WATERSHED}
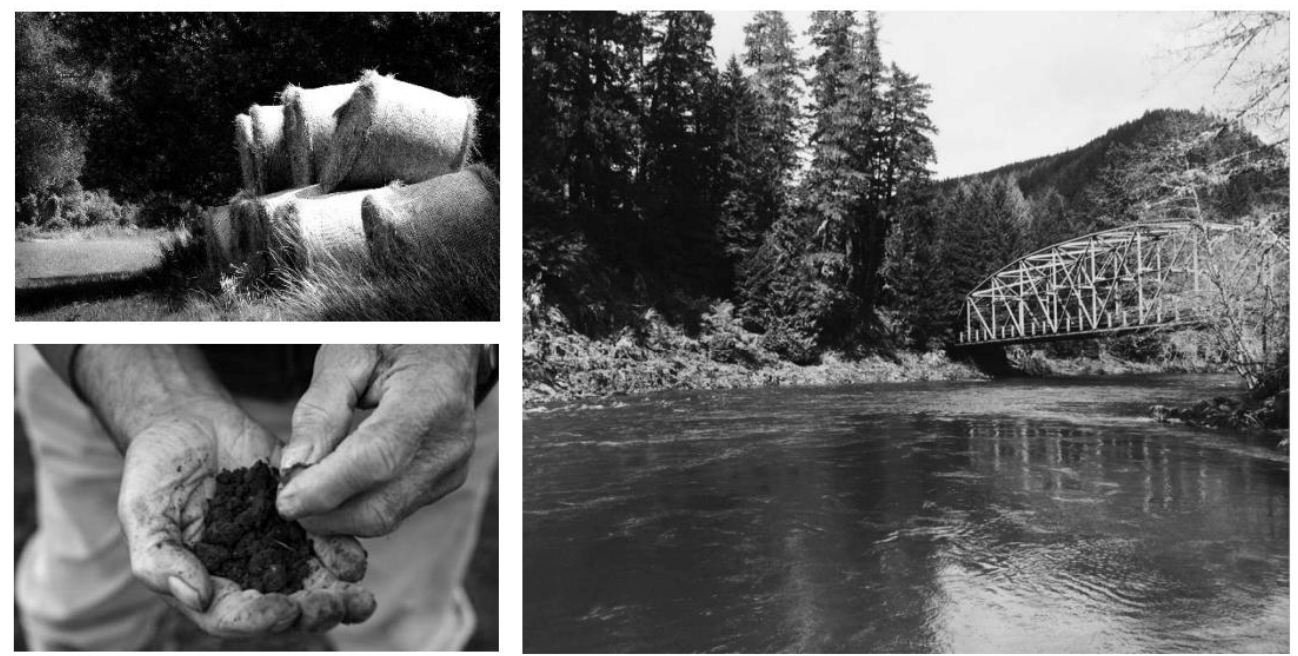

As a landowner in the Clackamas River Watershed, you play an important role in a landscape connected by the flow of water, and your land provides a variety of benefits to downstream drinking water consumers, recreational users, and wildlife. There is growing interest amongst water resource managers in programs that protect watershed health by working with landowners to restore or maintain their property in a way that benefits and preserves water quality and supply. This survey is part of an effort to learn more about what kind of a program might be appropriate for improving and maintaining the health of the Clackamas River watershed.

Survey Instructions

- Please carefully read each question and make your responses clear

- Feel free to write in any additional comments anywhere on the survey

- Please mail your completed survey back in the prepaid envelope provided

- All of your answers will be kept completely confidential

\section{龟 Portland State

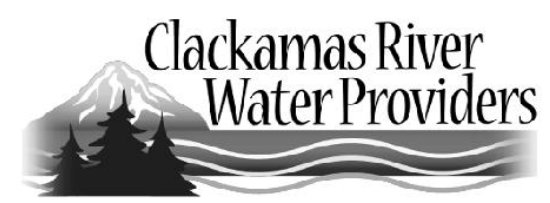




\section{YOUR LAND IN}

\section{THE CLACKAMAS}

RIVER WATERSHED

Please answer the following questions regarding your property to help

provide a more complete picture of current land uses in the watershed.

1 How many years have you owned property in the Clackamas River watershed?

2 Of the land you own, do you rent or lease any of it to others?
Yes
What for?
No

3 Do any of the following options characterize the land uses of the property you own or lease in the

3 Clackamas River watershed? (Check all that apply)
$\square$ My main residence
$\square$ Ranching
$\square$ Dairy
$\square$ Annual crops
$\square$ Fruit crops
$\square$ Vineyard
$\square$ Hazelnuts or walnuts
$\square$ Timber
$\square$ Nursery
$\square$ Grass seed
$\square$ Grass / Pasture

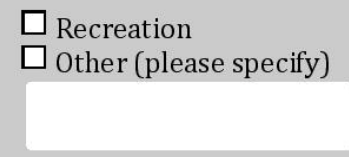

4 How many livestock (including horses, cows, and chickens) do you keep at least part of the time on your properties in the Clackamas River watershed?

\begin{tabular}{l|llll} 
Cattle & Horses & Pigs/Hogs & Chickens & Other (specify)
\end{tabular}

5 What was the value of agricultural or forestry sales from your land in the watershed in 2014 ?
$\mathrm{O}_{\$ 0}$
$\mathrm{O}<\$ 1,000$
\$1,000 - $\$ 9,999$
O $\$ 10,000-\$ 49,999$
O $\$ 50,000$ - $\$ 99,999$
O $>\$ 100,000$

6 How important are the following factors when you are making decisions regarding your land?

\begin{tabular}{|c|c|c|c|}
\hline Select one response for each item & $\begin{array}{l}\text { Not at all } \\
\text { Important }\end{array}$ & $\begin{array}{l}\text { Somewhat } \\
\text { Important }\end{array}$ & $\begin{array}{r}\text { Very } \\
\text { Important }\end{array}$ \\
\hline Produce high quality farm or timber products for market & 0 & $\bigcirc$ & $\bigcirc$ \\
\hline Grow/manage a business through my land's production & $\bigcirc$ & 0 & $\mathrm{O}$ \\
\hline Enhance my land's investment value & $\mathrm{O}$ & $\mathrm{O}$ & $\bigcirc$ \\
\hline Enhance my property's development potential & O & 0 & O \\
\hline Provide income for me and my family & O & $\bigcirc$ & $\bigcirc$ \\
\hline Provide a safe and comfortable home for me and my family & 0 & 0 & 0 \\
\hline Leave an asset for future generations of my family & O & 0 & O \\
\hline Provide recreational opportunities for me and my family & O & O & O \\
\hline Protect the health of waterways on or near my property & $\mathrm{O}$ & 0 & $\mathrm{O}$ \\
\hline Preserve open space or aesthetic beauty & 0 & 0 & 0 \\
\hline Protect local wildlife or native vegetation & 0 & 0 & 0 \\
\hline
\end{tabular}

Page 1 
YOUR LAND

MANAGEMENT

EXPERIENCES

Reporting on your land management practices and experiences will help water resource managers more fully understand the role that landowners play in the watershed.

(a) Please check any of the practices utilized on your land in the boxes to the left.

7 (b) Then, regardless of whether or not you checked the box in part a, please indicate how much of an impact you think these practices have on river water quality.

\begin{tabular}{|c|c|c|c|c|c|c|}
\hline \multirow{2}{*}{ (a) } & \multirow{2}{*}{ Check all practices that apply } & \multirow{2}{*}{ (b) } & \multicolumn{4}{|c|}{ Impact on Water Quality } \\
\hline & & & Low & Moderate & & High \\
\hline$\square$ & Use of synthetic fertilizers & & 0 & 0 & 0 & 0 \\
\hline$\square$ & Nutrient management plan & & $\mathrm{O}$ & $\bigcirc$ & 0 & 0 \\
\hline$\square$ & Broadcast pesticide application & & 0 & 0 & 0 & 0 \\
\hline$\square$ & Precision pesticide application & & 0 & 0 & 0 & 0 \\
\hline$\square$ & Integrated pest management & & 0 & 0 & 0 & 0 \\
\hline$\square$ & Organic farming & & 0 & 0 & 0 & 0 \\
\hline$\square$ & Storm water runoff control & & 0 & 0 & 0 & 0 \\
\hline$\square$ & High efficiency irrigation & & 0 & 0 & 0 & 0 \\
\hline$\square$ & Livestock exclusion zones around streams & & $\mathrm{O}$ & 0 & 0 & 0 \\
\hline$\square$ & Drainage tiles & & $\mathrm{O}$ & 0 & 0 & 0 \\
\hline$\square$ & Invasive species control & & 0 & 0 & 0 & 0 \\
\hline$\square$ & Land set aside for wildlife protection & & $\mathrm{O}$ & 0 & 0 & 0 \\
\hline
\end{tabular}

(a) Have you ever participated in any of the following voluntary conservation programs on any of the 8 land you own? If so, please check the box on the left for all that apply.

(b) Then, for the boxes you checked, tell us whether your experience was positive or negative.

\begin{tabular}{|c|c|c|c|c|c|}
\hline (a) & Check all programs that apply & (b) & $\begin{array}{c}\text { Very } \\
\text { Negative }\end{array}$ & $\begin{array}{c}\text { Neither } \\
\text { positive nor } \\
\text { negative }\end{array}$ & $\begin{array}{c}\text { Very } \\
\text { Positive }\end{array}$ \\
\hline$\square$ & A federal conservation program (e.g. CREP or EQIP) & & O & 0 & 0 \\
\hline$\square$ & A state of Oregon conservation program & & O & O & 0 \\
\hline$\square$ & $\begin{array}{l}\text { A local conservation program (e.g. a watershed council or } \\
\text { conservation district) }\end{array}$ & & $\bigcirc$ & $\mathrm{O}$ & 0 \\
\hline
\end{tabular}

9 Do any of the below statements about conservation real estate apply to you?

\begin{tabular}{lll}
\hline $\begin{array}{l}\text { Select one response for each item } \\
\text { Some or all of my land is covered by a conservation easement held by a conservation } \\
\text { organization or agency. }\end{array}$ & Yes & No \\
\hline $\begin{array}{l}\text { Ihave sold, donated, or otherwise transferred the title to land I previously owned to a } \\
\text { conservation organization or agency. }\end{array}$ & $\bigcirc$ & $\bigcirc$ \\
\hline
\end{tabular}

Page 2 
10 Please report the degree to which you agree with the following opinions. In general, conservation programs are...

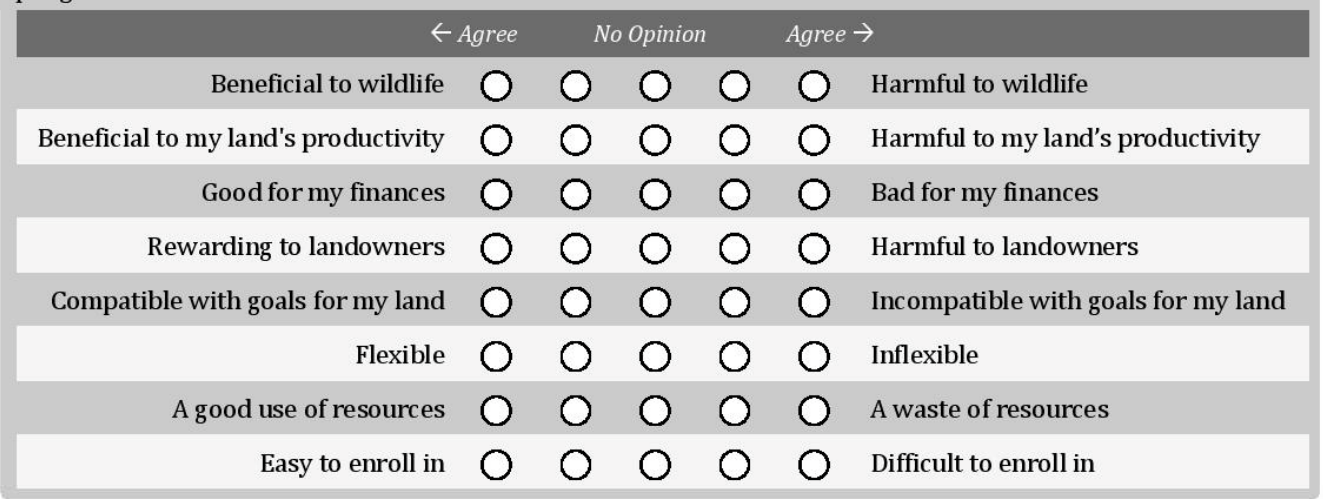

YOUR OPINIONS ON WATERSHED CONSERVATION
Please take the opportunity to fill out the following information regarding what types of practices and features you would like to see in a watershed conservation program.

A watershed conservation program may be able to help you to accomplish some of the goals listed

11 below while keeping your land in production. Assuming such a program is established in the Clackamas River watershed, how likely would you be to work with the program on any of the following goals?

\begin{tabular}{|c|c|c|c|c|c|}
\hline Select one response for each item & $\begin{array}{c}\text { Very } \\
\text { Unlikely }\end{array}$ & & $\begin{array}{l}\text { Neither } \\
\text { Likely nor } \\
\text { Unlikely }\end{array}$ & & $\begin{array}{l}\text { Very } \\
\text { Likely }\end{array}$ \\
\hline Reducing fertilizer use & 0 & 0 & 0 & 0 & 0 \\
\hline Reducing pesticide use & 0 & 0 & O & 0 & $\mathrm{O}$ \\
\hline Improving irrigation efficiency & $\mathrm{O}$ & $\mathrm{O}$ & $\mathrm{O}$ & 0 & $\mathrm{O}$ \\
\hline Transitioning to organic production & $\mathrm{O}$ & 0 & O & 0 & O \\
\hline Improving storm water runoff control & $\bigcirc$ & $\mathrm{O}$ & $\bigcirc$ & 0 & $\bigcirc$ \\
\hline Adding livestock exclusion zones around streams & 0 & 0 & O & 0 & O \\
\hline Controlling invasive species & $\mathrm{O}$ & 0 & $\mathrm{O}$ & 0 & 0 \\
\hline Enhancing wildlife habitat & $\mathrm{O}$ & 0 & 0 & 0 & O \\
\hline Maintaining healthy streamside and floodplain forests & $\mathrm{O}$ & 0 & $\mathrm{O}$ & 0 & 0 \\
\hline Restoring degraded stream and floodplain areas & $\mathrm{O}$ & 0 & 0 & 0 & 0 \\
\hline $\begin{array}{l}\text { Planting new forests along streams that are not currently } \\
\text { forested }\end{array}$ & $\cap$ & 0 & $\bigcirc$ & 0 & O \\
\hline
\end{tabular}

Page 3 
12 Would the following increase your interest in working with a watershed conservation program?

\begin{tabular}{|c|c|c|c|c|c|}
\hline Select one response for each item & Definitely Not & & Not Sure & & Definitely Yes \\
\hline Annual cash incentives for participating & 0 & 0 & 0 & 0 & 0 \\
\hline One-time cash bonus for signing up & 0 & $\mathrm{O}$ & O & 0 & $\mathrm{O}$ \\
\hline A cash bonus for joint participation with neighbors & 0 & 0 & 0 & 0 & 0 \\
\hline Discounts at local retailers & $\mathrm{O}$ & $\mathrm{O}$ & 0 & 0 & 0 \\
\hline Improved marketing for products from my land & 0 & 0 & 0 & 0 & 0 \\
\hline Educational/training opportunities & $\mathrm{O}$ & $\mathrm{O}$ & 0 & 0 & 0 \\
\hline Zero-interest loans & 0 & 0 & 0 & 0 & 0 \\
\hline Dedicated staff to help you implement your project & $\mathrm{O}$ & $\mathrm{O}$ & $\mathrm{O}$ & 0 & 0 \\
\hline
\end{tabular}

13 How likely would you be to enroll in a watershed conservation program if it required you to work with the following organizations to implement the program or project?

\begin{tabular}{|c|c|c|c|c|c|}
\hline Select one response for each item & Very Unlikely & & Not Sure & & Very Likely \\
\hline Natural Resources Conservation Services & O & O & O & O & O \\
\hline Clackamas Soil \& Water Conservation District & O & 0 & O & O & O \\
\hline US Fish and Wildlife Service & 0 & 0 & O & 0 & O \\
\hline Clackamas Pesticide Stewardship Partnership & O & 0 & 0 & 0 & 0 \\
\hline Oregon Department of Environmental Quality & O & $\bigcirc$ & O & 0 & O \\
\hline Oregon Department of Agriculture & O & 0 & 0 & $\mathrm{O}$ & $\mathrm{O}$ \\
\hline Oregon Department of Fish and Wildlife & O & 0 & 0 & 0 & 0 \\
\hline Producer Organizations & O & 0 & 0 & 0 & 0 \\
\hline Clackamas River Basin Council & 0 & 0 & 0 & $\bigcirc$ & O \\
\hline Clackamas River Water Providers & O & 0 & 0 & 0 & 0 \\
\hline Other non-profit conservation organizations & $\mathrm{O}$ & 0 & 0 & 0 & 0 \\
\hline
\end{tabular}

14 Would you be willing to agree to any of the following in a watershed conservation program?

\begin{tabular}{|c|c|c|c|c|c|}
\hline Select one response for each item & Definite & & Not Sure & \multicolumn{2}{|c|}{ Definitely Yes } \\
\hline A 10 year contract & $\mathrm{O}$ & 0 & $\mathrm{O}$ & 0 & 0 \\
\hline A 20 year contract & O & O & O & 0 & 0 \\
\hline A deed restriction lasting the length of the contract & 0 & O & O & 0 & 0 \\
\hline Annual reporting to the project sponsor & O & 0 & 0 & 0 & 0 \\
\hline Specific management actions prior to enrollment & 0 & 0 & $\mathrm{O}$ & 0 & 0 \\
\hline Regular project maintenance and monitoring & $\mathrm{O}$ & 0 & O & $\mathrm{O}$ & $\mathrm{O}$ \\
\hline
\end{tabular}

Page 4 
To what extent do you agree or disagree with the following statements about why you might NOT participate in a watershed conservation program?

\begin{tabular}{|c|c|c|c|}
\hline Select one response for each item & $\begin{array}{l}\text { Strongly } \\
\text { Disagree }\end{array}$ & $\begin{array}{c}\text { No } \\
\text { Opinion }\end{array}$ & $\begin{array}{r}\text { Strongly } \\
\text { Agree }\end{array}$ \\
\hline I still don't know enough about these programs & & & O \\
\hline I don't trust the organizations or agencies that run these programs & 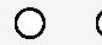 & O & O \\
\hline I'm concerned about legal or regulatory implications & & O & O \\
\hline My neighbors or community would give me a hard time & & & O \\
\hline No one else in my community participates in these types of programs & O & & O \\
\hline I won't own the property long enough to make it worth my while & O & 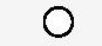 & O \\
\hline I'm uncomfortable with the attention programs like these bring to me & 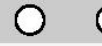 & & O \\
\hline I don't have enough time to participate in a program like this & $\mathrm{O}$ & O & $\mathrm{O}$ \\
\hline My finances won't allow it & 0 & 0 & 0 \\
\hline Enrollment would make it harder to run my business & $\checkmark$ & 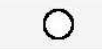 & O \\
\hline
\end{tabular}

In general, do you agree or disagree with the following statements regarding watershed conservation 6 in the Clackamas River watershed?

\begin{tabular}{|c|c|c|c|}
\hline Select one response for each item & $\begin{array}{l}\text { Strongly } \\
\text { Disagree }\end{array}$ & $\begin{array}{l}\text { No } \\
\text { Opinion }\end{array}$ & $\begin{array}{r}\text { Strongly } \\
\text { Agree }\end{array}$ \\
\hline Watershed conservation benefits everyone in the watershed & 0 & 0 & O \\
\hline Watershed conservation is just the right thing to do & $\mathrm{O}$ & $\mathrm{O}$ & O \\
\hline The effects of water pollution on public health are worse than we realize & O & O & O \\
\hline Pollution generated on my land harms people downstream & $\mathrm{O}$ & $\mathrm{O}$ & O \\
\hline Development within the watershed threatens water quality & O & O & O \\
\hline Functioning stream ecosystems are important for a clean water supply & O & O & $\cap$ \\
\hline Watershed conservation will threaten my livelihood & $\mathrm{O}$ & O & $\mathrm{O}$ \\
\hline Watershed conservation might limit my choice and personal freedoms & $\mathrm{O}$ & O & O \\
\hline $\begin{array}{l}\text { While some local areas may have seen declines in water quality, overall } \\
\text { water quality in the watershed is not in decline }\end{array}$ & $\mathrm{OC}$ & $\mathrm{O}$ & O \\
\hline Claims regarding high pollution levels in the watershed are exaggerated & 0 & 0 & 0 \\
\hline
\end{tabular}

Now that you know a little bit more about the potential features of a watershed conservation program 17 in the Clackamas River watershed, how likely would you say you are to participate in such a program if the program was tailored to your responses above?
$O_{\text {Very Unlikely }}$
Unlikely
$\mathrm{O}_{\text {Not Sure }}$
Likely
Very Likely 


\section{VEGETATIVE}

BUFFERS ON

An effective way to maintain water quality is to keep vegetated buffers

YOUR LAND

18 Does a stream, agricultural ditch, slough, or wetland exist anywhere on your property?

O Yes $\quad O_{\text {No (If no, skip to Question \#23) }}$

19 Do you currently have a vegetative buffer around streams or waterways on your property? (select all that apply)

$\square$ No

$\square$ Yes, I have riparian buffers (native trees, shrubs, and grasses alongside waterways)

$\square$ Yes, I have filter strips (non-harvested grasses alongside waterways)

$\square$ Yes, I have grassed waterways (strips of grass seeded within cropland to slow water flow)
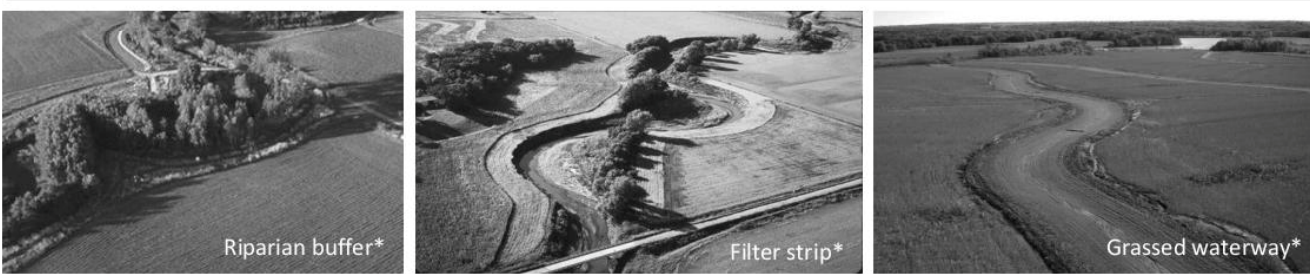

20 On average, about how wide is the vegetative buffer surrounding the waterways on your property?
$\mathrm{O}_{\mathrm{N} / \mathrm{A}}$
O $5 \mathrm{ft}$
$\bigcirc_{10 \mathrm{ft}} \bigcirc_{20 \mathrm{ft}}$
$35 \mathrm{ft}$
${ }_{50 \mathrm{ft}}$
$100 \mathrm{ft}$ or more

21 Do you currently receive any payments for maintaining a vegetative buffer around your streams (e.g. 1 the federal Conservation Reserve Enhancement Program (CREP))?

$\mathrm{O}_{\mathrm{N} / \mathrm{A}}$

Yes, I receive payments for my vegetative buffer in the amount of $\$$ per acre

No, I do not currently receive payments for my vegetative buffer

22 A watershed conservation program may be able to pay you to place or keep land in buffers. What level of payment would motivate you to plant or maintain a buffer of at least 35 feet in width?

\begin{tabular}{|c|c|c|c|c|c|}
\hline Select one response for each item & $\begin{array}{c}\text { Definitely } \\
\text { Not }\end{array}$ & $\begin{array}{c}\text { Probably } \\
\text { Not }\end{array}$ & Not Sure & $\begin{array}{c}\text { Probably } \\
\text { Yes }\end{array}$ & $\begin{array}{c}\text { Definitely } \\
\text { Yes }\end{array}$ \\
\hline No payment required & 0 & 0 & 0 & 0 & 0 \\
\hline$\$ 50$ per acre / year & 0 & 0 & 0 & 0 & 0 \\
\hline$\$ 100$ per acre / year & 0 & 0 & 0 & 0 & 0 \\
\hline$\$ 200$ per acre / year & 0 & 0 & 0 & 0 & 0 \\
\hline$\$ 400$ per acre / year & 0 & 0 & 0 & 0 & 0 \\
\hline$\$ 600$ per acre / year & 0 & 0 & 0 & 0 & 0 \\
\hline$\$ 800$ per acre / year & 0 & 0 & 0 & 0 & 0 \\
\hline
\end{tabular}


FINALLY, PLEASE

TELL US A LITTLE

ABOUT YOURSELF

Remember, your responses are entirely confidential. When you have finished

the survey, don't forget to mail it back to us in the enclosed envelope.

23 What is your gender? OMale OFemale

24 What year were you born?

25 What is the highest level of education that you have completed?

Less than high school degree

High school degree or equivalent

Associate's or other 2-year degree

Some college, no degree

Bachelor's degree (4 year)

Graduate or professional degree

26 What is your political tendency?
$\bigcirc$ Very Liberal
Somewhat Conservative
Somewhat Liberal
Very Conservative
Moderate

27 Please estimate your total household income in 2014 before taxes. (Check one item only)
Less than $\$ 25,000$
O $\$ 25,000-\$ 49,999$
\$75,000 - $\$ 99,999$
$\$ 50,000-\$ \$ 74,999$
$\$ 100,000-\$ 149,999$
$\$ 150,000$ or more

28 Approximately what percentage of your household's income is provided by your land in the Clackamas River watershed?

\section{USE THE SPACE BELOW TO WRITE ANY ADDITIONAL COMMENTS}

THANK YOU FOR YOUR TIME AND SUPPORT OF THIS STUDY!

Matt DeAngelo

M.S. Graduate Student

503-451-0394 / deangel2@pdx.edu
Max Nielsen-Pincus, PhD

Assistant Professor

Portland

State 


\section{APPENDIX B. DATA SUMMARY REPORT}

This report was prepared for the Clackamas River Water Providers and was submitted in January of 2015. It presents raw data and general trends noted in the survey, and is intended for use by practitioners as well as for distribution to the public.

\section{The 2015 Clackamas River Watershed Survey:}

Landowner perspectives on watershed conservation programs
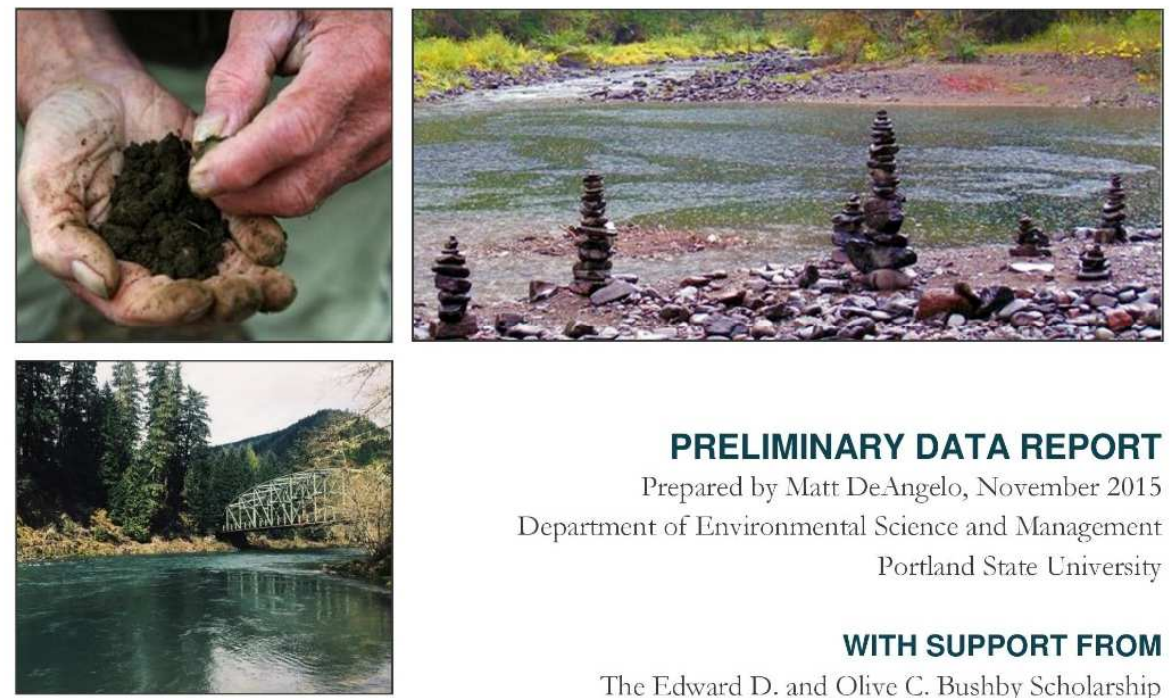

PRELIMINARY DATA REPORT

Prepared by Matt DeAngelo, November 2015 Department of Environmental Science and Management Portland State University

WITH SUPPORT FROM

The Edward D. and Olive C. Bushby Scholarship The Nielsen-Pincus Natural Resources and Management Lab The Clackamas River Water Providers 
THANKS \& ACKNOWLEDGMENTS

I would like to thank the following individuals for their help and support in this survey:

Max Nielsen-Pincus, Portland State University

Kim Swan, Clackamas River Water Providers

Maksim Zemtsov, Research assistant

Elyse Cogburn, Research assistant

A special thanks to the 275 respondents who took the time to fill out the survey, provide comments, and contact us to provide insight into your responses. This effort is an attempt to understand how conservation programs can better serve you, and without your support, this survey effort would be impossible. 
TABLE OF CONTENTS

1. Using This Report...................................................

2. Executive Summary................................................. 1

Background 1

Survey Sample $\quad 2$

Key Findings 3

3. Demographics............................................................... 4

Gender, Ige, and Education 5

Income and Political Tendency 6

Years Owning Property $\quad 7$

4. Property Characteristics............................................... 4

Land Usage and Property Size $\quad 7$

Agricultural and Forestry Sales 8

Land Management Practices $\quad 8$

Vegetative Buffers 9

5. Respondent Grouping.............................................. 10

Demographic Comparison of Groups 11

6. Experiences with Land Management........................... 12

Factors Influencing Land Management 12

Perception of Water Quality Impacts 14

Attitudes towards Conservation Programs

7. Perspectives on Watershed Stewardship.........................17

Likelihood of Working towards Stewardship Goals 17

Desired Incentives for Participation 18

Preferred Partner Organizations $\quad 20$

Agreement to Contractual Features $\quad 21$

Barriers to Participation $\quad 22$

Beliefs about Watershed Conservation $\quad 23$

Payments for Vegetative Buffers $\quad 24$

8. Raw Data Summary................................................. 26 


\section{USING THIS REPORT}

This report presents a summary of data collected from a survey of rural landowners in the Clackamas River watershed, OR. 'Ihe report begins with an executive summary, which outlines the purpose and methods of the survey. We highlight some key trends noted in the survey data, but we leave interpretation largely up to the reader. In the following sections, we graphically and numerically summarize responses to all questions to provide an overview of the data. In some instances, we have slightly modified the wording of survey questions for presentation clarity - to see question items and data in their raw form, please see the raw data summary in the final section of this report.

Any additional questions regarding the content of this report or methods of data collection may be directed to Matt DeAngelo (deangel2@pdx.edu). 


\section{EXECUTIVE SUMMARY}

Between August and November of 2015, we conducted a survey of private forestry, agricultural, and residential landowners to investigate landowner interest in and preferences for watershed stewardship programs in the Clackamas River watershed, Oregon. The research involved a survey of private forestry, agricultural, and residential landowners with more than 2 acres of property in the Clackamas River watershed. This report presents a summary of findings from the survey.

\section{Background}

The Clackamas River is the center of a multi-use watershed characterized by a patchwork of agricultural, semi-urban, and public lands. Eight separate drinking water utilities pump drinking water from the Clackamas River and supply water to over 300,000 customers in Washington and Clackamas Counties. In 2005, an Intergovernmental Agreement for Joint Funding for Watershed Activities between these water utilities and Clackamas County Water Environment Services formalized collaboration for work on water quality and watershed related projects. In 2007, the Clackamas River Water Providers (CRWP) was formed as a central organization to implement these activitics $^{1}$. In their 2010 Drinking Water Protection Plan, the CRWP outlined two primary goals for maintaining the Clackamas River as a high quality drinking water source:

- Identify, prevent, minimize and mitigate activities that have known or potentially harmful impacts on drinking water quality so that the Clackamas River can be preserved as a high quality drinking water source that meets human future needs and minimizes drinking water treatment costs.

- Promote public awareness and stewardship of healthy watershed ecology in collaboration with other stakeholders.

As one of several strategies to address these goals, the CRWP highlighted the need to work with commercial and small acreage rural landowners in a program to promote watershed stewardship. Key goals of a watershed stewardship program would include restoring or maintaining existing riparian zones and limiting inputs of nonpoint source pollutants ${ }^{2}$ such as pesticides, fertilizers, and bacterial loadings into the water supply. This research project intended to reach out to private landowners to understand how to best work with this important population on watershed stewardship initiatives. The primary objectives of this research were to:

1 The Clackamas River Water Providers (2010) Drinking Water Protection Plan for the Clackamas River

${ }^{2}$ Non-point Source Pollutant | a pollutant that cannot be attributed to a single source 
- Determine the interest level of watershed landowners for participation in a watershed stewardship program;

- Evaluate potential features of a program that are likely to encourage enrollment;

- Identify key barriers to enrollment in watershed stewardship programs;

- Identify key differences between likely and unlikely program participants.

Most survey questions utilized a form of the Likert scale ${ }^{3}$ to inquire about current land management practices; perceived impact of land management on downstream water quality; perceptions of watershed stewardship programs; and overall interest in participation with a watershed stewardship program. The results of this survey are intended to provide practical insight into structuring a successful watershed stewardship program for the Clackamas River watershed.

\section{Survey Sample}

Iandowners were considered eligible for the survey based on the following criteria:

- Property is outside of the Urban Growth Boundary

- Property is at least 2 acres in size

- Property has been zoned as agricultural, rural, or forestry land

- Property is within at least 100 feet from a stream

- Any nursery operating within the watershed, regardless of property size, was considered eligible

The survey was administered via mail and web to 1,031 landowners in the Clackamas River watershed. 72 surveys $(6.5 \%)$ were returned as undeliverable, leading to an effective sample of 959 . To enhance response rate, landowners were contacted four times from August to September via the Dillman Tailored Design Method, which included an initial postcard, followed up by a first round of surveys, a reminder postcard, and a second wave of surveys for nonrespondents ${ }^{4}$. We received 275 valid responses - a $28.7 \%$ response rate (Table 1). Though response rate was lower than anticipated, it is not unprecedented for this population; a previous questionnaire of agricultural landowners in the watershed conducted by the Clackamas River Basin Council in $2013^{5}$ used the same methods and reported a $20.3 \%$ response rate.

${ }^{3}$ Likert R (1932). A technique for the Measurement of Attitudes. Archives of Psychology 140:1-55

${ }^{4}$ Dillman (2000). Mail and Internet Surveys - the Tailored Design Method (2nd ed.) New York: Wiley

${ }^{5}$ Clackamas River Basin Council (2013). Organic and Sustainable Farming Certification Report 
Table 1. Number of contacts and response rate of selected groups.

\begin{tabular}{|lcc|}
\hline Group & No. Contacted & Response \\
\hline Small acreage landowners $(2-10$ acres $)$ & 294 & $97(32.7 \%)$ \\
\hline Large acreage landowners $(>10$ acres) & 585 & $165(28.2 \%)$ \\
\hline Nurscrics & 80 & $11(13.8 \%)$ \\
Total & 959 & $275(28.7 \%)$ \\
\hline
\end{tabular}

\section{Key Findings}

A few key themes emerged common to most respondents. There was widespread agreement that functioning stream ecosystems are important for a clean water supply, and a majority of respondents stressed that they manage their land to protect environmental attributes such as open space, clean water, and wildlife. Respondents tended to agree that conservation programs can provide benefits to wildlife, and they expressed the highest interest in working with watershed stewardship programs to control invasive species on their property. Most respondents agreed that the best way to increase their interest in working with a watershed stewardship program would be to offer cash payments for watershed stewardship work, and to avoid long-term contracts and deed restrictions. I Iowever, we noted some key differences between respondents who stated that they would be likely to enroll in a watershed stewardship program, versus those who said they were unlikely to enroll.

Respondents who specified that they were likely to enroll in a watershed stewardship program...

1. more frequently expressed interest in working with a watershed stewardship program on riparian habitat and wildlife restoration goals.

2. more frequently expressed the belief that water pollution is bad for human health and perceived a relationship between land management practices and water quality. In particular, they much more frequently thought fertilizers, pesticides, and livestock impact water quality.

3. more frequently expressed belief that watershed stewardship programs have environmental and social benefits.

Respondents who specified that they were unlikely to enroll in a watershed stewardship program...

1. more frequently manage their land to enhance development potential or to manage a farm or timber business. Concurrently, they less frequently thought that conservation programs were compatible with their goals for their land.

2. more frequently perceived barriers to enrollment with a watershed stewardship program. In particular, they much more frequently expressed distrust in agencies or organizations that run these sorts of programs.

3. more frequently expressed concern that watershed conservation may lead to increased regulatory pressurc. 
The above trends suggest that, in general, respondents were concerned for water quality and expressed an interest in environmental stewardship, but they differed in their attitudes towards watershed stewardship programs. While most respondents were motivated to protect water quality through their own initiative in land management, unlikely program participants did not see the benefit of working with a watershed stewardship program to accomplish these goals. Additionally, a lack of trust in the organizations and agencies involved in conservation programs played a key role in differentiating likely and unlikely participants. This sentiment is perfectly summarized by the following comment provided by a respondent:

"I believe that water quality is important to me, my children, and society. IIowever, I strongly distrust agencies, especially fanatical entironmental agencies that do not take into account cold hard financial realities. So any program would require building trust." 


\section{DEMOGRAPHICS}

In order to evaluate how well our sample represented our population of landowners, we collected basic demographic information and compared the demographics of our population to known demographics of the study area. Because our sample included a combination of residential landowners, small acreage farmers/foresters, and commercial producers, no single existing demographic data source adequately described our population. Therefore, we compared our sample to both known demographics of farmers in Clackamas County ${ }^{6}$ as well as known demographics of residents residing in the same census blocks as our sample . $^{7}$

\section{Gender | Question 23}

$64 \%$ of respondents were male and $36 \%$ were female (Table 2). These numbers fall roughly halfway between the proportions identified amongst Clackamas County farmers and census block residents, suggesting that our sample was a good representation of gender in our population.

\begin{tabular}{|c|c|c|c|}
\hline Gender & Sample & $\begin{array}{l}\text { County } \\
\text { Farmers }\end{array}$ & $\begin{array}{l}\text { Census Block } \\
\text { Residents }\end{array}$ \\
\hline Nale & $64 \%$ & $78 \%$ & $51 \%$ \\
\hline Female & $36 \%$ & $22 \%$ & $49 \%$ \\
\hline
\end{tabular}

\section{Age | Question 24}

The mean age of respondents was 63 years, with $47 \%$ of respondents aged 65 and over. By comparison, $33 \%$ of farmers in Clackamas County and $22 \%$ of census block residents were aged 65 and older (Table 3). This indicates that our sample is possibly biased towards older residents, and thus may not be fully representative of our population of interest. However, it is important to note that statistics from county farms and census block residents include both individuals who lease and who own property, whereas our sample includes only individuals who own property. 'Therefore, it is possible that landowners in general tend to be older than the average farmer or resident.

Table 3. Age of respondents $(n=248)$ compared with county farmer and resident populations.

\begin{tabular}{|lccc|}
\hline Years & Sample & $\begin{array}{c}\text { County } \\
\text { Farmers }\end{array}$ & $\begin{array}{c}\text { Census Block } \\
\text { Residents }\end{array}$ \\
\hline 25 to 34 & $2 \%$ & $3 \%$ & $13 \%$ \\
\hline 35 to 44 & $3 \%$ & $8 \%$ & $16 \%$ \\
\hline 45 to 54 & $18 \%$ & $23 \%$ & $23 \%$ \\
\hline 55 to 64 & $30 \%$ & $33 \%$ & $26 \%$ \\
\hline 65 and over & $47 \%$ & $33 \%$ & $22 \%$ \\
\hline
\end{tabular}

${ }^{6}$ United States Department of Agriculture (2012) Census of Agriculture

7 United States Census Bureau (2009 - 2013) American Community Survey 


\section{Education | Question 25}

Our sample was highly educated, with $48 \%$ having received a bachelor's degree or higher, and only $1 \%$ having not completed high school (Table 4). By comparison, $21 \%$ of census block residents have received a bachelor's degree or higher, and $9 \%$ have not completed high school. This may indicate a bias in our sample, or it may indicate that landowners in general tend to be more educated. Furthermore, the older age of our sample may have allowed for more time to complete advanced degrees. Educational attainment was not available for county farmers.

Table 4. Educational attainment of respondents $(n=261)$ compared with county resident population.

\begin{tabular}{|lcc|}
\hline Educational Attainment & Sample & $\begin{array}{c}\text { Census Block } \\
\text { Residents }\end{array}$ \\
\hline Less than High School & $1 \%$ & $9 \%$ \\
\hline High School Graduate or more & $13 \%$ & $32 \%$ \\
\hline Some college or more & $38 \%$ & $38 \%$ \\
\hline Bachelor's Degree or more & $23 \%$ & $14 \%$ \\
\hline Graduate or Professional Degrec & $25 \%$ & $7 \%$
\end{tabular}

Income | Question 27

Our sample reported substantially higher annual household incomes than census block residents, with $37 \%$ reporting an income of at least $\$ 100,000 /$ year and only $5 \%$ reporting an income of less than $\$ 25,000 /$ year (Table 5). By comparison, $28 \%$ of census block residents reported an income of at least $\$ 100,000 /$ year and $15 \%$ reported an income of less than $\$ 25,000 /$ year. Household income was not available for county farmers.

Table 5. Household income of respondents $(n=225)$ compared with county resident population.

\begin{tabular}{|lcc|}
\hline Household Income & Sample & $\begin{array}{c}\text { Census Block } \\
\text { Residents }\end{array}$ \\
\hline Less than $25 \mathrm{~K}$ & $5 \%$ & $15 \%$ \\
\hline 25 to $50 \mathrm{~K}$ & $14 \%$ & $20 \%$ \\
\hline 50 to $75 \mathrm{~K}$ & $25 \%$ & $20 \%$ \\
\hline 75 to $100 \mathrm{~K}$ & $19 \%$ & $17 \%$ \\
\hline 100 to $150 \mathrm{~K}$ & $17 \%$ & $19 \%$ \\
\hline $150 \mathrm{~K}$ or more & $20 \%$ & $9 \%$ \\
\hline
\end{tabular}

\section{Political Tendency | Question 26}

Our sample was substantially skewed towards conservative political tendencies, with $47 \%$ of respondents reporting their political tendency as either somewhat or very conservative (Figure 1). Conversely, $27 \%$ of respondents identified themselves as either somewhat or very liberal. By comparison, Clackamas County voters have favored democratic candidates in 
the last two presidential elections ${ }^{8}$, but our sample represents a more rural population than Clackamas County as a whole, and rural voters tend to hold more conservative values?

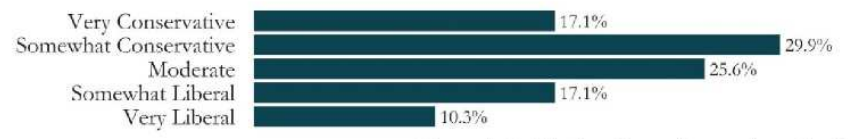

Figure 1. Political lendency of respondents $(n=235)$.

\section{Years Owning Property | Question 1}

The mean number of years that respondents owned their current property was 29.9 years, compared with 21.5 years for Clackamas County farmers (Table 6). While this indicates that our sample may have owned property substantially longer than our population of interest, several respondents indicated property ownership for 70 up to 168 years. Presumably, these respondents answered for years of family ownership. However, when these responses were removed, the mean property ownership remaincd above the County average at 26.9 ycars.

\begin{tabular}{|c|c|c|}
\hline Years & Sample & $\begin{array}{l}\text { County } \\
\text { Farms }\end{array}$ \\
\hline 2 or less & $1 \%$ & $2 \%$ \\
\hline 2 to 4 & $6 \%$ & $4 \%$ \\
\hline 4 to 10 & $7 \%$ & $14 \%$ \\
\hline 10 or more & $86 \%$ & $79 \%$ \\
\hline
\end{tabular}

${ }^{8}$ Clackamas County General Election Results

${ }^{9}$ McKee (2008) Rural Voters and the Polarization of American Presidential Elections. Univ. of S. Florida Petersburg. 


\section{PROPERTY CHARACTERISTICS}

To ensure that our sample represented the wide diversity of property types within the Clackamas River watershed, we evaluated the land usage, property size, and land management practices utilized by our sample.

\section{Land Usage | Question 3}

A large majority of respondents $(85 \%)$ considered their property in the Clackamas River watershed to be their primary residence (Figure 2). By comparison, $91 \%$ of Clackamas County farmers live on their farm properties ${ }^{10}$. Other important land uses include production of timber $(44 \%)$, grass and pasturelands $(34 \%)$, and production of hay $(20 \%)$. All other land uses were reported by fewer than $20 \%$ of respondents.

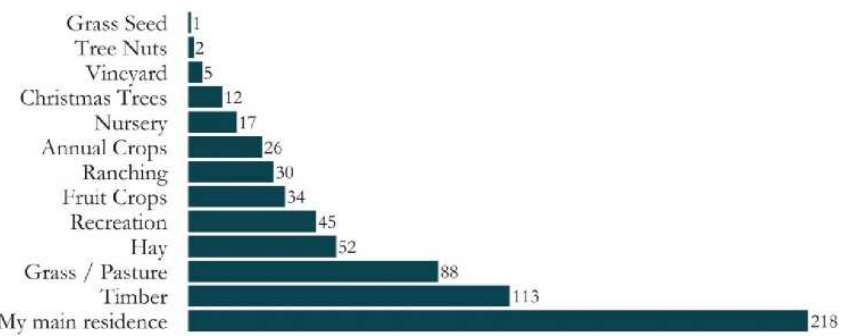

Figure 2. Count of respondents $(n=256)$ reporting listed land uses.

\section{Property Size}

Based on available tax lot data, we calculated the total number of acres within the watershed owned by each respondent (Table 7). The mean acreage owned by respondents was 105 acres, compared with an average farm size of 43 acres in Clackamas County as a whole. This difference in property size may be due to our exclusion of properties within the urban growth boundary, which are more restricted in size. Nonetheless, our sample may hold a significant bias towards large-acreage property owners.

Table 7. Tolal acreage onned by respondents $(n=240)$ compared with county farmer population.

\begin{tabular}{|lcc|}
\hline Acres & Sample & $\begin{array}{c}\text { County } \\
\text { Farms }\end{array}$ \\
\hline 1 to 9 acres & $32 \%$ & $38 \%$ \\
10 to 49 acres & $43 \%$ & $44 \%$ \\
\hline 50 to 179 acres & $12 \%$ & $15 \%$ \\
180 to 499 acres & $8 \%$ & $3 \%$ \\
\hline 500 to 999 acres & $3 \%$ & $1 \%$ \\
\hline 1000 or more acres & $2 \%$ & $<1 \%$ \\
\hline
\end{tabular}

${ }^{10}$ United States Department of Agriculture (2012) Census of Agriculture 


\section{Agricultural and Forestry Sales | Question 5}

We asked a question regarding the value of agricultural sales in 2014, and out of 254 respondents, 149 of them $(59 \%)$ reported no agricultural sales. Table 8 shows data only for the 105 respondents who reported agricultural sales in 2014. Respondents generally reported higher value agricultural sales than Clackamas County farmers in general did in 2012; $42 \%$ of respondents reported sales over $\$ 10,000$, whereas $28 \%$ of Clackamas County farmers reported similar sales. This difference could either be due to the different years of measurement, or our sample could be slightly biased towards higher value agricultural producers.

$\begin{aligned} & \text { Table } 8 \text {. Agricultural and/or forestry sales of respondents }(n=105) \text { compared } \\
& \text { Agriculth county farmers }\end{aligned}$
\begin{tabular}{lcc} 
Sample & $\begin{array}{c}\text { County } \\
\text { Farms }\end{array}$ \\
\hline Less than $\$ 1 \mathrm{~K}$ & $22 \%$ & $28 \%$ \\
\hline S1K to $\$ 10 \mathrm{~K}$ & $36 \%$ & $45 \%$ \\
\hline S10K to $\$ 50 \mathrm{~K}$ & $20 \%$ & $17 \%$ \\
\hline S50K to $\$ 100 \mathrm{~K}$ & $8 \%$ & $4 \%$ \\
\hline More than $\$ 100 \mathrm{~K}$ & $14 \%$ & $7 \%$
\end{tabular}

\section{Land Management Practices | Questions 7-9}

In question 8, we asked respondents whether they utilized a variety of land management practices on their land. Out of the 199 respondents who marked at least one of the listed land management practices, 107 marked invasive species control and 83 marked the use of synthetic fertilizers. Only 22 respondents marked the use of an integrated pest management plan, and only 21 marked the use of broadcast pesticide application practices.

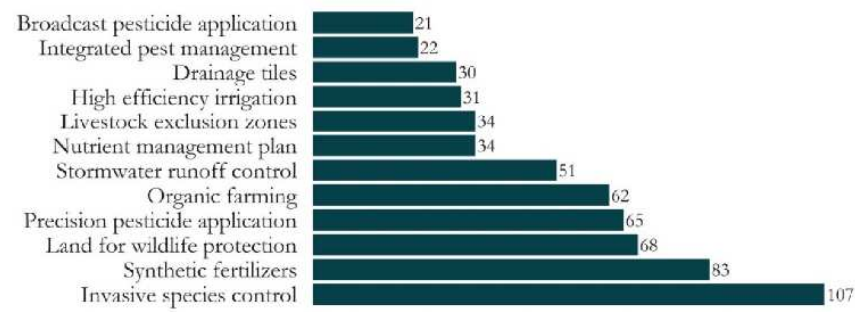

Figure 3. Count of respondents ( $n=199$ marked at least 1) reporting listed land management practices.

We also asked respondents to report whether they had participated in past land stewardship or conservation programs (questions 8 and 9), and we found that very few respondents had past participation with such programs. 10 individuals reported participation in a federal program, 14 individuals reported participation in a state program, and 24 individuals reported 
participation in other sorts of programs. Only 2 individuals marked that they had either enrolled or donated land to a conservation easement.

Vegetative Buffers | Question 20

We asked whether a stream, agricultural ditch, slough, or wetland exists anywhere on the respondent's property. Of the 255 who answered this question, $191(75 \%)$ answered affirmatively. We then asked whether they had a vegetative buffer around their stream, and if so, to identify the type. Out of 180 respondents reporting some sort of buffer on their stream, 157 reported a riparian buffer, 28 reported having a filter strip, and 18 reported having grassed waterways. Last, we asked participants the average width of their vegetative buffer (Figure 4). $45 \%$ reported having a buffer of greater than 100 feet in width; $26 \%$ reported a buffer of 35 to 50 feet in width; and $29 \%$ reported having a buffer between 5 and 20 feet in width (Figure 3).

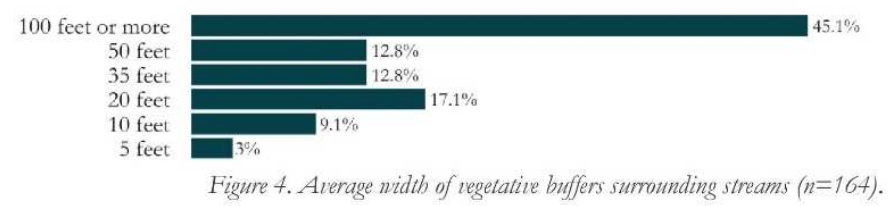




\section{RESPONDENT GROUPING}

One of the driving objectives behind this research was to identify key differences between likely and unlikely watershed stewardship program participants. By understanding what differentiates a likely participant from an unlikely participant, water resource managers may target outreach efforts to address some of these key dividing issues, and watershed conservation programs may be designed to achieve higher enrollment.

In the 2015 Clackamas Landowner Survey, we asked a series of questions relating to a hypothetical watershed conservation program. Questions pertained to (1) factors influencing land management decisions, (2) perception of the relationship between land management and water quality, (3) attitudes towards conservation programs general, (4) attitudes towards potential features of watershed conservation programs, (5) perceived barriers to participation in watershed conservation programs, and (6) beliefs about the need for watershed conservation in the Clackamas River watershed. These questions were designed to showcase the broad array of forms a watershed conservation program could takc. Following these questions, we asked,

"Now that you know a little bit more about the potential features of a watershed conservation program in the Clackamas River watershed, how likely would you say you are to participate in such a program if the program was tailored to your responses above?" (Question 17)

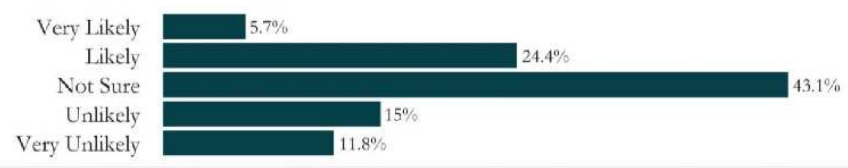

Figure 5. Respondents' $(n=246)$ willingness to participate in a watershed conseriation program.

In order to see differences between likely and unlikely participants, we split our sample into three groups - the Yes Group (those who answered "likely" or "very likely" to participate, $n=74$ ), the No Group (those who answered "unlikely" or "very unlikely" to participate, $n=66$ ), and the Maybe Group (those who answered that they were "not sure", $n=106$ ). About $30 \%$ of respondents were placed in the Yes Group, $27 \%$ of respondents were placed in the No Group, and $43 \%$ of respondents were placed in the Maybe Group (Figure 5). 


\section{Demographic Comparison of Groups}

We compared the demographics between these three groups, and found no substantial difference in property size, educational attainment, household income, location of residence, number of years owning property, value of agricultural sales, or size of vegetative buffer. The Yes Group tended to be younger (mean age 59) compared with the Maybe Group (mean age 62) and the No Group (mean age 69). This may indicate that age plays a significant role in determining an individual's willingness to participate in watershed stewardship programs. Figure 6 shows that the Yes and No Groups tended to be made up primarily of male respondents, whereas the Maybe Group tended to comprise primarily of female respondents.

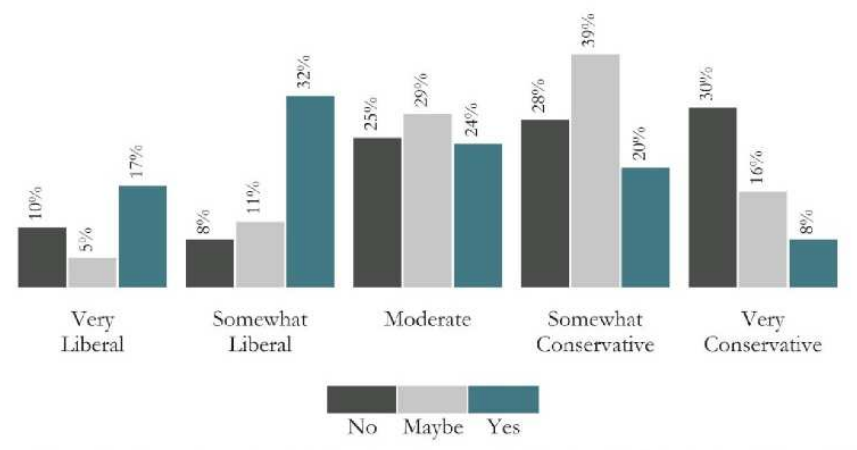

Figure 7. Comparison of political tendency between the $\mathrm{No}(n=61)$, Maybe $(n=87)$, and Yes $(n=66)$ Groups.

Figure 7 shows that $49 \%$ of the Yes Group identified themselves as liberal or very liberal, whereas only $18 \%$ of the No Group identified themselves as such. There was no substantial difference in the number of respondents considering themselves politically moderate.

For each section presented throughout this report, we evaluate responses of our entirc sample, and then compare how responses differed between these three groups. 


\section{EXPERIENCES WITH LAND MANAGEMENT}

The 2015 Clackamas I andowner survey included a series of questions relating to past and present experiences with land management. We asked about the importance of various factors influencing land management decisions, utilization of specific land management practices, past experience with conservation programs, and attitudes towards conservation programs. These questions are intended to help inform water resource managers by providing insight into the diverse suite of factors that a landowner in the Clackamas River watershed must consider when managing their land.

Factors Influencing Land Management | Question 6

We asked, "How important are the following factors when making decisions regarding your land?"

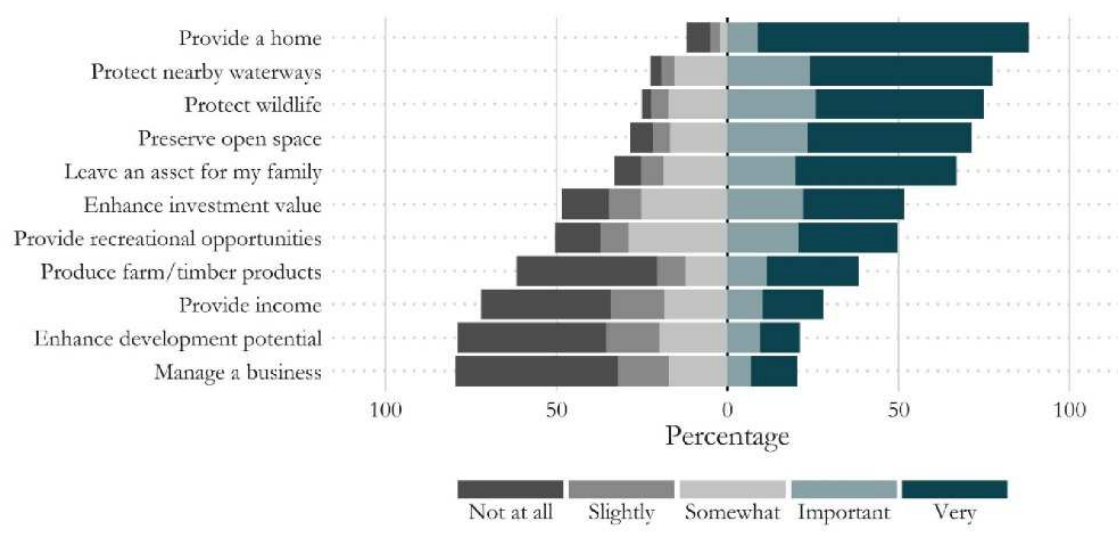

Figure 8. Influential factors for land management decisions among respondents ( $n=250$ to 260).

Figure 8 shows that the single most important factor influencing land management decisions amongst respondents was "to provide a safe and comfortable home for me and my family", with $88 \%$ of respondents marking this item as important or very important. Environmental factors were also highly rated by a majority of respondents, with over $70 \%$ marking the protection of local waterways $(78 \%)$, the protection of wildlife and native vegetation $(75 \%)$, and the preservation of open space $(71 \%)$ as important or very important. The production of farm or timber products, provision of income, enhancement of the property's development potential and business considerations were ranked as the least important factors. 
Box 1. Land production, business, and income considerations were generally not considered important factors in land management decisions. However, these factors were considered substantially more important by landowners with agricultural or forestry sales of greater than $\$ 1000$.

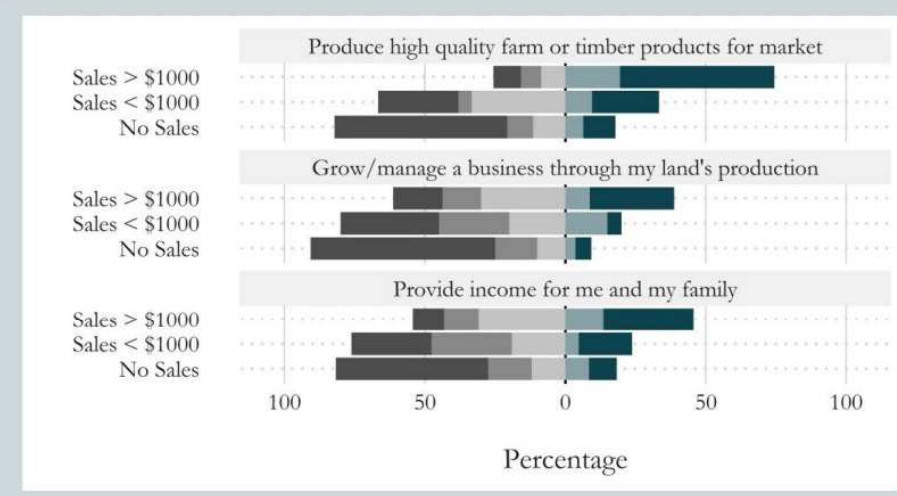

Table 9. Perrentage of respondents who reported the item as an "important" or "very important" factor in making land management decisions. The column "Difference" indicates the difference

\begin{tabular}{|c|l|c|c|c|c|}
\hline between the Yes Grout and the No Grout. & \multicolumn{3}{|c|}{$\begin{array}{c}\text { Group } \\
\text { Maybe }\end{array}$} & Yes & Difference \\
\hline n & & No & \\
\hline 237 & Preserve open space & $60 \%$ & $66 \%$ & $88 \%$ & $28 \%$ \\
\hline 239 & Protect wildlife & $65 \%$ & $71 \%$ & $92 \%$ & $27 \%$ \\
\hline 237 & Protect nearby waterways & $68 \%$ & $71 \%$ & $93 \%$ & $25 \%$ \\
\hline 235 & Provide recreational opportunitics & $43 \%$ & $46 \%$ & $59 \%$ & $16 \%$ \\
\hline 231 & Provide a home & $84 \%$ & $88 \%$ & $92 \%$ & $8 \%$ \\
\hline 229 & Enhance investment value & $52 \%$ & $45 \%$ & $58 \%$ & $6 \%$ \\
\hline 237 & Lcavc an asset for my family & $73 \%$ & $65 \%$ & $68 \%$ & $-5 \%$ \\
\hline 233 & Produce farm/timber products & $41 \%$ & $36 \%$ & $35 \%$ & $-6 \%$ \\
\hline 231 & Provide income & $34 \%$ & $24 \%$ & $28 \%$ & $-6 \%$ \\
\hline 233 & Manage a business & $25 \%$ & $18 \%$ & $15 \%$ & $-10 \%$ \\
\hline 235 & Enhance development potential & $30 \%$ & $18 \%$ & $16 \%$ & $-14 \%$ \\
\hline
\end{tabular}

Table 9 shows that respondents in the Yes Group more frequently marked that environmental or recreational factors were important influences on their land management decisions. Compared with the No Group, the Yes Group marked "preserve open space" $28 \%$ more frequently, "protect wildlife" $27 \%$ more frequently, "protect nearby waterways" $25 \%$ more frequently, and "provide recreational opportunities" $16 \%$ more frequently. Conversely, respondents in the Yes Group less frequently marked practical considerations 
as important influences on their land management decisions. Compared with the No Group, the Yes Group marked "enhance development potential" $14 \%$ less frequently and "manage a business" $10 \%$ less frequently. Respondents in the No and Maybe Groups most often marked "provide a home," whereas respondents in the Yes Group most often marked "protect nearby waterways." Respondents in all three groups least often marked "manage a business."

Perception of Water Quality Impacts | Question 7

We asked, "Please indicate how much of an impact you think these practices have on river water quality."

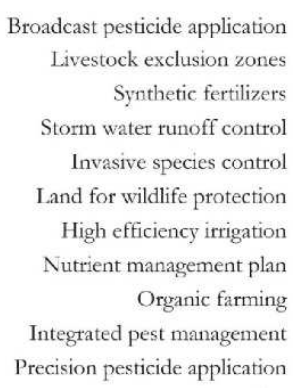

100

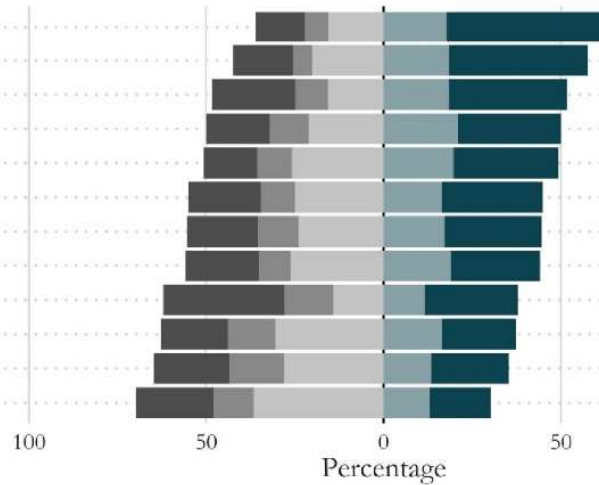

Percentage

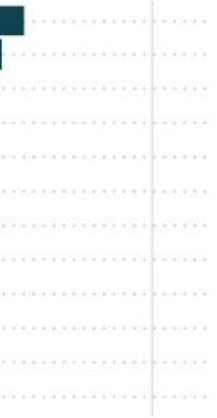

100

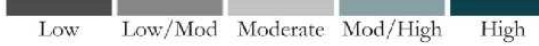

Figure 9. Respondents'perceptions of water quality impacts ( $n=164$ to 217).

Figure 9 shows the impact that respondents perceive common land management practices to have on water quality. Note that the term impact was not defined as a positive or negative relationship to water quality; instead, this question was asked to gain insight into the degree with which landowners perceive a relalionship between land management and water quality. Respondents perceived broadcast pesticide application to have the greatest impact on water quality, with $64 \%$ of respondents reporting this activity to have a moderately high to very high impact on water quality. Livestock exclusion zones around streams (58\%), use of synthetic fertilizers $(52 \%)$, and storm water runoff control $(50 \%)$ were all reported as important or very important by more than half of respondents. 
Table 10. Perventage of respondents who reported the item as having a "moderately high" or "high" impact on water quality. The column "Difference" indicates the difference between the Yes Group and the No Group.

\begin{tabular}{|c|l|c|c|c|c|}
\hline $\mathbf{n}$ & & No & $\begin{array}{c}\text { Group } \\
\text { Maybe }\end{array}$ & Yes & Difference \\
\hline 200 & Synthetic fertilizers & $27 \%$ & $60 \%$ & $64 \%$ & $37 \%$ \\
\hline 166 & Broadcast pesticide application & $44 \%$ & $64 \%$ & $78 \%$ & $34 \%$ \\
\hline 169 & Livestock exclusion zones & $41 \%$ & $56 \%$ & $75 \%$ & $34 \%$ \\
\hline 151 & Integrated pest management & $18 \%$ & $41 \%$ & $47 \%$ & $29 \%$ \\
\hline 166 & Nutrient management plan & $32 \%$ & $41 \%$ & $60 \%$ & $28 \%$ \\
\hline 176 & Precision pesticide application & $23 \%$ & $37 \%$ & $47 \%$ & $24 \%$ \\
\hline 182 & Land for wildlife protection & $35 \%$ & $41 \%$ & $59 \%$ & $24 \%$ \\
\hline 154 & Drainage tiles & $20 \%$ & $30 \%$ & $36 \%$ & $16 \%$ \\
\hline 175 & Storm water runoff control & $42 \%$ & $49 \%$ & $57 \%$ & $15 \%$ \\
\hline 172 & Organic farming & $33 \%$ & $37 \%$ & $45 \%$ & $12 \%$ \\
\hline 161 & High efficiency irrigation & $43 \%$ & $41 \%$ & $47 \%$ & $4 \%$ \\
\hline 195 & Invasive species control & $54 \%$ & $49 \%$ & $49 \%$ & $-5 \%$ \\
\hline & & & & & \\
\hline
\end{tabular}

Table 10 shows that for nearly all items, respondents in the Yes Group more frequently perceived the listed land management actions as having a high impact on water quality. Compared with the No Group, the Yes Group marked "synthetic fertilizers" $37 \%$ more frequently, "broadcast pesticide application" $34 \%$ more frequently, "livestock exclusion zones" $34 \%$ more frequently, "integrated pest management" $29 \%$ more frequently, and "nutrient management plan" $28 \%$ more frequently. Respondents in the No Group most often marked "invasive species control," whereas respondents in the Maybe and Yes Groups most often marked "broadcast pesticide application." Conversely, respondents in all three groups least often marked "drainage tiles."

\section{Attitudes towards Conservation Programs | Question 10}

We asked, "Please report the degree to which you agree with the following opinions. In general, conservation programs are..."

Figure 10 shows that, in general, respondents held either positive or neutral attitudes regarding conservation programs. In particular, respondents were highly positive regarding the bencfits to wildlife, with $83 \%$ reporting that conservation programs had either positive or very positive impacts on wildlife. Respondents generally reported that conservation programs were a good use of resources $(52 \%)$, rewarding to landowners $(48 \%)$, compatible with goals for their land $(46 \%)$ and beneficial to their lands productivity $(46 \%)$. A majority of respondents expressed neutral attitudes regarding the impact of conservation programs on their finances, the flexibility of conservation programs, or the ease of enrollment in conservation programs. 
Beneficial to wildlife

A good use of resources

Rewarding to landowners

Compatible with my goals

Beneficial for land productivity

Good for my finances

Flexible

Easy to enroll in

100

50

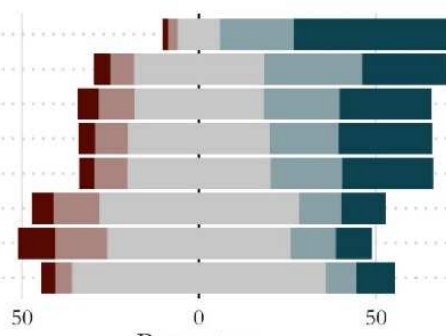

Percentage

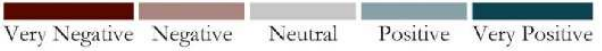

Figure 10. Respondents' attitudes towards conservation programs ( $n=255$ to 259).

Table 11 shows that the Yes Group had more positive attitudes towards conservation programs. Compared with the No Group, the Yes Group marked "compatible with my goals" $45 \%$ more frequently, "beneficial for land productivity" $40 \%$ more frequently, "rewarding to landowners" $39 \%$ more frequently, and "a good use of resources" $39 \%$ more frequently. Respondents in all three groups most often marked "beneficial to wildlife." Conversely, respondents in the No Group least often marked "good for my finances," respondents in the Maybe Group least often marked "Flexible," and respondents in the Yes Group least often marked "easy to enroll in."

Table 11. Percentage of respondents who reported a "positive" or "very positive" attitude regarding each statement about conservation programs. The column "Difference" indicates the difference between the Yes Group and the No Group.

\begin{tabular}{|c|l|c|c|c|c|}
\hline $\mathbf{n}$ & & No & $\begin{array}{c}\text { Group } \\
\text { Maybe }\end{array}$ & Yes & Difference \\
\hline 233 & Compatible with my goals & $28 \%$ & $36 \%$ & $73 \%$ & $45 \%$ \\
\hline 233 & Bencficial for land productivity & $25 \%$ & $46 \%$ & $65 \%$ & $40 \%$ \\
\hline 233 & Rewarding to landowners & $31 \%$ & $43 \%$ & $70 \%$ & $39 \%$ \\
\hline 231 & A good use of resources & $34 \%$ & $49 \%$ & $73 \%$ & $39 \%$ \\
\hline 233 & Good for my finances & $13 \%$ & $21 \%$ & $39 \%$ & $26 \%$ \\
\hline 232 & Beneficial to wildlife & $71 \%$ & $84 \%$ & $93 \%$ & $22 \%$ \\
\hline 233 & Flexible & $20 \%$ & $14 \%$ & $38 \%$ & $18 \%$ \\
\hline 231 & Easy to enroll in & $18 \%$ & $15 \%$ & $29 \%$ & $11 \%$ \\
\hline
\end{tabular}




\section{PERSPECTIVES ON WATERSHED STEWARDSHIP}

The 2015 Clackamas Landowner survey included a series of questions regarding preferences for a hypothetical watershed stewardship program. We asked about interest in achieving watershed stewardship goals, desired incentives for participation, interest in working with selected agencies and organizations, perceived barriers to participation, and beliefs regarding the need for watershed stewardship in the Clackamas River watershed.

Likelihood of working towards stewardship goals | Question 11 We asked, "How likely would you be to work with a watershed conservation program on any of the following goals?"

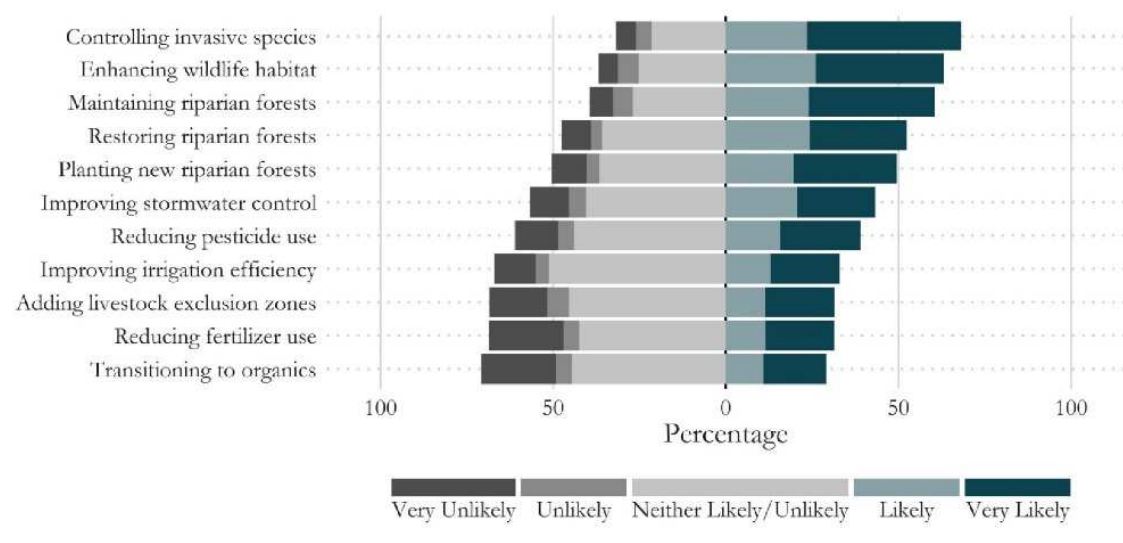

Figure 11. Respondents' likelihood of morking lowards conservation goals $(n=238$ to 251).

Figure $\mathbf{1 1}$ shows that many respondents reported that they would be either likely or very likely to work towards habitat restoration goals such as controlling invasive species $(68 \%)$, enhancing wildlife habitat $(61 \%)$, maintaining healthy streamside forests $(61 \%)$, restoring floodplains $(52 \%)$, or planting new riparian forests $(50 \%)$. Fewer respondents reported that they were likely or very likely to work towards more specific land management goals such as improving storm water runoff control $(43 \%)$, reducing pesticide usc $(39 \%)$, improving irrigation efficiency $(33 \%)$, adding livestock cxclusion zones around streams $(32 \%)$, reducing fertilizer use $(31 \%)$, and transitioning to organic production $(29 \%)$. 
Table 12. Percentage of respondents who answered "likely" or "very likely" to work with a watershed conservation program on the listed goals. The column "Difference" indicates the difference between the Yes Group and the No Group.

\begin{tabular}{|c|l|c|c|c|c|}
\hline $\mathbf{n}$ & & No & $\begin{array}{c}\text { Group } \\
\text { Maybe }\end{array}$ & Yes & Difference \\
\hline 231 & Planting new riparian forests & $18 \%$ & $47 \%$ & $78 \%$ & $60 \%$ \\
\hline 231 & Restoring riparian forests & $22 \%$ & $51 \%$ & $78 \%$ & $56 \%$ \\
\hline 233 & Maintaining riparian forests & $31 \%$ & $61 \%$ & $85 \%$ & $54 \%$ \\
\hline 234 & Enhancing wildlife habitat & $35 \%$ & $66 \%$ & $84 \%$ & $49 \%$ \\
\hline 226 & Reducing pesticide use & $14 \%$ & $33 \%$ & $62 \%$ & $48 \%$ \\
\hline 231 & Improving storm watcr control & $19 \%$ & $38 \%$ & $65 \%$ & $46 \%$ \\
\hline 229 & Reducing fertilizcr use & $7 \%$ & $29 \%$ & $51 \%$ & $44 \%$ \\
\hline 223 & Adding livestock exclusion zones & $11 \%$ & $26 \%$ & $54 \%$ & $43 \%$ \\
\hline 235 & Improving irrigation efficiency & $10 \%$ & $27 \%$ & $52 \%$ & $42 \%$ \\
\hline 226 & Controlling invasive species & $48 \%$ & $66 \%$ & $88 \%$ & $40 \%$ \\
\hline & & $12 \%$ & $22 \%$ & $51 \%$ & $39 \%$ \\
\hline
\end{tabular}

Table 12 shows that the Yes Group most frequently expressed interest in working towards all listed goals and expressed an exceptionally high interest in working towards environmental goals. Compared with the No Group, the Yes Group marked "planting new riparian forests" $60 \%$ more frequently, "restoring riparian forests" $56 \%$ more frequently, "maintaining riparian forests" $54 \%$ more frequently, and "enhancing wildlife habitat" $49 \%$ morc frequently. Respondents in all three groups most often marked "controlling invasive species." Conversely, respondents in the No Group least often marked "reducing fertilizer use," whereas respondents in the Maybe and Yes Groups least often marked "transitioning to organics."

\section{Desired Incentives for Enrollment | Question 12}

We asked, "Would the following increase your interest in working with a watershed conservation program?"

Figure 12 shows which incentives are most likely to increase respondent interest in watershed stewardship programs. The highest number of respondents marked "probably yes" or "definitely yes" for annual cash incentives $(51 \%)$, a onc-time cash bonus $(45 \%)$ and dedicated staff to help implement projects $(43 \%)$. Respondents expressed a moderate degree of interest in discounts at local retailers, a bonus for working with neighbors, and educational/training opportunities. Respondents expresed a high degree of uncertainty or disinterest in zero-interest loans or improved marketing opportunities. 


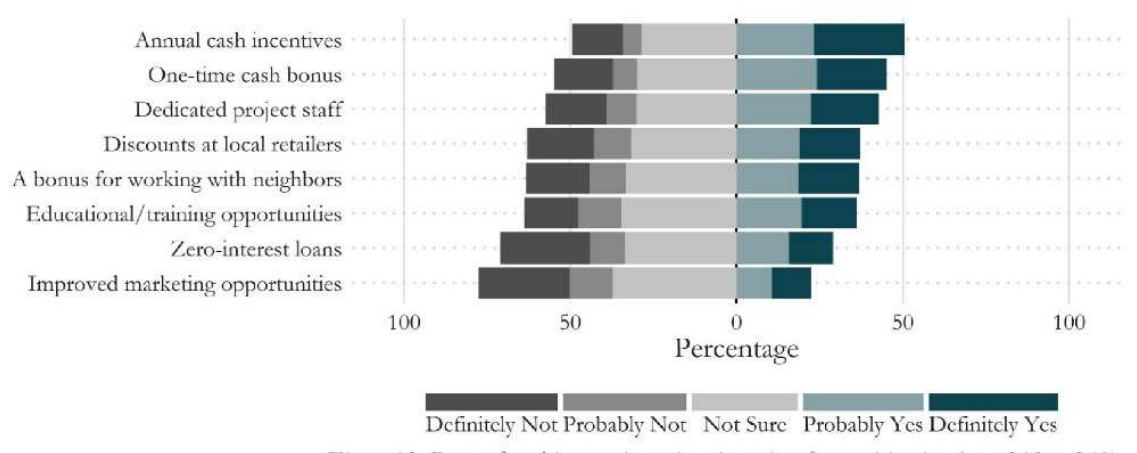

Figure 12. Respondents' interest in various incentives for parlicipation ( $n=243$ to 249).

Box 2. Respondents with sales over $\$ 1000$ in 2014 were much more likely to be interested in annual cash incentives, a one time cash bonus, and improved marking opportunities for products from their land.

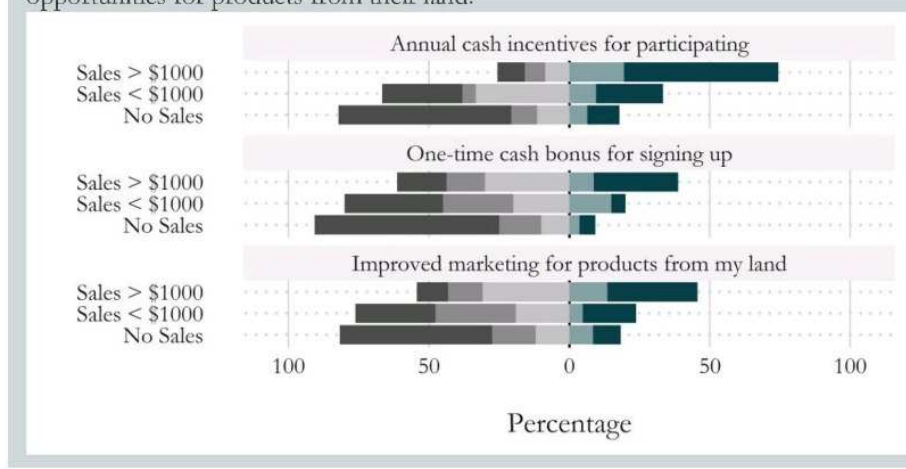

Table 13 shows that incentives will probably increase interest amongst respondents in the Yes Group. Compared with the No Group, the Yes markcd"dedicated project staff" $49 \%$ more frequently, "annual cash incentives" $46 \%$ more frequently, "one-time cash bonus" $45 \%$ more frequently, and "educational/training opportunities" $44 \%$ more frequently. Respondents in all three groups most often marked "annual cash incentives." Conversely, respondents in the No Group least often marked

"educational/training opportunities," whereas respondents in the Maybe and Yes Groups least often marked "improved marketing opportunitics." 
Table 13. Perrentage of respondents who answered "yes" or "definitely yes" to interest in incentives. The column "Difference" indicates the difference between the Yes Group and the No Group.

\begin{tabular}{|c|c|c|c|c|c|}
\hline \multirow{2}{*}{$\mathrm{n}$} & & \multicolumn{3}{|c|}{ Group } & \multirow{2}{*}{ Difference } \\
\hline & & No & Maybe & Yes & \\
\hline 229 & Dedicated project staff & $20 \%$ & $33 \%$ & $69 \%$ & $49 \%$ \\
\hline 233 & Annual cash incentives & $28 \%$ & $47 \%$ & $74 \%$ & $46 \%$ \\
\hline 2.31 & One-time cash bonus & $23 \%$ & $42 \%$ & $68 \%$ & $45 \%$ \\
\hline 229 & Educational/training opportunities & $10 \%$ & $35 \%$ & $54 \%$ & $44 \%$ \\
\hline 230 & A bonus for working with neighbors & $18 \%$ & $35 \%$ & $55 \%$ & $37 \%$ \\
\hline 227 & Discounts at local retailers & $20 \%$ & $37 \%$ & $54 \%$ & $34 \%$ \\
\hline 231 & Zero-interest loans & $15 \%$ & $26 \%$ & $39 \%$ & $24 \%$ \\
\hline 228 & Improved marketing opportunities & $14 \%$ & $17 \%$ & $31 \%$ & $17 \%$ \\
\hline
\end{tabular}

Preferred Partner Organizations | Question 13

We asked, "How likely would you be to enroll in a watershed conservation program if it required you to work with the following organizations to implement the program or project?"

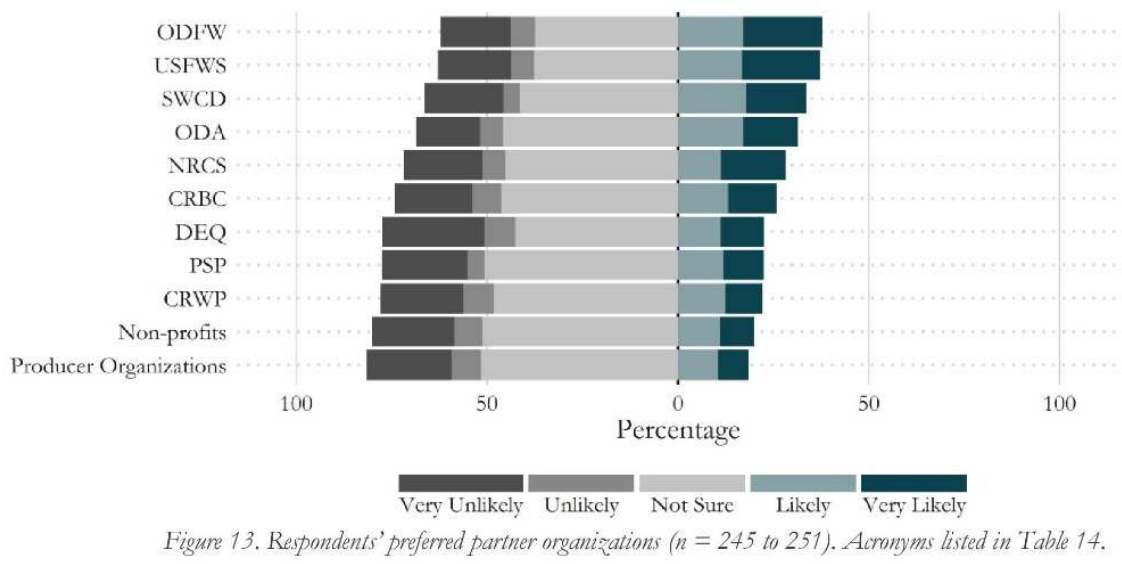

Figure 13 shows respondents likelihood of working with potential partner organizations. Respondents generally expressed uncertainty, with at least $37 \%$ of respondents marking "Not Sure" for all items. However, the greatest number of respondents marked likely or very likely to work with Oregon Department of Fish and Wildlife $(38 \%)$ and the US Fish and Wildlife Service $(37 \%)$. 
Table 14. Perrentage of respondents who answered "likely" or "very likely" to work with the listed organizations. The column "Difference" indicates the difference between Group Yes and Group No.

\begin{tabular}{|c|c|c|c|c|c|}
\hline \multirow{2}{*}{ n } & & \multicolumn{3}{|c|}{ Group } & \multirow{2}{*}{ Difference } \\
\hline & & No & Maybe & Yes & \\
\hline 234 & CRBC (Clackamas River Basin Council) & $8 \%$ & $14 \%$ & $56 \%$ & $48 \%$ \\
\hline 231 & NRCS (Natural Resources Conservation Services) & $10 \%$ & $16 \%$ & $54 \%$ & $44 \%$ \\
\hline 234 & USFWS (US Fish and Wildlife Service) & $19 \%$ & $23 \%$ & $63 \%$ & $44 \%$ \\
\hline 234 & ODFW (Oregon Dept. of Fish and Wildlife) & $21 \%$ & $22 \%$ & $64 \%$ & $43 \%$ \\
\hline 230 & SWCD (Soil \& Water Conservation District) & $12 \%$ & $19 \%$ & $54 \%$ & $42 \%$ \\
\hline 238 & PSP (Clackamas Pesticide Stewardship Partnership) & $8 \%$ & $12 \%$ & $49 \%$ & $41 \%$ \\
\hline 229 & Other non-profit conservation organizations & $7 \%$ & $8 \%$ & $46 \%$ & $39 \%$ \\
\hline 232 & DEQ (Oregon Dept. of Environmental Quality) & $10 \%$ & $10 \%$ & $48 \%$ & $38 \%$ \\
\hline 232 & CRIWP (Clackamas River Water Providers) & $11 \%$ & $9 \%$ & $46 \%$ & $35 \%$ \\
\hline 234 & ODA (Oregon Dept. of Agriculture) & $18 \%$ & $21 \%$ & $50 \%$ & $32 \%$ \\
\hline 232 & Producer Organizations & $13 \%$ & $9 \%$ & $32 \%$ & $19 \%$ \\
\hline
\end{tabular}

Table 14 shows that for all organizations, respondents in the Yes Group expressed higher interest in working with the listed organizations. Notably, the Yes Group marked the Clackamas River Basin Council 48\% more frequently. Respondents in all three groups most often marked the Oregon Department of Fish and Wildlife. Conversely, respondents in the No and Maybe Groups least often marked non-profits, whereas those in the Yes Group least often marked producer organizations.

\section{Agreement to Contractual Features | Question 14}

We asked, "Would you be willing to agree to any of the following in a watershed conservation program?"

Regular maintenance and monitoring Annual reporting requirements

Management actions prior to enrollment

A 10 year contract

A 20 year contract

A deed restriction
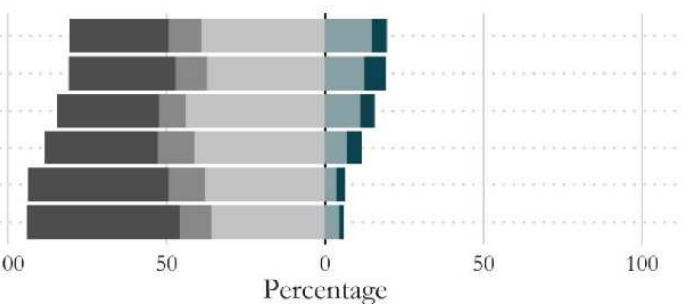

Definitely Not Probably Not Not Sure Probably Yes Definitely Yes

Figure 14. Respondents' millingness to agree to contractual obligations $(n=248$ to 251).

Figure 14 shows that respondents were generally uncertain or unwilling to commit to contractual obligations. In particular, $46 \%$ of respondents marked probably or definitely not to signing a 10 year contract, $56 \%$ to signing a 20 year contract, and $58 \%$ to signing a deed restriction. 
Table 15. Percentage of respondents who answered "yes" or "definitely yes" to agreeing to the listed features. The column "Difference" indicates the difference between Group Yes and Group No.

\begin{tabular}{|c|c|c|c|c|c|}
\hline \multirow[b]{2}{*}{$\mathbf{n}$} & & \multicolumn{3}{|c|}{ Group } & \multirow{2}{*}{ Difference } \\
\hline & & No & Maybe & Yes & \\
\hline 234 & Annual reporting requirements & $3 \%$ & $9 \%$ & $45 \%$ & $42 \%$ \\
\hline 234 & Regular maintenance and monitoring & $3 \%$ & $10 \%$ & $42 \%$ & $39 \%$ \\
\hline 2.34 & Management actions prior to enrollment & $6 \%$ & $7 \%$ & $32 \%$ & $26 \%$ \\
\hline 234 & A 10 year contract & $5 \%$ & $3 \%$ & $25 \%$ & $20 \%$ \\
\hline 232 & A deed restriction & $3 \%$ & $3 \%$ & $13 \%$ & $10 \%$ \\
\hline 234 & A 20 year contract & $6 \%$ & $2 \%$ & $11 \%$ & $5 \%$ \\
\hline
\end{tabular}

Table 14 shows that the Yes Group was more willing to agree to contractual features than the No or Maybe Groups. Compared with the No Group, the Yes Group marked "annual reporting requirements" $42 \%$ more frequently and "regular maintenance and monitoring" 39\% more frequently. Respondents in the Maybe Group most often marked "regular maintenace and monitoring," whereas respondents in the Yes Group most often marked "annual reporting requirements." Respondents in both groups least often marked "a 20 year contract." Fewer than $6 \%$ of respondents in the No Group marked that they would be willing to agree to any of the listed items.

\section{Barriers to Participation | Question 15}

We asked, "To what extent do you agree or disagree with the following statements about why you might NOT participate in a watershed conservation program?"

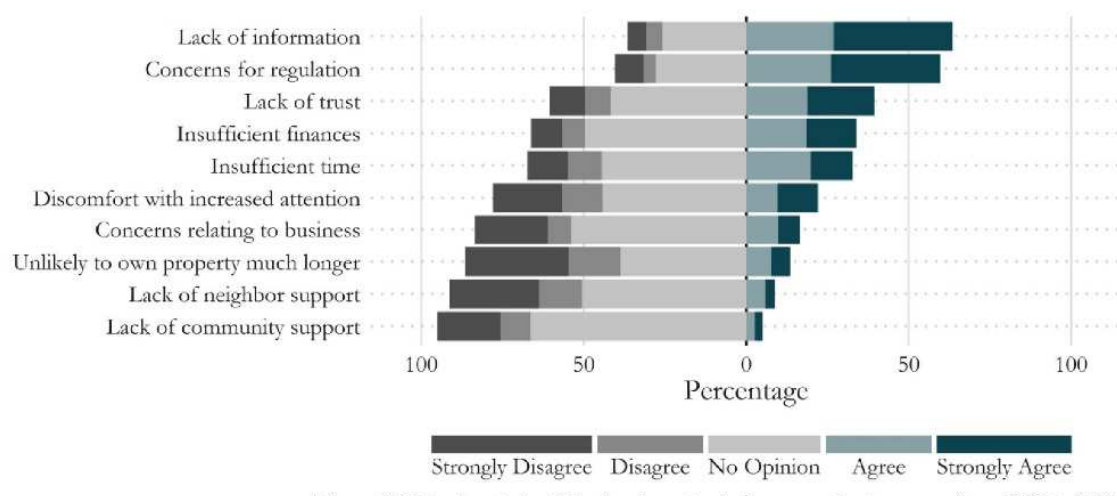

Figure 15. Barriers to participation in watershed conservation programs $(n=238$ to 242).

Figure 15 shows reasons why respondents would not participate in a watershed conservation program. The majority $(64 \%)$ either agreed or strongly agreed that they did not have enough information; this is logical given that all 
questions were pertaining to a hypothetical conservation program. $60 \%$ of respondents agreed that they were concerned about regulatory implications, and $49 \%$ noted a lack of trust of organizations that run conservation programs. Few people agreed that lack of neighbor support $(9 \%)$ or community support $(5 \%)$ would prevent them from participating.

Table 16. Perventage of respondents who answered "agree" or "strongly agree" to the listed barriers. The column "Difference" indicates the difference between Group Yes and Group No.

\begin{tabular}{|c|l|c|c|c|c|}
\hline n & & No & $\begin{array}{c}\text { Maybe } \\
\text { Maybe }\end{array}$ & Difference \\
\hline 275 & Lack of information & $40 \%$ & $70 \%$ & $74 \%$ & $34 \%$ \\
\hline 272 & Concerns for regulation & $53 \%$ & $64 \%$ & $60 \%$ & $7 \%$ \\
\hline 272 & Lack of neighbor support & $10 \%$ & $10 \%$ & $7 \%$ & $-3 \%$ \\
\hline 272 & Lack of community support & $7 \%$ & $6 \%$ & $3 \%$ & $-4 \%$ \\
\hline 275 & Insufficient finances & $34 \%$ & $38 \%$ & $26 \%$ & $-8 \%$ \\
\hline 272 & Unlikely to own property much longer & $22 \%$ & $10 \%$ & $12 \%$ & $-10 \%$ \\
\hline 274 & Discomfort with increased attention & $30 \%$ & $25 \%$ & $14 \%$ & $-16 \%$ \\
\hline 274 & Insufficient time & $43 \%$ & $33 \%$ & $26 \%$ & $-17 \%$ \\
\hline 270 & Conccrns rclating to busincss & $31 \%$ & $12 \%$ & $12 \%$ & $-19 \%$ \\
\hline 273 & Lack of trust & $48 \%$ & $47 \%$ & $23 \%$ & $-25 \%$ \\
\hline
\end{tabular}

Table 16 shows that, in general, the Yes Group perceived fewer barriers. Compared with the No Group, the Yes Group marked "discomfort with increased attention" $16 \%$ less frequently, "insufficient time" $17 \%$ less frequently, "concerns relating to business" $19 \%$ less frequently, and "lack of trust" $25 \%$ less frequently. Respondents in the No Group most often marked "concern for regulations," whereas respondents in the Maybe and Yes Groups most often marked "lack of information." Conversely, respondents in all three groups least often marked "lack of community support."

\section{Beliefs about Watershed Conservation | Question 16}

\section{We asked, "In general, do you agree or disagree with the following statements regarding watershed conservation in the Clackamas River watershed?"}

Figure 16 shows that many respondents either agreed or strongly agreed that functioning stream ecosystems are important for a clean water supply $(88 \%)$, watershed conservation is the right thing to do $(65 \%)$, watershed conservation benefits everyone in the watershed $(62 \%)$, water pollution is detrimental to human health (59\%), and development within the watershed threatens water quality $(57 \%)$. Despite this recognition of the important of water quality, $45 \%$ of respondents agreed or strongly agreed that watershed conscrvation might limit their choice and personal freedoms. $48 \%$ of respondents disagreed that pollution from their property has impacts downstream. 
Healthy streams provide clean water Conservation is the right thing to do

Conservation benefits everyone Water pollution is bad for health Development threatens water quality Conservation limits my freedoms Pollution here has impacts downstream

Water quality is not in decline

Pollution levels are exaggerated

Conservation threatens my livelihood
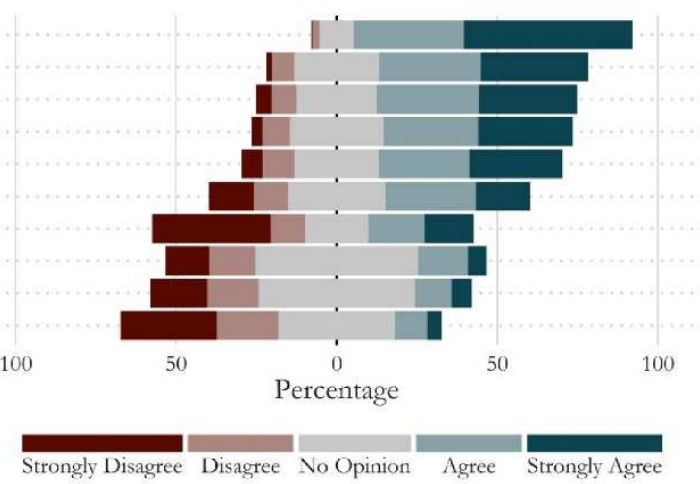

Figure 16. Respondents' beliefs regarding watershed conservation ( $n=240$ to 245).

Table 17 shows that the Yes Group more frequently believed that watershed stewardship programs have environmental and societal benefits. Compared with the No Group, the Yes Group marked "conservation is the right thing to do" $52 \%$ more frequently, "conservation benefits everyone" $49 \%$ more frequently, mark "development threatens water quality" $35 \%$ more frequently, and "water pollution is bad for health" $34 \%$ more frequently. Additionally, the Yes Group was less likely to hold negative beliefs about watershed conservation. Compared with the No Group, the Yes Group marked "conservation threatens my livelihood" $20 \%$ less frequently, "conservation limits my frecdoms" $22 \%$ less frequently, and "water quality is not in declinc" $22 \%$ less frequently. Respondents in all three groups most often marked "healthy streams provide clean water." The No Group least often marked "pollution here has impacts downstream," whereas the Maybe and Yes Groups least often marked "conservation threatens my livelihood."

Table 17. Perrentage of respondents who answered "agree" or "strongly" to the listed beliefs. The column "Difference" indicates the difference between Group Yes and Group No.

\begin{tabular}{|c|l|c|c|c|c|}
\hline n & & No & $\begin{array}{c}\text { Group } \\
\text { Maybe }\end{array}$ & Yes & Difference \\
\hline 236 & Conservation is the right thing to do & $37 \%$ & $64 \%$ & $89 \%$ & $52 \%$ \\
\hline 237 & Conservation bencfits creryonc & $39 \%$ & $60 \%$ & $88 \%$ & $49 \%$ \\
\hline 235 & Devclopment threatens water quality & $39 \%$ & $57 \%$ & $74 \%$ & $35 \%$ \\
\hline 237 & Water pollution is bad for health & $39 \%$ & $60 \%$ & $73 \%$ & $34 \%$ \\
\hline 235 & Healthy streams provide clean water & $71 \%$ & $87 \%$ & $99 \%$ & $28 \%$ \\
\hline 237 & Pollution here has impacts downstream & $23 \%$ & $27 \%$ & $48 \%$ & $25 \%$ \\
\hline 236 & Pollution levels are exaggerated & $29 \%$ & $16 \%$ & $11 \%$ & $-18 \%$ \\
\hline 233 & Conservation threatens my livelihood & $28 \%$ & $11 \%$ & $8 \%$ & $-20 \%$ \\
\hline 237 & Conservation limits my freedoms & $60 \%$ & $42 \%$ & $38 \%$ & $-22 \%$ \\
\hline 236 & Water quality is not in decline & $34 \%$ & $21 \%$ & $12 \%$ & $-22 \%$ \\
\hline
\end{tabular}


Payments for Vegetative Buffers | Question 22

We asked, "A watershed conservation program may be able to pay you to place or keep land in buffers. What level of payment would motivate you to plant or maintain a buffer of at least 35 feet in width?"

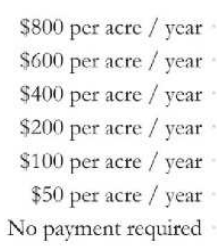

$\$ 800$ per acre / year
$\$ 600$ per acre / year
$\$ 400$ per acre / year
$\$ 200$ per acre / year
$\$ 100$ per acre / year
$\$ 50$ per acre / year
No payment required

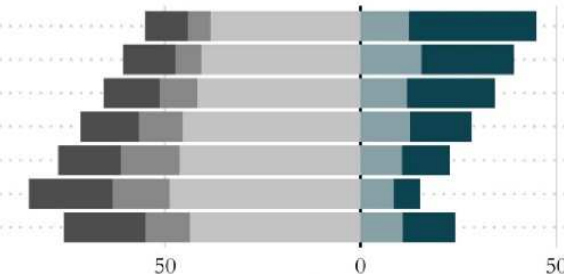

Percentage

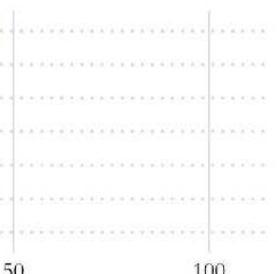

50

Definitely Not Probably Not Not Sure Probably Yes Definitely Yes

Figure 17. Payments required to plant or maintain an acre of vegetative buffer $(n=131$ to 149).

Figure 17 shows an expected trend; as payments for buffers increase, more landowners reported an interest in placing or maintaining vegetative buffers on their land. Only $15 \%$ of landowners would plant or maintain vegetative buffers for $\$ 50$ per acre/year, whereas $45 \%$ of landowners would plant or maintain a vegetative buffer for $\$ 800$ per acre/year. Interestingly, $28 \%$ of respondents reported that no payment is required to plant or maintain buffers; this is a greater portion than those who reported $\$ 50$ or $\$ 100$ per acre/year.

Table 18. Percentage of respondents who answered "probably yes" or "definitely yes" to the listed payments. The column "Difference" indicates the difference betmeen Group Yes and Group No.

\begin{tabular}{|c|c|c|c|c|c|}
\hline $\mathbf{n}$ & & No & $\begin{array}{l}\text { Group } \\
\text { Maybe }\end{array}$ & Yes & Difference \\
\hline 146 & No payment required & $21 \%$ & $17 \%$ & $35 \%$ & $14 \%$ \\
\hline 128 & $\$ 50$ per acre / year & $0 \%$ & $11 \%$ & $29 \%$ & $29 \%$ \\
\hline 129 & $\$ 100$ per acre / year & $0 \%$ & $22 \%$ & $37 \%$ & $37 \%$ \\
\hline 131 & $\$ 200$ per acre / year & $8 \%$ & $22 \%$ & $49 \%$ & $41 \%$ \\
\hline 131 & $\$ 400$ per acre / year & $17 \%$ & $27 \%$ & $56 \%$ & $39 \%$ \\
\hline 132 & $\$ 600$ per acre / year & $28 \%$ & $30 \%$ & $60 \%$ & $32 \%$ \\
\hline 135 & $\$ 800$ per acre / ycar & $27 \%$ & $37 \%$ & $60 \%$ & $33 \%$ \\
\hline
\end{tabular}

Table 18 shows that the Yes Group was more willing to enroll at lower levels of payment than the No Group. Note that the drop in respondents between "No payment required" and " $\$ 50$ per acre / year" was particularly pronounced amongst respondents in the No Group. This may indicate that these respondents are particularly unwilling to accept payment for watershed stewardship work. 


\section{Raw Data Summary}

\begin{tabular}{|c|c|c|c|c|c|c|}
\hline $\mathrm{n}$ & & Not at all & Slightly & Somewhat & Important & Very \\
\hline 260 & Provide a safe and comfortable home for me and my family & $6.9 \%$ & $2.7 \%$ & $2.3 \%$ & $8.8 \%$ & $79.2 \%$ \\
\hline 258 & Protect the health of waterways on or near my property & $3.1 \%$ & $3.9 \%$ & $15.5 \%$ & $24 \%$ & $53.5 \%$ \\
\hline 260 & Protect local wildlife or native vegetation & $2.7 \%$ & $5 \%$ & $17.3 \%$ & $25.8 \%$ & $49.2 \%$ \\
\hline 256 & Preserve open space or aesthetic beauty & $6.6 \%$ & $5.1 \%$ & $16.8 \%$ & $23.4 \%$ & $48 \%$ \\
\hline 257 & Leave an asset for future generations of my family & $7.8 \%$ & $6.6 \%$ & $18.7 \%$ & $19.8 \%$ & $47.1 \%$ \\
\hline 254 & Enhance my land's investment value & $13.8 \%$ & $9.4 \%$ & $25.2 \%$ & $22 \%$ & $29.5 \%$ \\
\hline 256 & Provide recreational opportunitics for $\mathrm{me}$ and $\mathrm{my}$ family & $13.3 \%$ & $8.2 \%$ & $28.9 \%$ & $20.7 \%$ & $28.9 \%$ \\
\hline 253 & Produce high quality farm or timber products for market & $41.1 \%$ & $8.3 \%$ & $12.3 \%$ & $11.5 \%$ & $26.9 \%$ \\
\hline 254 & Provide income for me and my family & $37.8 \%$ & $15.7 \%$ & $18.5 \%$ & $10.2 \%$ & $17.7 \%$ \\
\hline 251 & Enhance my property's development potential & $43.4 \%$ & $15.5 \%$ & $19.9 \%$ & $9.6 \%$ & $11.6 \%$ \\
\hline 250 & Grow/manage a business through mv land's production & $47.6 \%$ & $14.8 \%$ & $17.2 \%$ & $6.8 \%$ & $13.6 \%$ \\
\hline
\end{tabular}

\begin{tabular}{|c|c|c|c|c|c|c|}
\hline $\mathrm{n}$ & & Low & Low/Mod & Moderate & Mod/High & High \\
\hline 180 & Broadcast pesticide application & $13.9 \%$ & $6.7 \%$ & $15.6 \%$ & $17.8 \%$ & $46.1 \%$ \\
\hline 184 & Livestock exclusion zones around streams & $16.8 \%$ & $5.4 \%$ & $20.1 \%$ & $18.5 \%$ & $39.1 \%$ \\
\hline 217 & Use of synthetic fertilizers & $23.5 \%$ & $9.2 \%$ & $15.7 \%$ & $18.4 \%$ & $33.2 \%$ \\
\hline 190 & Storm water runoff control & $17.9^{\circ} \%$ & $11.1 \%$ & $21.1 \%$ & $21.1 \%$ & $28.9 \%$ \\
\hline 213 & Invasive species control & $15 \%$ & $9.9 \%$ & $25.8 \%$ & $19.7 \%$ & $29.6 \%$ \\
\hline 196 & Land set aside for wildlife protection & $20.4 \%$ & $9.7 \%$ & $25 \%$ & $16.3 \%$ & $28.6 \%$ \\
\hline 175 & High efficiency irrigation & $20 \%$ & $11.4 \%$ & $24 \%$ & $17.1 \%$ & $27.4 \%$ \\
\hline 179 & Nutrient management plan & $20.7 \%$ & $8.9 \%$ & $26.3 \%$ & $19 \%$ & $25.1 \%$ \\
\hline 190 & Organic farming & $34.2 \%$ & $13.7 \%$ & $14.2 \%$ & $11.6 \%$ & $26.3 \%$ \\
\hline 164 & Integrated pest management & $18.9 \%$ & $13.4 \%$ & $30.5 \%$ & $16.5 \%$ & $20.7 \%$ \\
\hline 193 & Precision pesticide application & $21.2 \%$ & $15.5 \%$ & $28 \%$ & $13.5 \%$ & $21.8 \%$ \\
\hline 169 & Drainage tiles & $21.9 \%$ & $11.2 \%$ & $36.7 \%$ & $13 \%$ & $17.2 \%$ \\
\hline
\end{tabular}

\begin{tabular}{|c|c|c|c|c|c|c|c|}
\hline $\mathrm{n}$ & & $\leftarrow$ Agre & & Neutral & & gree $\rightarrow$ & \\
\hline 259 & Beneficial to wildlife & $1.5 \%$ & $2.7 \%$ & $12 \%$ & $20.8 \%$ & $62.9 \%$ & Harmful to wildlife \\
\hline 256 & A good use of resources & $4.7 \%$ & $6.6 \%$ & $36.7 \%$ & $27.7 \%$ & $24.2 \%$ & $A$ waste of resources \\
\hline 257 & Rewarding to landowners & $5.8 \%$ & $10.1 \%$ & $36.6 \%$ & $21.4 \%$ & $26.1 \%$ & Harmful to landowners \\
\hline 257 & Compatible with goals for $\mathrm{my}$ land & $4.7 \%$ & $9.3 \%$ & $40.1 \%$ & $19.5 \%$ & $26.5 \%$ & Incompatible with goals for $\mathrm{my}$ land \\
\hline 257 & Beneficial to my land's productivity & $4.3 \%$ & $9.3 \%$ & $40.5 \%$ & $20.2 \%$ & $25.7 \%$ & Harmful to my land's productivity \\
\hline 257 & Good for my finances & $6.2 \%$ & $12.8 \%$ & $56.4 \%$ & $12.1 \%$ & $12.5 \%$ & Bad for my finances \\
\hline 257 & Flexible & $10.5 \%$ & $14.8 \%$ & $51.8 \%$ & $12.8 \%$ & $10.1 \%$ & Inflexible \\
\hline 255 & Easy to enroll in & $3.9 \%$ & $4.7 \%$ & $71.8 \%$ & $8.6 \%$ & $11 \%$ & Difficult to enroll in \\
\hline
\end{tabular}




\section{Raw Data Summary}

\begin{tabular}{l} 
Q11) How likely would you be to work with a watershed conservation program on any of the folloning goals? \\
\hline n
\end{tabular}

\begin{tabular}{l} 
Q12) W ould the folloning increase your interest in norking with a watershed conservation program? \\
\hline n
\end{tabular}

\begin{tabular}{|c|c|c|c|c|c|c|}
\hline $\mathrm{n}$ & & Vcry Unlikcly & Unlikcly & Not Surc & Likely & Very Likcly \\
\hline 251 & Oregon Department of Fish and Wildlife & $18.3 \%$ & $6.4 \%$ & $37.5 \%$ & $17.1 \%$ & $20.7 \%$ \\
\hline 250 & US Fish and Wildlife Service & $19.2 \%$ & $6 \%$ & $37.6 \%$ & $16.8 \%$ & $20.4 \%$ \\
\hline 247 & Clackamas Soil \& Watcr Conscrvation District & $20.6 \%$ & $4.5 \%$ & $41.3 \%$ & $17.8 \%$ & $15.8 \%$ \\
\hline 251 & Oregon Department of Agriculture & $16.7 \%$ & $6 \%$ & $45.8 \%$ & $17.1 \%$ & $14.3 \%$ \\
\hline 248 & Natural Resources Conservation Services & $20.6 \%$ & $6 \%$ & $45.2 \%$ & $11.3 \%$ & $16.9 \%$ \\
\hline 251 & Clackamas River Basin Council & $20.3 \%$ & $7.6 \%$ & $46.2^{\mathrm{y}} \%$ & $13.1 \%$ & $12.7 \%$ \\
\hline 249 & Oregon Department of Environmental Quality & $26.9 \%$ & $8 \%$ & $42.6 \%$ & $11.2 \%$ & $11.2 \%$ \\
\hline 245 & Clackamas Pesticide Stewardship Partnership & $22.4 \%$ & $4.5 \%$ & $50.6 \%$ & $11.8 \%$ & $10.6 \%$ \\
\hline 249 & Clackamas River Water Providers & $21.7 \%$ & $8 \%$ & $48.2 \%$ & $12.4 \%$ & $9.6 \%$ \\
\hline 246 & Other non-profit conservation organizations & $21.5 \%$ & $7.3 \%$ & $51.2 \%$ & $11 \%$ & $8.9 \%$ \\
\hline 248 & Producer Organizations & $22.2 \%$ & $7.7 \%$ & $51.6 \%$ & $10.5 \%$ & $8.1 \%$ \\
\hline
\end{tabular}




\section{Raw Data Summary}

\begin{tabular}{|c|c|c|c|c|c|c|}
\hline $\mathrm{n}$ & & $\begin{array}{c}\text { Definitely } \\
\text { Not }\end{array}$ & $\begin{array}{c}\text { Probably } \\
\text { Not }\end{array}$ & Not Sure & $\begin{array}{c}\text { Probably } \\
\text { Yes }\end{array}$ & $\begin{array}{c}\text { Definitely } \\
\text { Yes }\end{array}$ \\
\hline 251 & Regular project maintenance and monitoring & $31.1 \%$ & $10.4 \%$ & $39 \%$ & $14.7 \%$ & $4.8 \%$ \\
\hline 250 & Annual reporting to the project sponsor & $33.6 \%$ & $10 \%$ & $37.2 \%$ & $12.4 \%$ & $6.8 \%$ \\
\hline 250 & Specific management actions prior to enrollment & $32 \%$ & $8.4 \%$ & $44 \%$ & $11.2 \%$ & $4.4 \%$ \\
\hline 250 & A 10 year contract & $35.6 \%$ & $11.6 \%$ & $41.2 \%$ & $6.8 \%$ & $4.8 \%$ \\
\hline 251 & A 20 ycar contract & $44.2^{\%} \%$ & $11.6 \%$ & $37.8 \%$ & $3.6 \%$ & $2.8 \%$ \\
\hline 248 & A deed restriction lasting the length of the contract & $48 \%$ & $10.1 \%$ & $35.9 \%$ & $4.4 \%$ & $1.6 \%$ \\
\hline
\end{tabular}

\begin{tabular}{l} 
Q15) To what exlent do you agree or disagree wilh lhe folloning slatemenls aboul why you mighl NOT parlicipale \\
in a watershed conservation program. \\
\hline n
\end{tabular}

\begin{tabular}{l} 
Q16) In general, do you agree or disagree with the folloning statements regarding watershed conservation in the \\
Clackeamas River watershed? \\
\hline n
\end{tabular}




\section{Raw Data Summary}

\begin{tabular}{|c|c|c|c|c|c|c|}
\hline $\mathrm{n}$ & & $\begin{array}{c}\text { Definitely } \\
\text { Not }\end{array}$ & $\begin{array}{c}\text { Probably } \\
\text { Not }\end{array}$ & Not Surc & $\begin{array}{c}\text { Probably } \\
\text { Yes }\end{array}$ & $\begin{array}{c}\text { Definitely } \\
\text { Yes }\end{array}$ \\
\hline 149 & No payment required & $20.8 \%$ & $11.4 \%$ & $43.6 \%$ & $10.7 \%$ & $13.4 \%$ \\
\hline 131 & $\$ 50$ per acre / year & $21.4 \%$ & $14.5 \%$ & $48.9 \%$ & $8.4 \%$ & $6.9 \%$ \\
\hline 132 & $\$ 100$ per acre / ycar & $15.9 \%$ & $15.2 \%$ & $46.2 \%$ & $10.6 \%$ & $12.1 \%$ \\
\hline 134 & $\$ 200$ per acre / year & $14.9 \%$ & $11.2 \%$ & $45.5 \%$ & $12.7 \%$ & $15.7 \%$ \\
\hline 134 & $\$ 400$ per acre / year & $14.2 \%$ & $9.7 \%$ & $41.8 \%$ & $11.9 \%$ & $22.4 \%$ \\
\hline 135 & $\$ 600$ per acre / year & $13.3 \%$ & $6.7 \%$ & $40.7 \%$ & $15.6 \%$ & $23.7 \%$ \\
\hline 138 & $\$ 800$ per acre / year & $10.9 \%$ & $5.8 \%$ & $38.4 \%$ & $12.3 \%$ & $32.6 \%$ \\
\hline
\end{tabular}




\section{APPENDIX C. INTERNAL REVIEW BOARD HUMAN SUBJECTS APPROVAL}

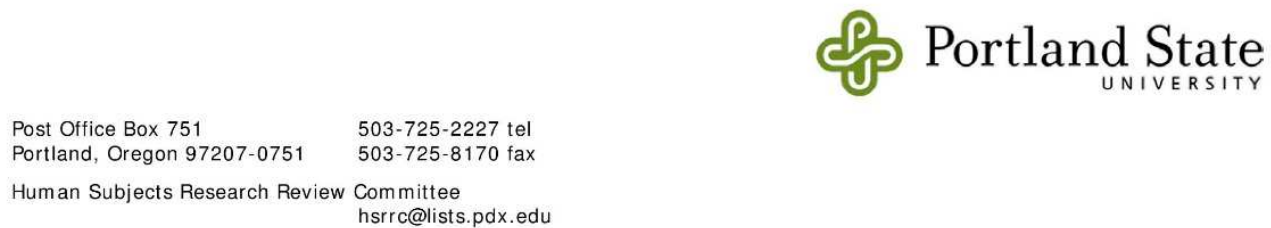

Date: June 12, 2015

To: $\quad$ Max Nielson-Pincus / Matthew DeAngelo

From: Karen Cellarius, HSRRC Chair

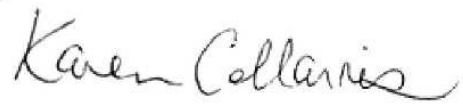

Re: $\quad$ HSRRC approval for your project titled, "Clackamas River Source Water Protection Research" HSRRC Proposal \# 153464

Approval-Expiration: June 12, 2015 - June 11, 2016

Review Type: Expedited, Category 7

In accordance with your request, the PSU Human Subjects Research Review Committee has reviewed your request for approval of the project referenced above for compliance with PSU and DHHS policies and regulations covering the protection of human subjects. The Committee is satisfied that your provisions for protecting the rights and welfare of all subjects participating in the research are adequate, and your project is approved. Please note the following requirements:

Approval: You are approved to conduct this research study only during the period of approval cited above; and the research must be conducted according to the plans and protocol submitted (approved copy enclosed).

Consent: Signed consent is waived from all participants in this study. A written consent statement is required.

Changes to Protocol: Any changes in the proposed study, whether to procedures, survey instruments, consent forms or cover letters, must be outlined and submitted to the Committee immediately. The proposed changes cannot be implemented before they have been reviewed and approved by the Committee.

Continuing Review: This approval will expire on 06/11/2016. It is the investigator's responsibility to ensure that a Continuing Review Report on the status of the project is submitted to the HSRRC two months before the expiration date, and that approval of the study is kept current. The IRB offices does not send out notifications of expiration dates. The Continuing Review Report is available at www.rsp.pdx.edu/compliance_human.php and in the Office of Research and Strategic Partnerships (RSP).

Adverse Reactions and/or Unanticipated Problems: If any adverse reactions or unanticipated problems occur as a result of this study, you are required to notify the Committee immediately. If the issue is serious, approval may be withdrawn pending an investigation by the Committee.

Completion of Study: Please notify the Committee as soon as your research has been completed. Study records, including protocols and signed consent forms for each participant, must be kept by the investigator in a secure location for three years following completion of the study (or per any requirements specified by the project's funding agency).

If you have questions or concerns, please contact the Office of Research Integrity in the PSU RSP at 503-725-2227. 